UNITED STATES ATOMIC ENERGY COMMISSION

UCRL-2528

INTERNAL CONVERSION OF GAMMA

RADIATION IN THE L SUBSHELLS (Thesis)

By

Thomas Oliver Passell

March 30, 1954

Radiation Laboratory

University of California

Berkeley, California

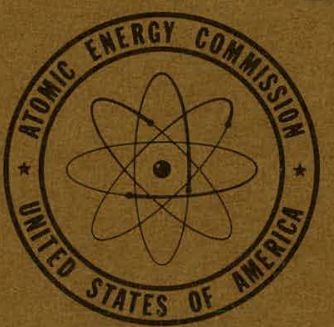

Technical Information Service, Oak Ridge, Tennesseo 


\section{DISCLAIMER}

This report was prepared as an account of work sponsored by an agency of the United States Government. Neither the United States Government nor any agency Thereof, nor any of their employees, makes any warranty, express or implied, or assumes any legal liability or responsibility for the accuracy, completeness, or usefulness of any information, apparatus, product, or process disclosed, or represents that its use would not infringe privately owned rights. Reference herein to any specific commercial product, process, or service by trade name, trademark, manufacturer, or otherwise does not necessarily constitute or imply its endorsement, recommendation, or favoring by the United States Government or any agency thereof. The views and opinions of authors expressed herein do not necessarily state or reflect those of the United States Government or any agency thereof. 


\section{DISCLAIMER}

Portions of this document may be illegible in electronic image products. Images are produced from the best available original document. 
Subject Category, CHEMISTRY.

Work performed under Contract No. W-7405-eng-48.

\author{
Approved: Professor Isadore Perlman, Chairman \\ Associate Professor Leo Brewer \\ Professor August Carl Helmholz
}

Issuance of this document does not constitute authority for declassification of classified material of the same or similar content and title by the same author.

This report has been reproduced with minimum alteration directly from manuscript provided the Technical Information Service in an effort to expedite availability of the information contained herein.

Reproduction of this information is encouraged by the United States Atomic Energy Commission. Arrangements for your republication of this document in whole or in part should be made with the author and the organization he represents.

Printed in USA, Price 70 cents. Available from the Office of Technical Services, Department of Commerce, Washington 25, D. C. 
UCRL-2528

\title{
INTERNAL CONVERSION OF GAMMA RADIATION IN THE L SUBSHELLS (Thesis)
}

\author{
By \\ Thomas Oliver Passell
}

March 30, 1954

$-1-$ 
List of Tables

List of Illustrations

ABSTRACT

I. INTRODUCTION

II. EXPERIMENTAL APPARATUS AND TECHNIQUES

A. The Double Focusing Beta Spectioneter: . . 6

1. Vacuum system $\quad$ - 7

$\begin{array}{ll}\text { 2. Counting system } & 7\end{array}$

3. Energy calibration 9

4. Semi-automatic operation .. . 10

B. Sample Preparation $\quad 10$

III. EXPERIMENTAL DATA $\quad \cdot \quad 12$

A. Americium 241 $\quad \ldots .12$

B. Americium 242m and $242^{\circ} 23$

C. Curium 242

D. Nèptunium 238 ? 37

E. Thallium 198m 41

F. Protactinium 228

G. Protactinium $230 \quad 56$

H, Neptunium 236 63

$\begin{array}{lll}\text { IV. DISCUSSION OF RESULTS } & 67\end{array}$

$\begin{array}{lll}\text { V. ACKNOW LEDGMENTS : } & 87\end{array}$

VI. APPENDIX I. Miscellaneous Data on the Isotopes $\mathrm{Pu}_{241}: 240, \mathrm{Pm}^{150}$, and $\mathrm{Fr}^{223}$

VII. APPENDIX II. A Twin Lens Beta Spectrometer for 94 Coincidence Measurements 


$$
-3-
$$

List of Tables

Page

1. Americium 241 electron lines . . . 14

2. Revised intensities of $\mathrm{Am}^{242 \mathrm{~m}}$ electron lines $\quad \therefore \quad 24$

3. Curium 242, electron lines - 34

4. Neptunium 239 electron lines 38

5. Thallium $198 \mathrm{~m}$ electron lines 44

6. Electron lines from $\mathrm{Pa}^{228}$ decay . . $\quad 55$

7. Electron lines of $\mathrm{Pa}^{230}$. . . . 58

8. Gamma rays of $\mathrm{Pa}{ }^{230} 62$

9. Electron lines of $\mathrm{Np}^{236} 64$

10. Summary of data on electric quadrupole transitions 85 
List of Illustrations

1. a,b) Electron spectrum of Am 241

Page

2. Decay scheme of Am? 241 .

15,16

3. Decay scheme of $\mathrm{Am}^{242 \mathrm{~m}}$ proposed by $\mathrm{O}^{\prime}$ Kelley et al. ${ }^{18}, 25$

4. Elcctron opectrum observed by Q'Kelley et al, $18 \quad \because \quad 26$

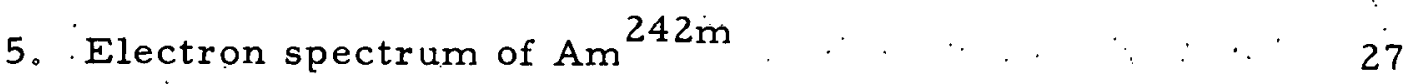

6. a, b) Electron spectrum of $\mathrm{Cm} 242 \quad \cdots \quad 32,33$

7. Decay scheme of $\mathrm{Cm}^{242} \quad: \quad \therefore \cdot 36$

8. Electron lines of $\mathrm{Np}^{238} \quad \ldots \quad \ldots \quad 39$

9. a, b) Thallium $198 \mathrm{~m}$ electron spectrum : $\quad 45,46$

10.: Experimental $L_{I I I} / L_{I}$ ratios for $M 4$ transitions in the region of atomic numbers near 80 versus energy in kev 48

11. Decay scheme of $\mathrm{Ti}^{198 \mathrm{~m}} \quad 51$

12. K Auger electrons of $\mathrm{T}^{198}-\mathrm{T}^{198 \mathrm{~m}}$

13. a,b) Gamma spectrum of $\mathrm{Pa}^{230} \quad 60,61$

14. Decay scheme of $\mathrm{Np}^{236} 68$

15. a-c) $L_{I}: L_{I I}: L_{\text {III }}$ ratios based on the calculations of $70-72$ Gellman et a1. 6

16. a-i) Curves for interpolating the tables of Gellman et alo ${ }_{0}^{6} 73-81$

17. Fermi-Kurie plot of $\mathrm{Pu}{ }^{241}$ beta spectrum 91

18. Block and schematic diagram of twin lens beta spectro- 95 meter and associated equipment. 


\section{INTERNAL CONVERSION OF GAMMA RADIATION IN THE L SUBSHE LLS \\ Thomas Oliver Passell \\ Radiation Laboratory and Department of Chemistry University of California, Berkeley, California}

March 30, 1954

ABSTRACT

Electron spectra from conversion of low energy nuclear gamma radiation (up, to a round $350 \mathrm{kev}$ ) in several isotopes of the heavier elements have been investigated using a double focusing beta spectrometer previously described of The following isotopes were studied: $\mathrm{Am}^{241}, \mathrm{Am}^{242 \mathrm{~m}}, \mathrm{Cm}^{242}, \mathrm{~Pa}^{228}$, $\mathrm{Pa}^{230}, \mathrm{~T}^{198 \mathrm{~m}}, \mathrm{~Np}^{238}$, and $\mathrm{Np}^{236}$. Decay schemes, some tentative, have been proposed for some of the above nuclides. Miscellaneous data on the following isotopes, $\mathrm{Pu}^{241}$, $\mathrm{Pu}^{240}, \mathrm{Pm}^{150}$, and $\mathrm{Fr}^{223}$, are summarized in Appendix I. A twin lens coincidence beta spectrometer, now in the assembly stage, is briefly described in Appendix II.

Agreement of experimentally determined $L$ conversion ratios with the most recent theoretical calculations were generally very good except for the clectric dipole case, where about twice the expected $\left(L_{I}+L_{I I}\right)$ conversion was found. 
INTERNAL CONVERSION OF GAMMA RADIATION

IN THE L.SUBSHELLS

Thomas Oliver Passell

Radiation Laboratory and Department of Chemistry

University of California, Berkeley, California

March 30, 1954

\section{INT RODUCTION}

A study of conversion electron spectra in the heavier elements was undertaken with the following objectives in mind:

1. The assignment of the multipolarity of transitions between nuclear energy states by comparison of $\mathrm{L}_{\mathrm{I}}: \mathrm{L}_{\mathrm{II}}: \mathrm{L}_{\mathrm{III}}$ conversion ratios with theoretical values.

2. The comparison of multipolarities assigned in this manner with those assigned from other types of experiments.

3. The elucidation of a more complete decay scheme for each of the nuclides studied.

II. EXPERIMENTAL APPARATUS AND TECHNIQUES
A. The Double-Focusing Beta Spectrometer

The instrument used in these investigations has been previously described ${ }^{1}$ so only the few modifications made are described here. Briefly, however, the double focusing spectrometer consists of a pancake-shaped iron magnet about 3 feet in diameter and about 1 foot in thickness with the center hollowed out so that the gap between the top and bottom pole pieces is smaller at the center than at the periphery. Thus, in addition to a co-axial magnetic field the re exists a co-radial component of magnetic field. The focusing properties of these two components of magnetic field (hence the name double ofocusing) are such that an image of the sample is formed at an angle of $255^{\circ}$ from the sample position. A Geiger counter at this image position is 
used as a detector. The magnetic field is varied by changing the current passing through the coil which is situated just inside the hollowed-out portion, but outside the vacuum chamber. The top ". half of the "pancake" may be unbolted and removed for making adjustments inside the chamber: Most of the changes madé wère in connection with the associated equipment such as the vacuum pumping system, the counter, the counter gas supply, the scaling unit, and the technique of sample preparation.

1. The vacuum pumping system. - When à thin plastic counter window ruptures or a counter becomes "fatigued"; it is necessary to reduce the vacuum chamber to atmospheric pressure and to raise the 700 pound top half of the iron "pancake" using an overhead block and tackle in order to gain access to the counter. Therefore a 2-inch modified Crane valve was placed between the vacuum chamber and the diffusion pump, allowing the latter to be kept operating while this operation is carried out. An additional forepump is used after reassembly until a pressure is reached at which the diffusion pump can again be opened to the system:

2. The counting system:-- End window counters were not very reliable so it was decided early to try the side window type. It was rumored that the latter type were far less subject to counter gas contaminants, counter wire type, and counter wall irregularities; and that if a length to diameter ratio of four or larger were maintained, usable Geiger voltage plateaus could be'expected. All five side window counters designed and put in use counted satisfactorily even though almost none of the traditional recipes for making counters was 
strictly followed. That is, no particular effort was made to keep the inside counter wall or central wire scrupulously clean or free from irregularities. , Tungsten, molybdenum, platinum, and stain. less steel central wires were tried with equal success. Stainless steel is recommended since it is of reasonable cost and is easily soldered. Brass was used for the counter body for three of the counters and copper for the fourth. Brass is recommended.

One of the more formidable problems in low energy beta spectrometry is the making of counter windows. The window must be of a thickness less than $100 \mu \mathrm{g} / \mathrm{cm}^{2}$ and preferably below $50 \mu \mathrm{g} / \mathrm{cm}^{2}$ if it is to have 100 percent transmission for electrons with energies below $20 \mathrm{kev}$. It must, of course, also be able to withstand the counter gas pressure of about 10 to $15 \mathrm{~cm}$ of mercury.

Support grids upon which are laid several layers of formvar, nylon, collodion, or plastic films are commonly used, but these grids often mask as much as 40 percent of the usable counter window area. With the kind assistance of Mr. Earl Hostetter of this laboratory a window grid was designed which masks less than 6 percent of the usable window area. The grids were made on the same principle as those designed by Mr. Hostetter for producing the electrostatic field in a time-of-flight isotope separator. ${ }^{2}$ In the present application, 0.0005-inch diameter tungsten wire was pressed into a small, grooved, copper cylinder which had been soldered to a brass disk of an appropriate size. The brass disk contained an O-ring groove for the vacuum seal to the counter. 
For the window material itself the writer has had consistent success with a vinyl chloride a vinyl acetate copolymer No. 1080 supplied by the Industrial Plastics Corporation, Oakland, California: The films were made in the traditional manner of allowing a drop of the liquid plastic (diluted 1:1 with No. 1080 thinner) to spread on a water surface. Distilled water to which a very small amount of concentrated ammonia had been added seemed to give the best results although the conditions did not seem to be critical. One three-layer window made in this fashion lasted for over a year of constant use at $15 \mathrm{~cm}$ total counter gas pressure. Its thickness was such that the transmission factor for $20 \mathrm{kev}$ electrons was about 100 percent and the cutoff was approximately 4 kev. One factor in the unusually long life of this window may be the practice of keeping the counter filled with gas only when in use.

The use of a 10 percent ethylene -90 percent argon gas mixture for the counter has been continued and gives satisfactory counter operation even with as much as l percent air contamination. Of course, it is more desirable to keep air contamination at a minimum. The more air contamination the higher the total gas pressure necessary to maintain the same Geiger region voltage plateau. The present counter has a 100 volt plateau at $12.5 \mathrm{~cm}$ total gas pressure.

3. Energy calibration of the spectrometer. - The residual magnetic field in the iron of the spectrometer can be reproduced with some degree of confidence by carrying out a magnetization cycle before each experiment. The cycle consists of reversing the direction of the current and operating at maximum current for three 
to five minutes; then for four times as long a time: operating at maximum current with current flow in the same direction as: is to be used in the experiment: This is followed by a momentary demagnetization with 1.5 amperes of alternating current. Even with this cycle of operations, several disturbing shifts have been noted in certain energy regions. Until such time as the spectrometer is equipped with a precise field measuring device, the instrument, in the writer's opinion, will be primarily useful for conversion line ratios and energy differences at high resolution.

Nuclides which have been useful in calibrating the instrument. are $\mathrm{Cs}^{137}, \mathrm{I}^{131}, \mathrm{Ta}^{182}, \mathrm{Ir}^{192}$, and $\mathrm{Am}^{241}$.

4. Semi-automatic operation.--The magnet current can be varied continuously very slowly by a motor and gear system. This makes possible the use of a traffic counter set to stamp at intervals of time small enough to allow the assumption of a point count for each stamp and long enough to allow the collection of enough counts for reasonably good statistics. This system was used to collect the data described below for $\mathrm{Am}^{241}, \mathrm{Cm}^{242}, \mathrm{~Pa}^{228}$, and $\mathrm{Pa}^{230}$.

\section{B. Sample Preparation}

Probably the most critical of all techniques in beta spectrometry is the preparation of the radioactive samples. "A much used samplemaking procedure is the evaporation of a drop of water containing the radioactivity on backings of plastic films similar to those used for counter windows. The writer has had generally more favorable results using thin gold, palladium, or aluminum leaf. The advantages of these metal leaves have been two. They allow the leakage of 
electric charges arising from radioactive decay which an insulating plastic film would build up to spectra-distorting proportions, and they may be more strongly heated than the plastic films. The thicknesses of these were found to be 87,157 , and $177 \mu \mathrm{g} / \mathrm{cm}^{2}$, respectively, by weighing a known area of leaf. The strength of two layers of gold leaf is about equal to one of the palladium or aluminum. The double layer of gold leaf has been used with intermittent success as a backing for samples, contained in reagents such as concentrated HF. Cases where the gold leaf failed may have been due to the choice of inferior leaves. Much more consistent success was obtained with the aluminum and palladium leaf so long as solutions of $<0.1 \underline{\mathrm{N}} \mathrm{HNO}_{3}$ and $<1 \mathrm{M} \mathrm{HCl}$, respectively, were used to transfer the radioactivity to the backings. Even these solutions weakened the leaf, however, and it is recommended that the activity be transferred to distilled water before evaporating from these backings. In cases where a macro. amount (of the order of several milligrams) of material had to be mounted, a 0.00025 inch thick platinum counting disk was used since sample thickness has a greater distorting effect on an electron spectrum than does the backing thickness.

At the present time a high geometry sublimator is in use in which the aluminum and palladium leaves are especially useful. High geometry is achieved by, the use of a V-shaped filament. Sublimation of the radioactivity onto the thin metal foils, assures both a uniformly thin deposit and a thin backing. The metal foils have an advantage over plastic films in their ability. to withstand the heat of a nearby filament more readily. The investigations of the $\mathrm{Tl}^{198 \mathrm{~m}}$ and 
$\mathrm{Np}^{238}$ spectra were performed with samples sublimated onto palladium leaf.

The new sublimator is mounted inside a glove box for work with the high level activities necessary in beta spectrometry. Of course, carrier free chemistry must still be carried out.on the radioactive sample to eliminate as much extraneous mass as possible. This mass does not readily sublimate onto the leaf and thereby greatly reduces the sublimation yield. It may, of course, in certain instances be possible to use the sublimation process as a means of separating certain elements from others, but to the writer's knowledge no extensive study has been made of its potentialities along this line.

\section{I. EXPERIMENT AL DATA}

\section{A. Americium 241}

1. L lines of $59.6,43.4,99$, and $33.2 \mathrm{kev}$ gamma rays:The electron spectrum of a sample of $\sim 2 \times 10^{8}$ alpha counts per minute of $\mathrm{Am}^{241}$ on an aluminum leaf backing is shown in Figs. la and Ib. The electron data are summarized in Table 1. The Am ${ }^{241}$ was obtained very pure by milking from the $\mathrm{Pu}^{241}$ parent. 'The sample was evaporated onto the backing from a solution of the activitiy in distilled water. Since samples of intense alpha activity such as this one can not be flamed to make the material adhere to the backing, great care must be used in transferring the samples between the glove box where these samples are prepared and the spectrometer. The newer technique of high geometry sublimation reduces this great hazard since in this case the activity forms a uniform, adherent layer. 
The $\mathrm{L}$ lines of the $59.6 \mathrm{kev}$. gamma ray are indicated by the numbers 9 and 11 in Fig. la. It is seen that in the case of the $L_{I}=L_{I I}$ line the normally almost vertical forward edge gives the indication of a hip, about one-seventh of the way down from the peak. This may be interpreted as evidence that the abundance of the $\mathrm{L}_{\text {II }}$ line is perhaps somewhat less than that of the $\mathrm{L}_{1}$ line. The $\mathrm{L}_{\text {III }}$ line was clearly resolved. The abundance of the $\mathrm{L}_{\mathrm{I}}-\mathrm{L}_{\mathrm{II}}$. line was corrected for the presence of the other spectral line known to occur at the same energy, namely the $43.4_{M}$ line. A similar correction was made for the $43.4 \mathrm{~N}$ line since it coincides in energy with the $59.6 \mathrm{~L}_{\mathrm{III}}$. The abundances of the $43.4 \mathrm{M}$ and $43.4 \mathrm{~N}$ lines were inferred from the $43.4 \Sigma \mathrm{L}$ abundance and the $\mathrm{L} / \mathrm{M}$ and $\mathrm{L} / \mathrm{N}$ ratios observed for the $44.1 \mathrm{kev}$ gamma ray in the decay of $\mathrm{Cm}^{242}$. Of course, the chief. difficulty in procuring reliable abundance measurements lies in the uncertainties involved with the extrapolation of the low energy tail of a given line. The author's policy has been to use well resolved lines as models for determining the tail of a line which was not so well resolved. In this case the $59.6{ }_{L_{\text {III }}}$ line was so used. The $\left(L_{I}+L_{I I}\right) / L_{I I I}$ ratio for the $59.6 \mathrm{kev}$ gamma ray is $4.4 \pm 1$. This value is in fair agreement with the value of around 6 obtained by Wolfson. 3

From an experiment using $\mathrm{Cm}^{242}$ the transmission of the spectrometer was determined (see Section III-C). From this value of the transmission ( 0.3 percent), an absolute alpha count of the Am ${ }^{241}$ sample, and the assumption of $0.4059 .6 \mathrm{kev}$ photons per alpha, ${ }^{4}$ the total conversion coefficient of the $59.6 \mathrm{kev}$ gamma was determined to be $0.92 \pm 0.1$. A previously reported value for the total conversion 
Table 1

Americium 241 Electron Lines

\begin{tabular}{|c|c|c|c|c|}
\hline $\begin{array}{l}\text { Designation } \\
\text { in Fig. la }\end{array}$ & $\begin{array}{c}\text { Gamma } \\
\text { energy } \\
\text { (kev) }\end{array}$ & $\begin{array}{l}\text { Electron } \\
\text { ênergy } \\
\text { (kev) }\end{array}$ & $\begin{array}{l}\text { Conversion } \\
\text { shell }\end{array}$ & $\begin{array}{c}\text { Intensity } \\
\mathrm{e}^{-} / \mathrm{a}\end{array}$ \\
\hline 5 & 26.3 & $25: 0$ & $\mathrm{~N}_{\text {II }}$ & 0.0068 \\
\hline 1 & 33.1 & 10.6 & $\mathbf{L}_{I}$ & 0.067 \\
\hline 2 & & 11.5 & $\mathrm{~L}_{\mathrm{II}}$ & \\
\hline 7 & & 27.3 & $\mathrm{M}_{\mathrm{I}}$ & 0.018 \\
\hline \multirow[t]{2}{*}{8} & & 28.7 & $\mathrm{M}_{\text {III }}$ & 0.0012 \\
\hline & & 31.7 & $\mathrm{~N}_{\mathrm{I}}$ & 0.004 \\
\hline 3 & 43.4 & $20.8^{:}$ & $\mathbf{L}_{\mathbf{I}}$ & 0.017 \\
\hline 4 & & 21.8 & $\mathbf{L}_{\text {II }}$ & 0.035 \\
\hline 6 & & 25.8 & $\mathbf{L}_{\text {III }}$ & 0.039 \\
\hline 10 & 56.4 & 38.8 & $\mathrm{~L}_{\text {III }}$ & 0.0015 \\
\hline 9 & 59.6 & 37.1 & 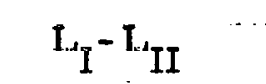 & 0.236 \\
\hline 11 & & 42.0 & $\mathbf{L}_{\text {III }}$ & 0.054 \\
\hline 12 & & 54.4 & $\dot{\mathrm{M}}_{\mathrm{II}}$ & 0.064 \\
\hline 13 &.$\quad \therefore$ & 59.2 & $\mathrm{~N}$ & 0.014 \\
\hline \multirow[t]{3}{*}{ (Figure lb) } & $99.5 \pm 1$ & 77.9 & $\mathbf{L}_{I}-\mathbf{L}_{I I}$ & 0.00062 \\
\hline & & 81.5 & $\mathrm{~L}_{\overline{\mathrm{I}} \overline{\mathrm{I}} \overline{\mathrm{I}}}$ & 0.00037 \\
\hline & & 95 & $\mathbf{M}$ & 0.00031 \\
\hline
\end{tabular}




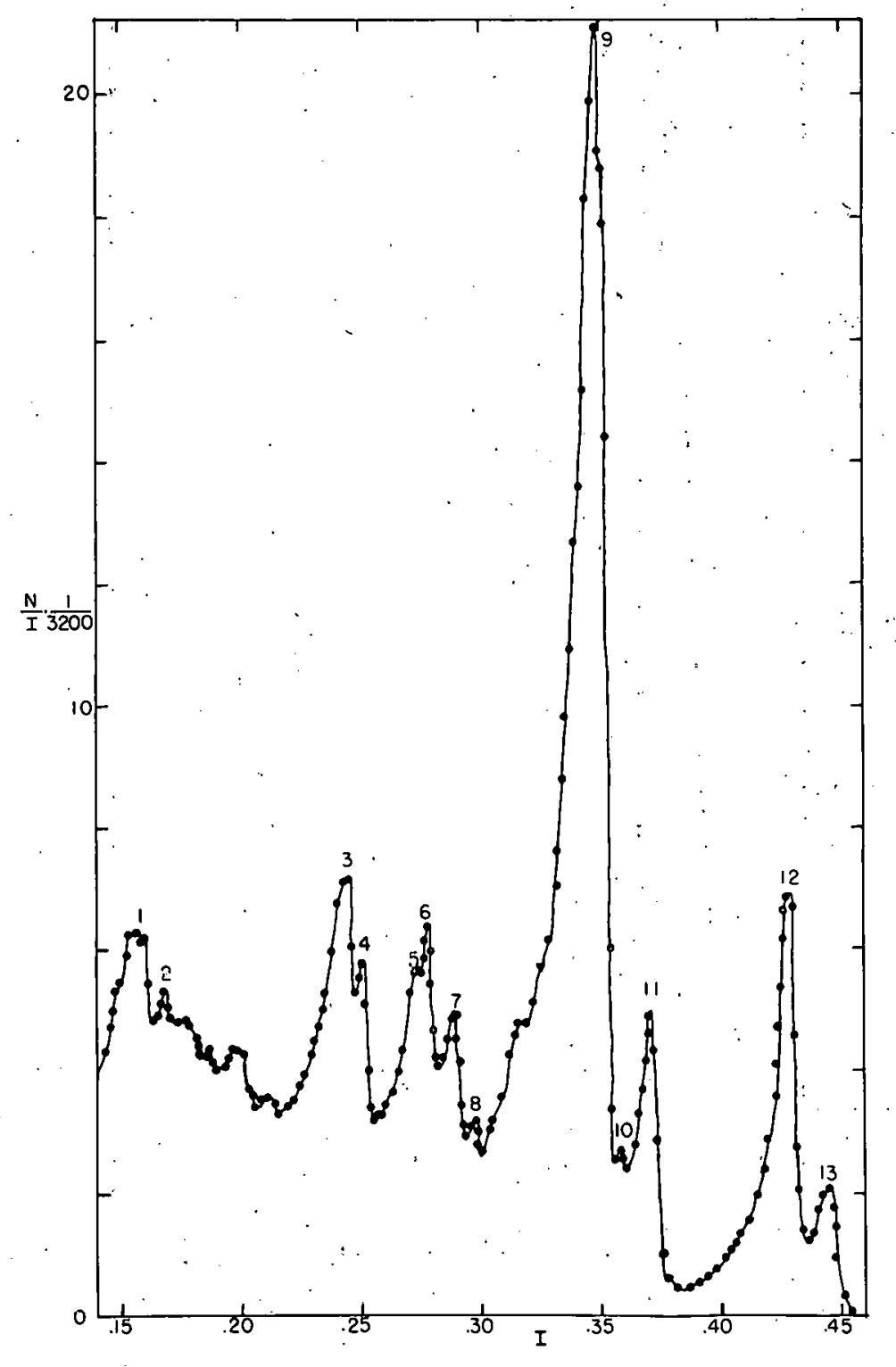

Fig. 1a-Electron spectrum of $\mathrm{Am}^{241}$. 
$-16-$

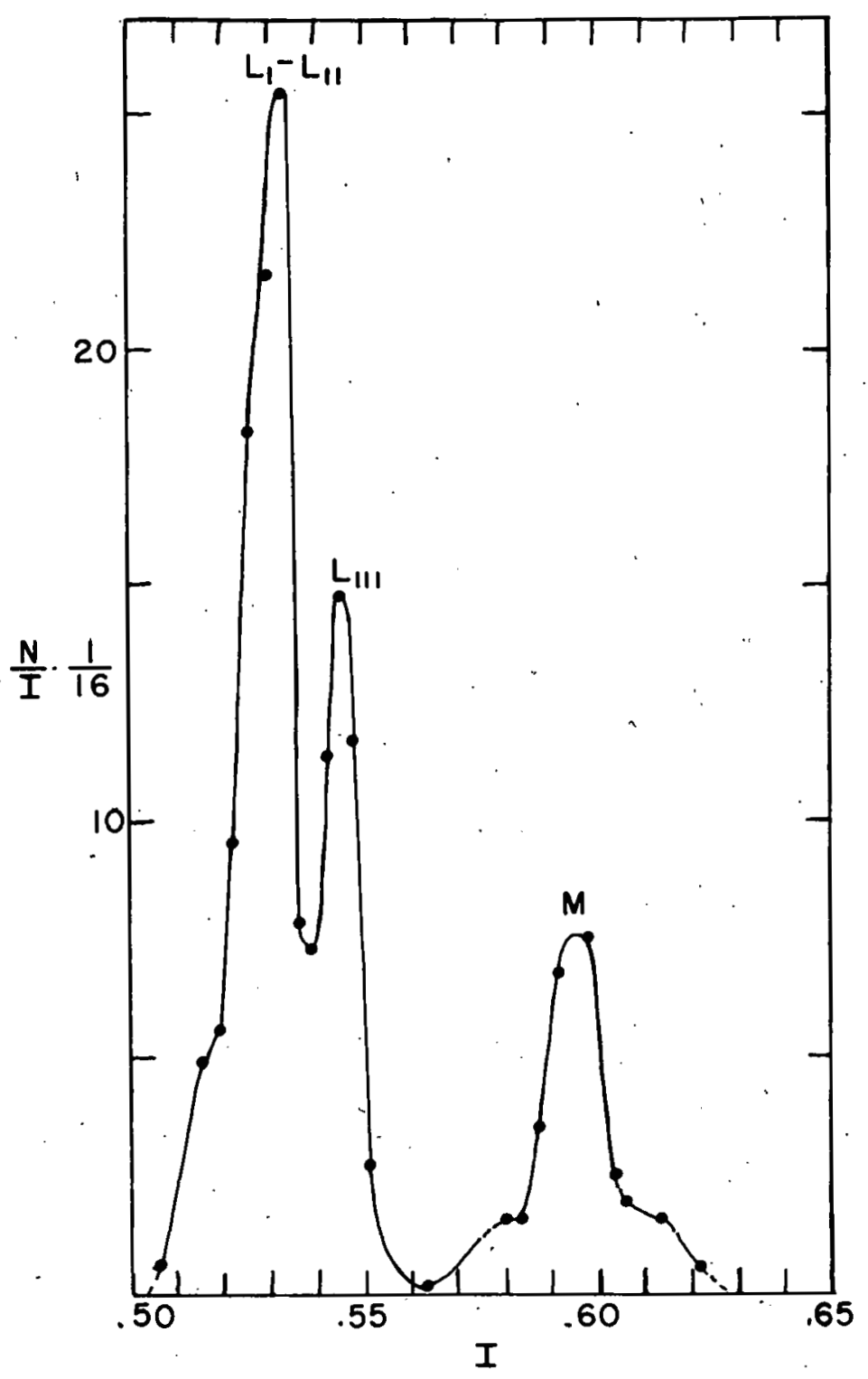

Fig. 1b-Electron spectrum of Aïm 241 . 
coefficient is $<1.5{ }^{5} \mathrm{O}^{\prime}$ Kelley ${ }^{1}$ reports the total $\mathrm{L}$ conversion coefficient to be about 0.7 which compares very favorably with our value of $0.72 \pm 0.07$. The $59.6 \mathrm{kev}$ gamma ray is given an $\mathrm{El}$ assignment on the basis of its total $L$ conversion coefficient.

Three lines of the spectrum were assignable to: the $\mathrm{L}_{I^{\prime}} \mathrm{L}_{\mathrm{II}^{\prime}}$ and $L_{\text {III }}$ lines, respectively, of a $43.4 \pm 0.5 \mathrm{kev}$ gamma ray. There are large uncertainties in the abundances listed in Table 1 ; but it appears that the conversion ratios are not inconsistent with the interpretation of the gamma as a mixture of $E 2$ and $M 1$ radiation. ${ }^{6}$ As can be seen from Fig。la, a line assigned as $26.3{ }_{\mathrm{N}}$ (line 5) appearis superimposed on the tail of the line assigned as $43.44_{\text {III }}$ (line 6$)$. From the very uncertain abundance of this $26.4 \mathrm{~N}$ line and the assumption that the $\mathrm{M} / \mathrm{N}$ ratio is the same for the $26.3 \mathrm{kev}$ as for the $59.6 \mathrm{kev}$ transition (both have been given El assignments) ${ }^{5}$ the abundance of the $26.4 \mathrm{M}$ (line 3) line may be calculated. This value is then subtracted from the value obtained for the one line which represents both the $26.4_{M}$ and $43.4_{L_{1}}$ (line 3 ) to give the intensity of the $43.4_{L_{1}}$ line. In spite of the very large uncertainties involved, it is felt that a not insignificant fraction of the $43.4 \mathrm{kev}$ transitions are converting in the $L_{1}$ shell. Since no gamma quanta of this energy have been observed to a very low limit, (<1 percent of the $59.6 \mathrm{kev}$ photon), 4,7 the assigniment cannot be El nor can it be of very high multipolarity since all of the alpha particles are in fast coincidence $(<0.15 \mu \mathrm{sec})^{5}$ with the $59.6 \mathrm{kev}$ photon. Thus we are left with a very strong probability that the radiation is either E2 or a mixture of $\mathrm{Ml}$ and $\mathrm{E} 2$. 
Lines assignable as the $\mathrm{L}_{\mathrm{I}}+\mathrm{L}_{\mathrm{II}}, \mathrm{L}_{\mathrm{III}}$, and $\mathrm{M}$ lines of a $99.5 \pm 1$ kev gamma ray: were observed as..shown in Fig. lb. The $\left(L_{I}+L_{I I}\right) / L_{I I I}$. ratio is 1.7. Jaffe has observed a $102 \mathrm{kev}$ gamma ray on a scintillation spectrometer. ${ }^{7}$ Wolfson $^{3}$ reports electron lines of a gamma ray of $99 \mathrm{kev}$ with an $\left(\mathrm{L}_{\mathrm{I}}+\mathrm{L}_{\mathrm{II}}\right) / \mathrm{L}_{\mathrm{III}}$ ratio of about $2 . \mathrm{Church}^{8}$ reports a gamma ray converting in neptunium in a sample containing Am $^{241}$ of $98.9 \pm 0.3 \mathrm{kev}$, which he assigns as $\mathrm{E} 2$ from the $\mathrm{L}_{\mathrm{II}} / \mathrm{L}_{\mathrm{III}}$ ratio. Since the expected ${ }^{6}\left(\mathrm{~L}_{\mathrm{I}}+\mathrm{L}_{\mathrm{II}}\right) / \mathrm{L}_{\mathrm{III}}$ ratio is 1.85 , the $\mathrm{E} 2$ assignment is reasonably certain.

Assignment of lines of the $33.2 \mathrm{kev}$ gamma ray was more difficult. Since Jaffe ${ }^{7}$ has determined the energies of one of the two cascading gamma rays de-exciting the $59.62 \mathrm{kev}$ level in $\mathrm{Np}^{237}$ to be $26.38 \pm 0.04$ kev, the energy of the other by difference would be $(59.62 \pm 0.06)$. $(26.38 \pm 0.04)=33.24 \pm 0.10 \mathrm{kev}$. The fact that the $26.4 \mathrm{kev}$ and $33.2 \mathrm{kev}$ gamma rays parallel the $59.6 \mathrm{kev}$ gamma ray has been established by the complex alpha spectrum. ${ }^{9}$ As can be seen from Table 1 and Fig. la, lines assignable to the $\mathrm{L}_{I^{\prime}} \mathrm{L}_{\mathrm{II}^{\prime}} \mathrm{M}_{I^{2}} \mathrm{M}_{\mathrm{III}}$, and $\mathrm{N}_{I}$ conversion of the $33.1 \mathrm{kev}$ gamma ray have been found. The Ml assignment was made from the fact that the $\mathrm{L}_{\mathrm{I}} / \mathrm{L}_{\mathrm{II}}$ ratio was $>5$ and that no line appeared where one would expect the $33.1 \mathrm{~L}_{\text {III }}$. Of course, the presence of Auger lines in that region preclude our setting any sort of limit on $L_{\text {III }}$ conversion. Line intensities below about $17 \mathrm{kev}$ are attenuated because of absorption in the window of the detector. Since the $33 .{ }^{2} \mathrm{~L}_{\mathrm{I}}$ line appears at $10.6 \mathrm{kev}$, it is evident that only the order of magnitude of abundances are reliable. The fact that the line assigned as $33.1_{L_{I}}$ stands out so prominently in spite of the increased window 
absorption gives one added confidence in the $\mathrm{Ml}$ assignment: This assignment is consistent with the designation of both the 59.6 and $26.4 \mathrm{kev}$ gamma rays as. E1 transitions.

2. Decay scheme of $\mathrm{Am}^{241}$ - - levels in $\mathrm{Np}^{237} \ldots$ - A decay scheme including all the presently available data is shown in Fig。 2 . The positions of the $33.2,59.6,103$, and $159 \mathrm{kev}$ levels were established from the complex alpha spectrum. 9 More recent work ${ }^{10}$ on this alpha spectrum indicates that the presence of a previously reported ${ }^{9}$ alpha group $11 \mathrm{kev}$ below the level marked 0 in Fig. 2 is due to an instrumental effect. The $270 \mathrm{kev}$ level is found in the beta decay of $\mathrm{U}^{237}$. 11

Jaffe has observed gamma rays of $\sim 210,168,128$, and $102 \mathrm{kev}$ in a scintillation spectrometer study. ${ }^{7}$ The alpha groups populating the $270 \mathrm{kev}$ and $438 \mathrm{kev}$ levels would have been in too small abundance to have been observed by Asaro. ${ }^{9}$ There is considerable doubt about the position of the 168 and $128 \mathrm{kev}$ gamma rays although the indicated ones seem quite reasonable.

The $L_{\text {III }}$ line (line 10) of a $56.4 \mathrm{kev}$ gamma was observed as shown in Fig. la and from its abundance one can deduce a total abundance of the 56. $4 \mathrm{kev}$ transition (assuming E2 character which is consistent with failure to observe the gamma quanta ${ }^{4,7}$ ). The 56 kev transition is very likely an E2 since its $L_{\text {III }}$ peak was observed. Of course it is not at all impossible that the $56.4 \mathrm{kev}$ transition includes a significant fraction of Ml radiation since the $L_{1}$ peak could not be resolved.

The maximum intensity possible for this gamma transition is 0.0142 per alpha since only 1.42 percent of the alphas populate the $158.5 \mathrm{kev}$ state level. The $99.5 \pm 1 \mathrm{kev}$ gamma ray is the other 
$-20-$

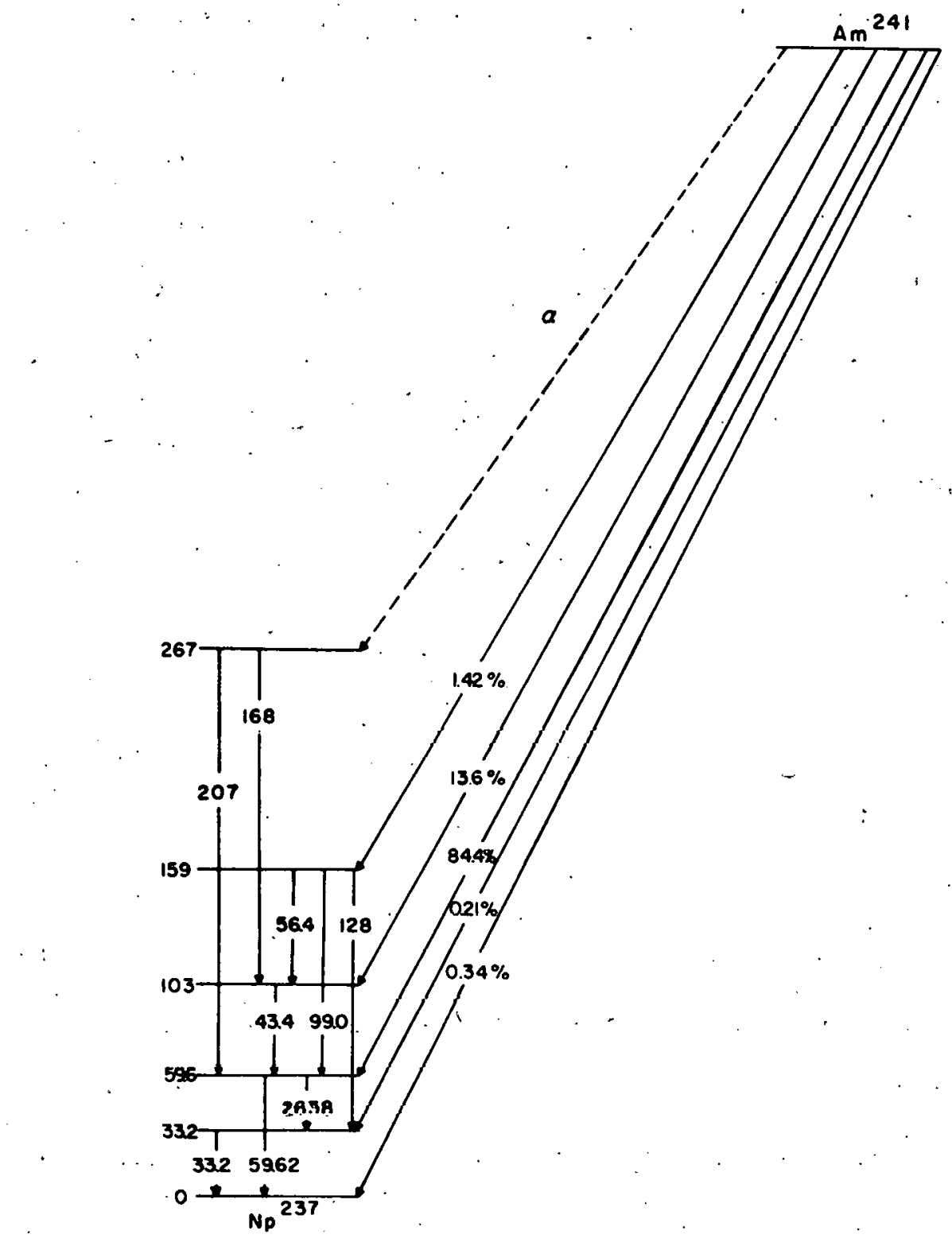

Fig. 2 -Decay scheme of Am 241 . 
possible means of de-exciting the $158.5 \mathrm{kev}$ level. The total abundance of the 99: $5 \pm 1 \mathrm{kev}$ transition; i.e., photons plus electrons per alpha, was determined to be 0.0018 from the value of $0.40 \pm 0.01559 .6 \mathrm{kev}$ photons per alpha, ${ }^{7}$ the $59.6 \mathrm{kev}$ gamma conversion coefficient of $0.92 \pm 0.10$, and a scintillation spectrometer experimental value of 0.00056 photons per alpha. ${ }^{7}$ Thus we may conclude that the $56.4 \mathrm{kev}-43.4 \mathrm{kev}$ gamma cascade is the chief means whereby the $158.5 \mathrm{kev}$ level is de-excited, but that the $98.9 \mathrm{kev}$ crossover transition is not of insignificant abundance. The limits of error on the absolute abundance of the $56.4 \mathrm{kev}$ transition's electrons are sufficient to encompass the value of 0.012 per alpha; which is the required value imposed by the alpha population to the $158.5 \mathrm{kev}$ level and the abundance of the 98.9 kev transition.

The $26.4 \mathrm{kev}$ transition has been assigned El character on the basis of its total conversion coefficient. This value $(4.75 \pm 1.5)$ was dediced from alpha populations of each level, the value of $0.40 \pm 0.015$ $59.6 \mathrm{kev}$ photons per alpha, ${ }^{4}$ the total conversion coefficient of the $59.6 \mathrm{kev}$ gamma ray $(0.92 \pm 0.10)$, the value of $0.0426 .4 \mathrm{kev}$ photons per alpha deduced from the work of Beling and co-workers, ${ }^{4}$ and the assumption that the decay scheme shown in Fig. 2 is correct for all states b elow the $158.5 \mathrm{kev}$ level. From this value of the total conversion coefficient and the $\mathrm{L} / \mathrm{M}+\mathrm{N}$ ratio of the $59.6 \mathrm{kev}$ El transition lassuming they are the same for both transitions), the total $\mathrm{L}$ conversion coefficient may be calculated to be $3.75 \pm 1.2$. This rules out an M1 or E2 assignment and is in fair agreement with that expected for an El assignment (2.3) 6 
Assuming the assignments of E2, character fwith a possible admixture of $M 1$ ) for the $98.9, \therefore 43.4$, and $56.4 \mathrm{kev}$ transitions, El character for the 59.6 and $26.4 \mathrm{kev}$ transitions, and.Ml character for the $33.1 \mathrm{kev}$ transition are correct, we may speculate as to spin . designations for the levels.in $\mathrm{Np}^{237}$. The ground state spin has been measured and found to be $5 / 20^{12,13}$. If the parity of the ground state is assumed to be odd, then the parity of the $33.1,59.6,103$, and 158.5 kev levels must be odd, even, even, and even, respectively. If the first excited state is the only observed level of an odd parity "rotational band ${ }^{814}$ and the next three higher levels are part of an even parity "band", then the levels are as follows:

$$
\begin{aligned}
& 9 / 2+\longrightarrow 158: 5
\end{aligned}
$$

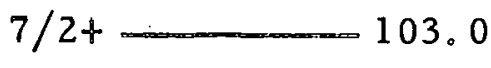

$$
\begin{aligned}
& 5 / 2+\square 59.6 \\
& 7 / 2=\square 33.1 \\
& 5 / 2+0
\end{aligned}
$$

The 128 and $168 \mathrm{kev}$ gamma rays which have been observed in very low abundance 10.000056 per alpha and $6.3 \times 10^{-6}$ per alpha, respectively) ${ }^{7}$ might possibly represent the transitions from the $11 / 2+$ level (expected at $227 \mathrm{kev}$ above ground) of the even parity band to the $103 \mathrm{kev}$ and $59.6 \mathrm{kev}$ levels respectively. 'l'he next higher liegativr. parity level is expected about $76 \mathrm{kev}$ above the ground state. This level has not been observed from the alpha decay, but its abundance is expected to be low from the trends in hindrance factors. 14

Electron lines were obșerved which could be assigned to the $\mathrm{L}_{\mathrm{I}} \mathrm{L}_{\mathrm{II}}$ conversion of gamma rays of 168.5 and $209.8 \mathrm{kev}$. However, these lines were of such low and uncertain intensity that no detailed arguments can 
be made from the data with any reasonable confidence. An unassigned electron line of $118 \mathrm{kev}$ was.also observed.

\section{B. Americium $242 \mathrm{~m}$ and 242}

1." L lines of the 41.0 and the $43.3 \mathrm{kev}$ transitions in the decay of $\mathrm{Am}^{242 \mathrm{~m}}$ - The two isomers of $\mathrm{Am}^{242}$ with half-lives of 16 hours and about 100 years, respectively, were first observed as neutron capture products of $\mathrm{Am}^{241} \cdot 15-17$. The low energy electron lines and beta spectrum of the 16 -hour isomer were studied previously by $O^{\prime}$ Kelley et al. ${ }^{18}$ Their work is summarized in Figs。 3 and 4.

The sample used in the present investigation was produced by a neutron bombardment of $\mathrm{Am}^{241}$ in the MTR reactor at Arco, Idaho. The low energy line spectrum observed fromithis sample appears in Fig. 6. The general features of this spectrum and its interpretation were discussed by Hoff. ${ }^{19}$ However, a revised set of abundances for the various lines will be presented, inasmuch as the relative $L$ shell conversion coefficients are of primary interest here. This revised list of line abundances appears in Table 2. It was obtained from the same data Hoff ${ }^{19}$ used, but is based upon a more detailed analysis of the line shapes. It is, however, still subject to very large uncertainties for several reasons. The first is the uncertainty in the exact level of scattered electron background. It is here assumed to be equal to the level of the epectrum at 0.38 amperes. A second factor is the unknown abundance of $\mathrm{L}$ Auger electrons which accentuate the intensity of the low energy tail of the $17.3 \mathrm{kev}$ line. The third and probably most serious factor is the uncertainty involved in determining the low energy tail of unresolved lines. 
Table 2

Revised Intensities of $\mathrm{Am}^{242 \mathrm{~m}}$. Electron Lines

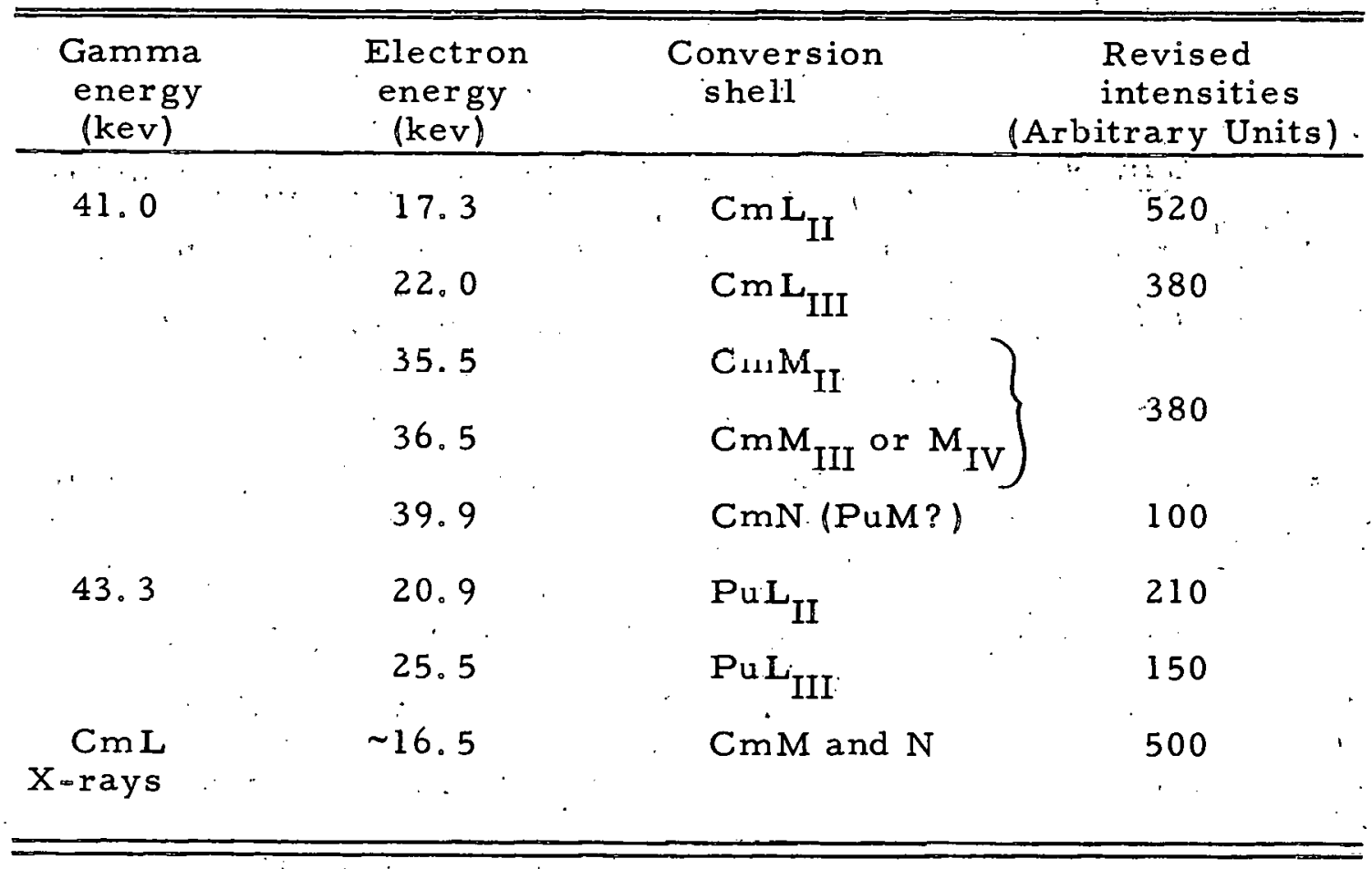




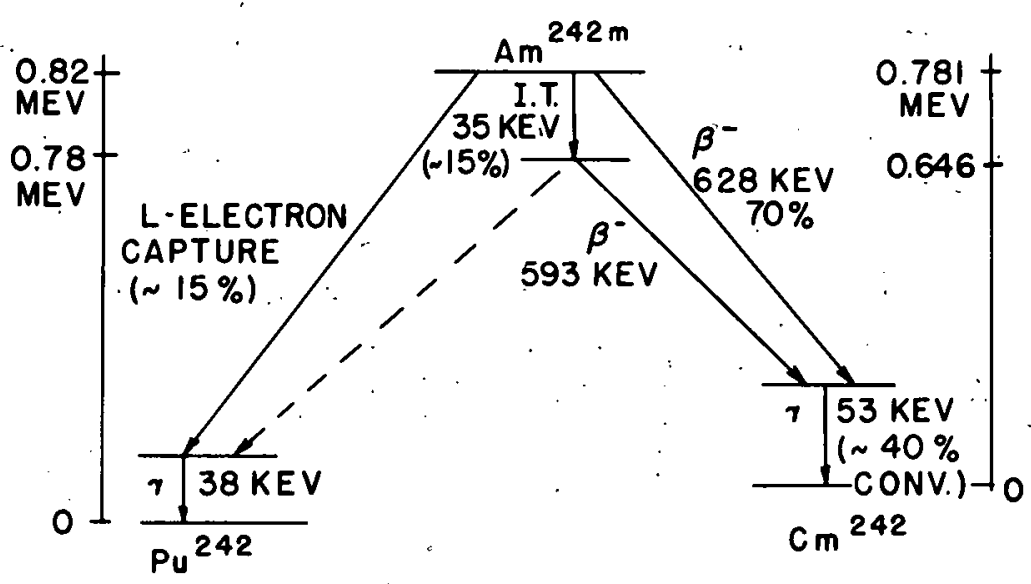

Fig. 3 - Decay scheme of $\mathrm{Am}^{242 \mathrm{~m}}$ proposed by O'Kelley et al. ${ }^{18}$. 


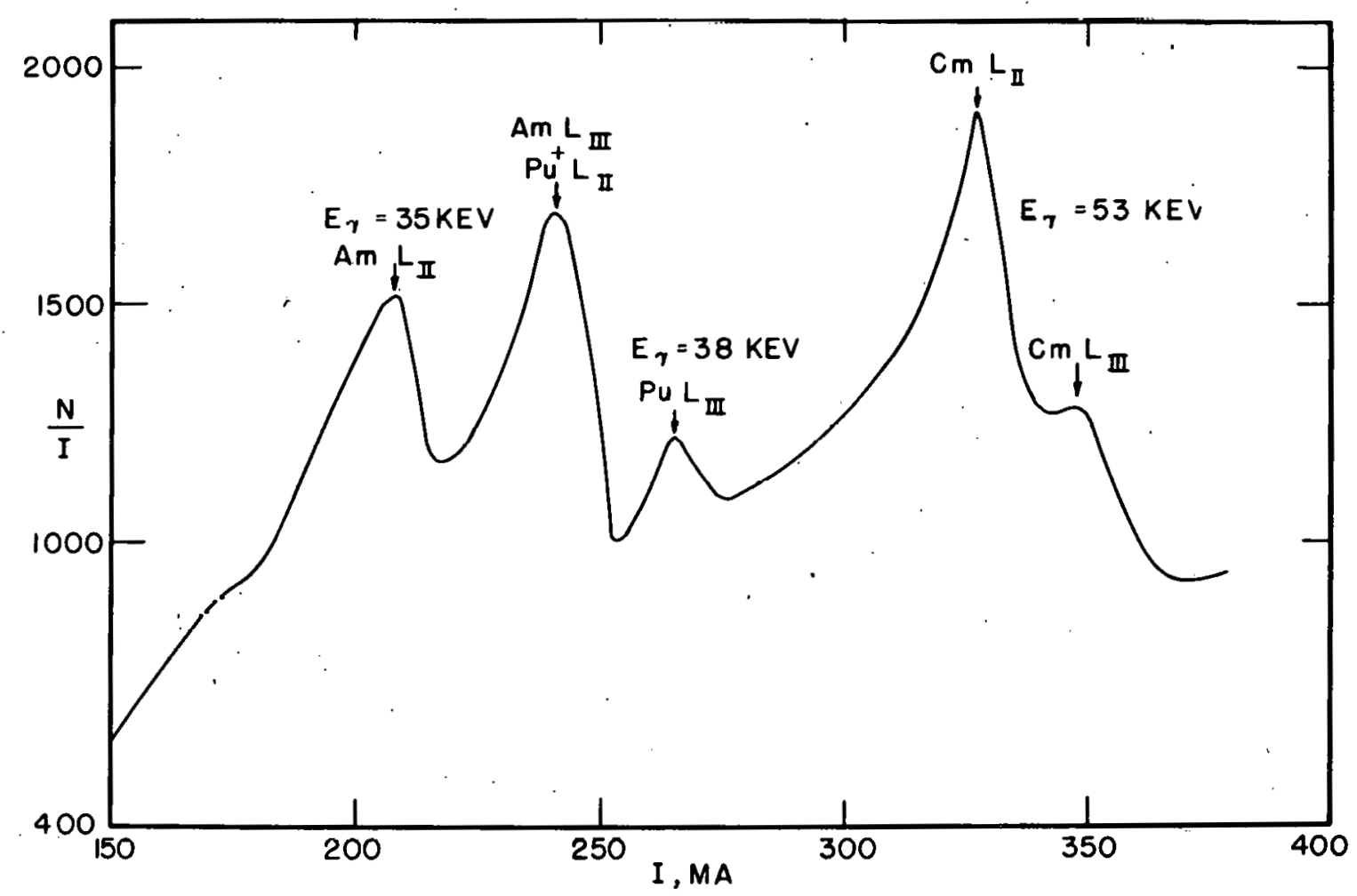

Fig. 4-Electron spectrum observed by $O^{\prime}$ Kelley et al. ${ }^{18}$. 


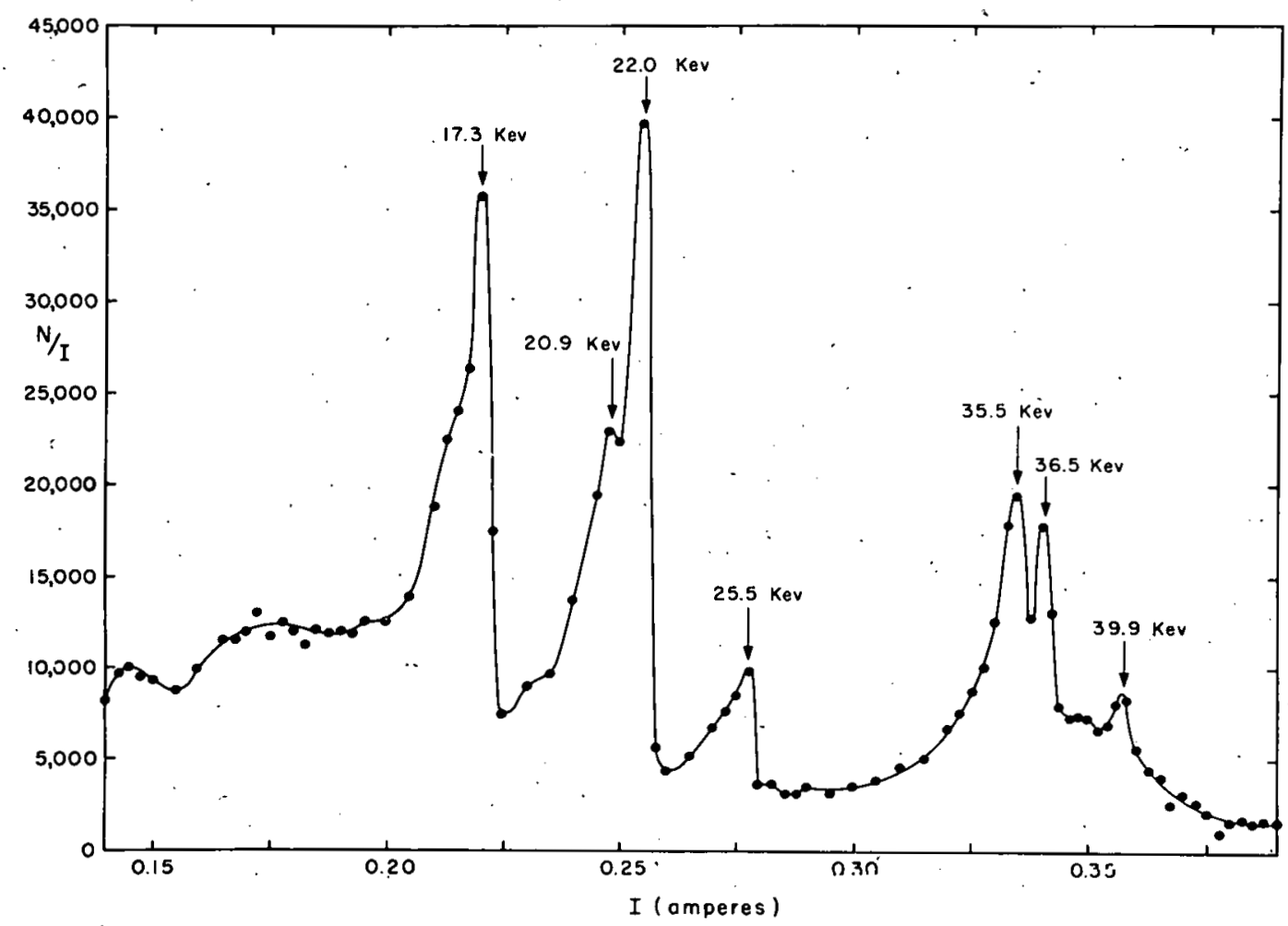

Fig. 5-Electron spectrum of $\mathrm{Am}^{242 \mathrm{~m}}$. 
With such uncertainties as these involved, the arguments based upon line intensities must be cautiously used. The $\mathrm{L}_{\mathrm{II}} / \mathrm{L}_{\mathrm{III}}$ conversion ratios are $1.37 \pm 0.4$ and $1.4 \pm 0.4$ for the 41.0 and $43.3 \mathrm{kev}$ gamma rays respectively. Of course, the fact that the $L_{\text {II }}$ and $L_{\text {III }}$ conversion electrons are of largest intensity indicates the radiation is quadrupole or higher multipole electric radiations since $E l$ and all magnetic radiations are expected to exhibit marked $L_{I}$ conversion lines。 6 The assignment of E2 character to both the 41.0 and $43.3 \mathrm{kev}$ radiations is consistent with the regularities noted among first excited states of even-even nuclei 20,21 and the theoretical calculations of Gellman et al. 6

2. Miscellaneous data on $\mathrm{Am}^{242 \mathrm{~m}}$ and $\mathrm{Am}^{242}$ - - The beta spectra of both the isomers of $\mathrm{Am}^{242}$ were run with separate samples. Both gave straight line Fermi-Kurie plots within the limits of experimental error. The end point of the 16 huur Aus $242 \mathrm{~m}$ bcta spectrum occurred at $620 \pm 10 \mathrm{kev}$ while that of the long-lived $\mathrm{Am}^{242}$ occurred at $585 \pm 10 \mathrm{kev}$. No electron lines were observed in the long - lived $\mathrm{Am}^{242}$ spectrum which could not reasonably be ascribed to the $\mathrm{Am}^{211}$ and $\mathrm{Cm}^{242}$ also present in the simple.

The integrated intensity of the Al1 $242 \mathrm{~m}$ bcta opoctrum at the. time the electron spectrum shown in Fig. 5 was taken amounted to $\sim 1900 \pm 500$ arbitrary units. This gives the value $0.7 \pm 0.2$ for the fraction of the $\mathrm{Am}^{242 \mathrm{~m}}$ beta decay populating the first excited state of $\mathrm{Cm}^{242}$. Hoff's ${ }^{19}$ estimate of this fraction was larger $(\sim 1.0)$ since he included the low-energy shoulder of the $4 l_{0} .0 L_{\text {II }}$ line with the abundance of that line. The subtraction of this shoulder from the $41.0{ }_{L_{\text {II }}}$ line 
abundance is reasonably justified by the expected presence of $L$ Auger lines in this region. Using the value of 0.57 for the $L_{I I}$ shell fluorescence yield given by Kinsey ${ }^{22}$ (which gives 0.43 for the $L_{\text {II }}$ Auger yield), the expected abundance of all the $\mathrm{L}_{\mathrm{II}}$ Augers from the $\mathrm{L}_{\text {II }}$ line abundances would be about 500 arbitrary units. The presence of $L_{I}$ Augers in the same region from $L_{I}$ electron capture ${ }^{19}$ added to the abundance of this line also. Thus, one can conclude that there are present sufficient $\mathrm{L}_{\mathrm{I}}$ or $\mathrm{L}_{\mathrm{II}}$ Auger electrons to account for the abundance assigned to the line in question.

3. Decay scheme of $\mathrm{Am}^{242 \mathrm{~m}}$ and $\mathrm{Am}^{242}$.-. Some very recent coincidence experiments performed by Stephens ${ }^{23}$ at this laboratory indicate $48 \pm 5$ percent and $52 \pm 5$ percent branchings of $\mathrm{Am}^{24.2 \mathrm{~m}}$ beta decay to the first excited and ground states of $\mathrm{Cm}^{242}$, respectively. These experiments lend added support to the necessity for a reinterpretation of the $41.0_{L_{\text {II }}}$ line intensity. Similar experiments performed by Stephens ${ }^{23}$ on the long-lived $\mathrm{Am}^{242}$ indicate a branching of $42 \pm 5$ pero cent for its beta decay to the first excited state of $\mathrm{Cm}^{242}$, the remainder again populating the ground state. The limits of error quoted above for the percent of branching do not include possible errors from uncertainties in 1. the value 0.5 used for the $L$ Auger yield and, 2) the value 0.8 used for the fraction ( $\dot{L}$ conversion electrons)/(total conversion electrons) for the $41,0 \pm 2 \mathrm{kev}$ gamma transition.

Recent experiments performed by $\mathrm{Church}^{8}$ give energies of $42.2 \pm 0.3$ and $44.6 \pm 0.3 \mathrm{kev}$, respectively, for the gamma rays following Am $242 \mathrm{~m}$ beta and electron capture decay, respectively. These agree with the values reported here within the limits of our absolute 
error which because of calibration difficulties was $\pm 2 \mathrm{kev}$. Consistent with the work of the author, Church also failed to. observe any electron lines which could be ascribed to the isomeric transition.

The absence of any electron lines ascribable to the isomeric : transition and the low intensities of americium $L$ x-rays ${ }^{7}$. leads one to set an upper limit of about 6 percent on the relative intensity of the isomeric transition. Church ${ }^{24}$ interprets this absence of any observeable isomeric transition as indicating a spin difference of at least three between the two isomers. This interpretation is not at all consistent with the recent results of Stephens. ${ }^{23}$ which shows that both isomers beta decay primarily to the ground $(0+)$ and first excited states $(2+)$ of $\mathrm{Cm}^{242}$. This peculiar situation leads one to think that the spin of both isomers might be zero and.that they have different parities. This is reasonably consistent with the ft values only if the Gamow-Teller selection rules are assumed to apply. A gamma transition between a $0+$ and a $0=$ state is absolutely forbidden both to emission of orbital electrons and to emission of gamma quanta.

Of course, another consequence of Stephens' results is that the beta spectrum maximum energies observed for each isomer quite probably correspond to the beta group populating the ground states of $\mathrm{Cm}^{242}$ in each case. Thus the revised decay scheme given by Hoff ${ }^{19}$ must again be revised in light of these more recent experiments. There are sufficient uncertainties remaining, however, so as to preclude the drawing of:a unique decay: scheme. 
C. Curium 242

1. L lines of $44.1 \pm 0.5$ and $102.0 \pm 1 \mathrm{kev}$ gamma rays. $-\infty$ Previous studies on the electron spectra have been made by Prohaska, 25 Dunlavey and Seaborg, ${ }^{26}$ and O'Kelley. ${ }^{1}$ Prohaska found coincidences between electrons of 37.5 and $25 \mathrm{kev}$ and alpha particles. Using the photographic emulsion technique, Dunlavey and Seaborg observed $L$ and $M$ electrons corresponding to a gamma ray of about $45 \mathrm{kev}$ in coincidence with alpha particles. Using the same instrument as the author, $O^{\prime}$ Kelley observed $L$ and $M$ electrons corresponding to a gamma ray of $43 \mathrm{kev}$. Asaro ${ }^{9}$ has investigated the complex alpha spectrum of $\mathrm{Cm}^{242}$ using a magnetic spectrograph. The present study was undertaken with the purpose of obtaining $\mathrm{L}_{\mathrm{II}} / \mathrm{L}_{\mathrm{III}}$ conversion ratios for the 44.1 and the $102.0 \mathrm{kev}$ gamma rays.

Two samples were made from about one microgram of $\mathrm{Cm}^{242}$. The curium had been obtained from neutron bombardments of Am 241 and was chemically very pure. Both samples were evaporated from a solution on a palladium leaf backing.

The electron spectra obtained with the two samples are presented in Figs. 6a and 6b. The more intense sample ( about $5 \times 10^{9}$ alpha disintegrations per minute) was used for the very low intensity electron lines from the $102 \mathrm{kev}$ transition. The lines of the more abundant $44 \mathrm{kev}$ transitions were run on an accurately alpha counted sample of $2.1 \times 10^{8}$ disintegrations per minute. From the integrated abundance of the lines of the 44 kev transition (assuming 100 percent conversion), ${ }^{9}$ a knowledge of the limiting inherent resulution of the spectrometer at the time of the experiment (l percent), the accurate alpha count of the 


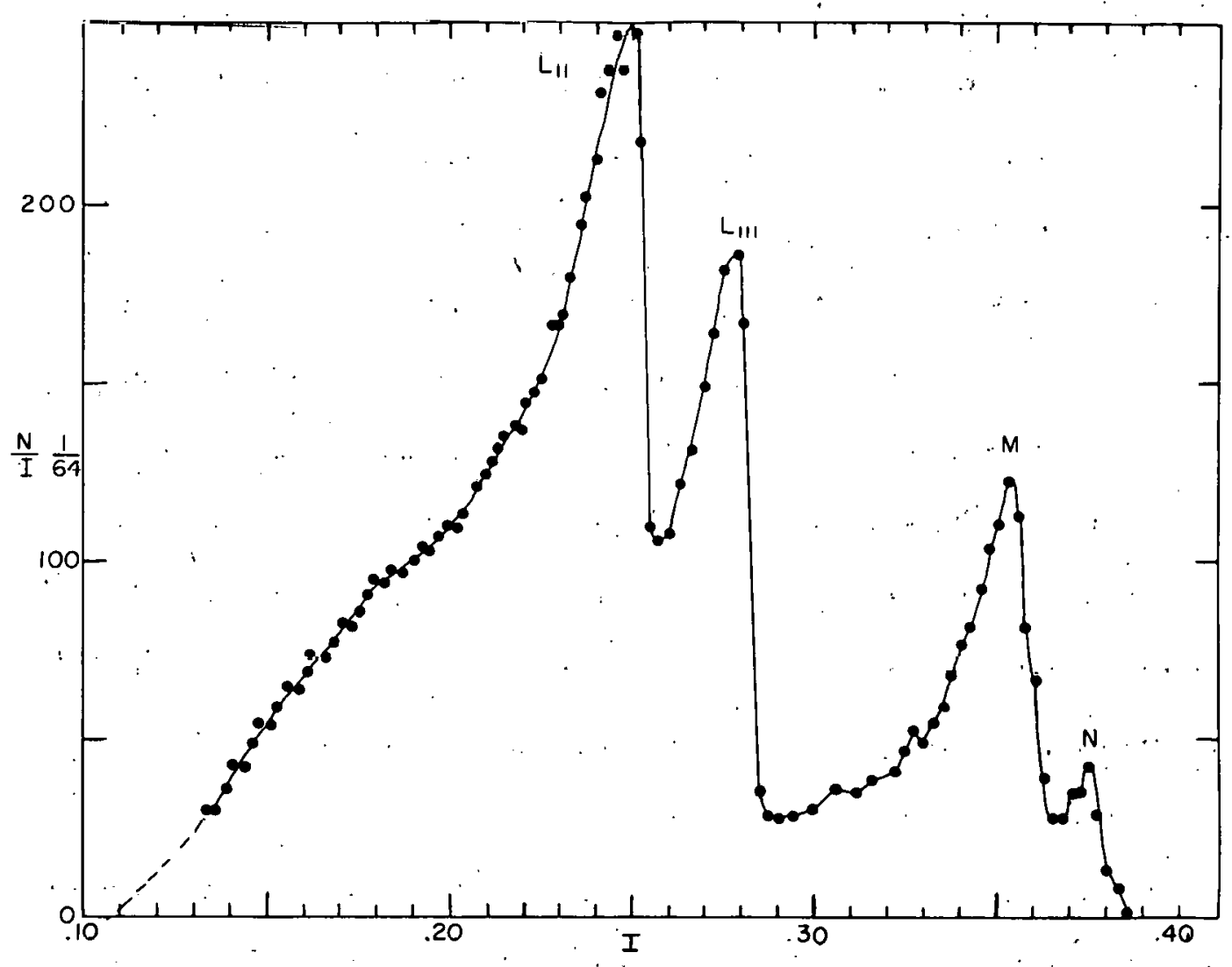

Fig. $6 \mathrm{a}-$ Electron spectrum of $\mathrm{Cm}^{242}$. 


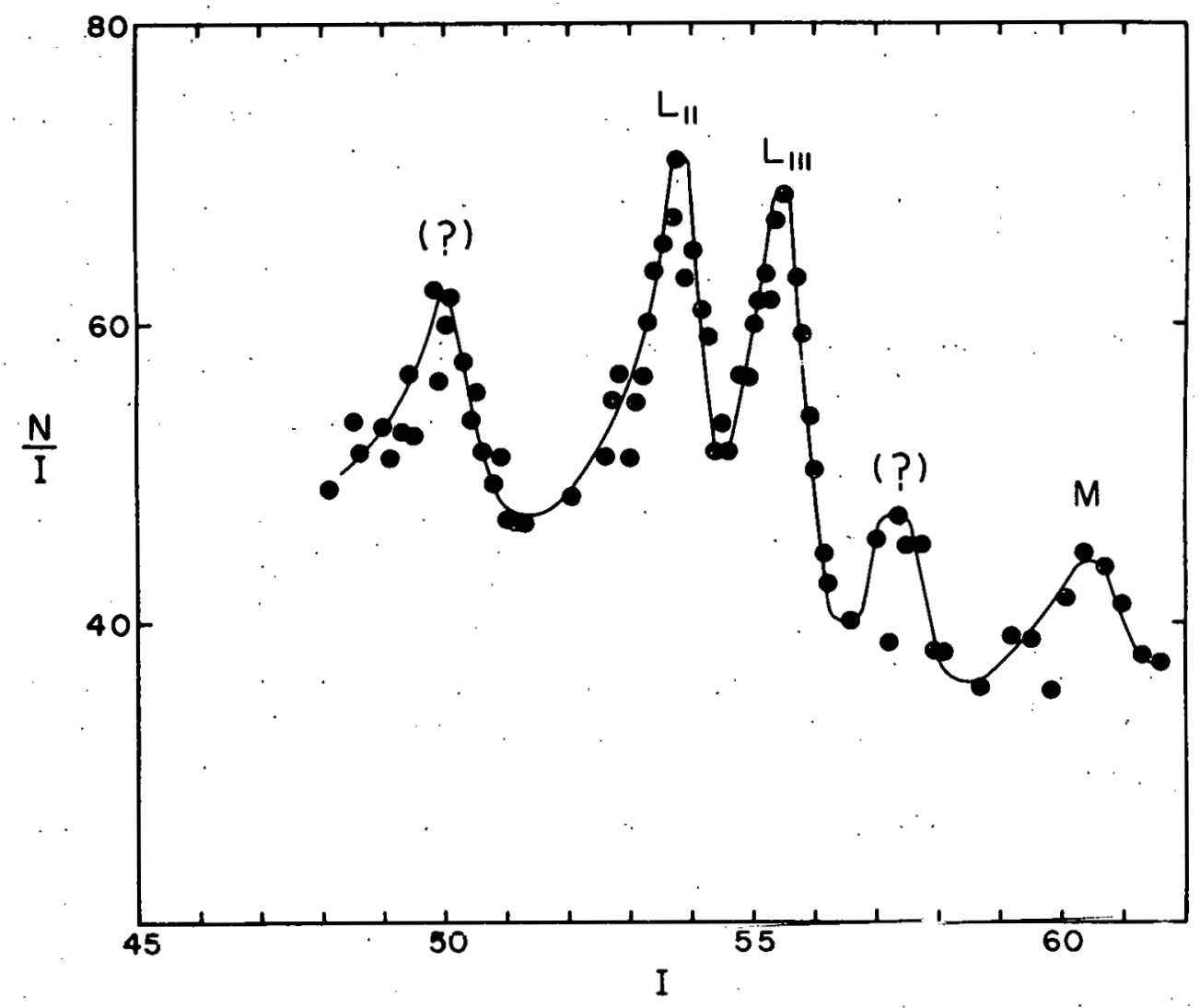

Fig. 6b-Electron spectrum of $\mathrm{Cm}^{242}$. 
sample, and a knowledge of the alpha population to the levels in $\mathrm{Cm}^{242}$ (see Fig. 7), the: transmission of the instrument can be calculated. The value thus obtained was 0.3 percent of $4 \pi$ 。

Table 3 presents the data obtained from the two samples of $\mathrm{Cm}^{242}$. The line abundances were normalized on the $44.1_{\mathrm{N}}$ line which was observed for both samples. The $\mathrm{L}_{\mathrm{II}} / \mathrm{L}_{\mathrm{III}}$ conversion ratio of the $44.1 \mathrm{kev}$ gamma ray calculated from the data is $1.4 .3 \pm 0.2$. Inrertainties in delermining the low energy tails of the incompletely resolved $L_{I I}$ and $L_{I I I}$ lines are the chi'ef reason for the large limits of error quoted above. The presence of $\mathrm{L}$ Auger electrons in the region of the low energy tail of the $44.1_{L_{I I}}$ line adds even more uncertainty to the abundance of this line.

Table 3 .

Curium 242 Electron Lines

\begin{tabular}{cccc}
\hline $\begin{array}{c}\text { Gamma } \\
\text { transition } \\
\text { (kev) }\end{array}$ & $\begin{array}{c}\text { Eleclruil } \\
\text { energy } \\
\text { (kev) }\end{array}$ & $\begin{array}{c}\text { Convorsion } \\
\text { shell }\end{array}$ & $\begin{array}{c}\text { Ahundance } \\
\text { (Arbitrary Units) }\end{array}$ \\
\hline 44.1 & 21.7 & $\mathrm{PuL}_{\mathrm{II}}$ & 12.1 \\
26.0 & $\mathrm{PuL}_{\mathrm{III}}$ & 8.4 \\
& 39.0 & $\mathrm{PuM}_{\mathrm{II}}$ & 5.1 \\
& 42.8 & $\mathrm{PuN}_{\mathrm{II}}$ & 0.9 \\
& 79.7 & $\mathrm{PuL}_{\mathrm{II}}$ & $\sim 0.001$ \\
1.02 .0 & 84.0 & $\mathrm{PuL}_{\mathrm{III}}$ & $\sim 0.001$ \\
\hline
\end{tabular}

The $L_{\text {II }}$ and $L_{\text {III }}$ lines of the $102.0 \mathrm{kev}$ transitions are seen to be in roughly the same intensity from the present work. The errors are quite large in these relative intensity measurements. This same gamma transition has been investigated from a sample of $\mathrm{Np}^{238}$ by 
Slutis et al. 27 and by the author (see $\left.\mathrm{Np}^{238}\right)$. As can be seen from Fig. 6b, the scattered electron background is very high. This high scattered electron background is due to the very high intensity of electrons from the $44.1 \mathrm{kev}$ transition relative to those of the $102.0 \mathrm{kev}$ transition. Slutis et al., ${ }^{27}$ report an $\mathrm{L}_{\mathrm{II}} / \mathrm{L}_{\mathrm{III}}$ ratio for the $102.0 \mathrm{kev}$ transition of 1.55 .

2. Decay scheme - levels in $\mathrm{Pu}^{238}--$ The present work is consistent with an E2 assignment for both the $44.1 \mathrm{kev}$ and $102.0 \mathrm{kev}$ transitions. The high total conversion coefficients $(640$ and 5 , respectively ${ }^{9}$ ) definitely rule out El assignments and the absence of appreciable $L_{I}$ conversion 27 in each case rule out any magnetic multipole assignments. ${ }^{6}$ Since the lifetimes of the first two excited states of $\mathrm{Pu}^{238}$ have been found $\mathrm{by}$ coincidence experiments on $\mathrm{Np}^{238} 28$ to be of the order of micro seconds, it can be assumed that the two radiations emitted in the decay of these two excited states are El, E2, M1; or M2. Thus we can consider the E2 assignment established for both the 102.0 and the 44.1 kev transitions. Work by the author on $\mathrm{Np}^{238}$ (see $\mathrm{Np}^{238}$ ) sets a low limit on the amount of $\mathrm{Ml}$ radiation admixed with the well-established E2 radiations.

The energies determined by Slatis et al., ${ }^{27}$ for these two gamma rays were $44.1 \pm 0.1 \mathrm{kev}$ and $102.1 \pm 0.2 \mathrm{kev}$. These values are in excellent agreement with those obtained in the present study, namely $44.1 \pm 0.5 \mathrm{kev}$ and $102.1 \pm 1 \mathrm{kev}$. The limits of error in the latter values were based upon uncertainties in calibration of the spectrometer. The use of three significant figures is justified by the much smaller uncertainties in energy differences. 


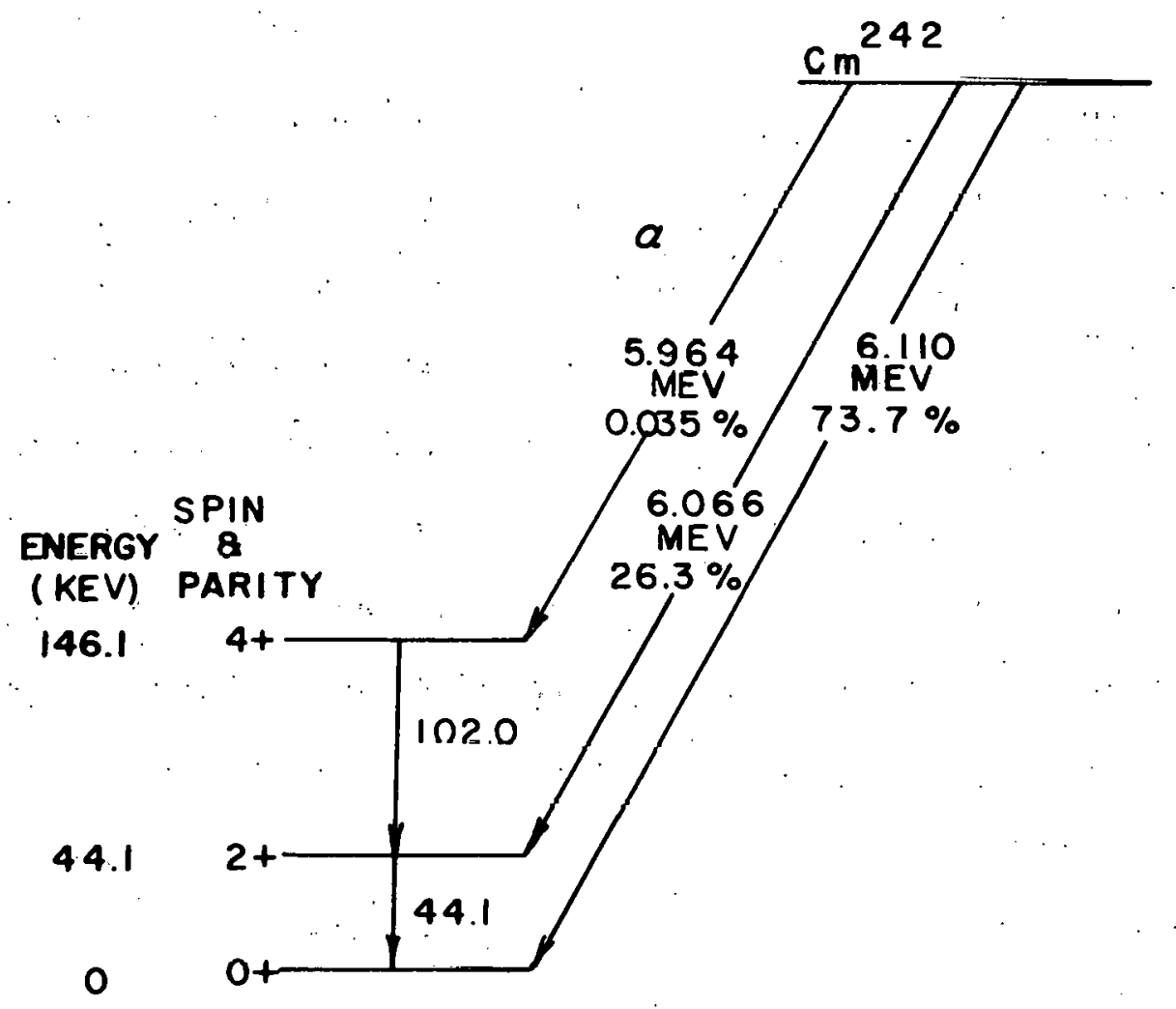

Fig. 7 - Decay scheme of $\mathrm{Cm}^{242}$. 
The author was not able to assign a number of electron lines of low intensity, two of which are shown in Fig.6b. It is not impossible, energy-wise; that some of these lines arise from an unknown amount of $\mathrm{Cm}^{243}$ contamination or from the $157 \mathrm{kev}$ radiation observed by Asaro ${ }^{9}$ in $\mathrm{Cm}^{242}$ decay. The abundance of the line (not shown) which. might be assigned as one of the L lines of a $157 \mathrm{kev}$ gamma ray is of about the intensity expected from the work of Asaro. 9

A decay scheme which incorporates the latest available data is shown in Fig. 7. The spin of the second excited state could equally well be $0+$ or $2+$.

\section{Neptunium 238}

1. L lines of the 44.1 and $102.0 \mathrm{kev}$ gamma rays. - -Neptunium 238 was first produced by Seaborg et al. ${ }^{29}$ in bombardments of uranium with $16 \mathrm{Mev}$ deuterons. Of the four groups of workers who have subsequently investigated the radiations of $\mathrm{Np}^{23827,28,30,31}$ two have used methods similar to those used in the present study. 27,28

The purpose of the present investigation was to obtain more accurate measurements of the $L$ conversion ratios for the $44.1 \mathrm{kev}$ and $102.0 \mathrm{kev}$ gamma rays.

The sample of $\mathrm{Np}^{238}$ used was produced by neutron bombardment of around one milligram of $\mathrm{Np}^{237}$ in the MTR reactor at Arco, Idaho. Chemical purification was achieved by using procedures which included an oxidation-reduction cycle and a final anion column separation. It should be noted that a significant amount of $\mathrm{Np}^{239}$ was produced by the second order neutron capture reaction in this bombardment. The Np 239 was detected by the observation of certain of its more intense electron 
lines. (See Fig. 8). The unmarked lines are those from $\mathrm{Np}^{239}$ The $\mathrm{Np}^{238}$ sample was prepared by sublimation of the activity from a tantalum filament onto a palladium leaf backing. Samples p repared in this way were invisible.

A momentum plot of part of the low energy electron spectrum of Np 238 is shown in Fig. 8. Lines of the $102.0 \mathrm{kev}$ gamma are not shown. The striking feature of the spectrum is the absence of low energy tails on the $44.1{ }_{L_{I I}}$ and $44.1 L_{I I I}$ lines. The use of the sublimation terihnique of sample preparation is responsible for the absence of the low energy tails. The electron line data are summarized in Table 4.

Table 4

Neptunium 238 Electron Lines

\begin{tabular}{|c|c|c|c|c|}
\hline $\begin{array}{c}\text { Gamma } \\
\text { energy } \\
\text { (kev) }\end{array}$ & $=$ & $\begin{array}{c}\text { Electron } \\
\text { energy } \\
\text { (kev) }\end{array}$ & $\begin{array}{l}\text { Conversion } \\
\text { shell }\end{array}$ & $\begin{array}{c}\text { Intensity } \\
\text { (Arbitrary Units) }\end{array}$ \\
\hline \multirow[t]{5}{*}{$44.1 \pm 0.5$} & & 21.0 & $P u \cdot L_{I}$ & $<5$ \\
\hline & & 21.8 & $\mathrm{PuL}_{\mathrm{II}}$ & 156 \\
\hline & & 26.0 & $\mathrm{Pu}_{\mathrm{III}}$ & 124 \\
\hline & & 38.7 & $\mathrm{PuM}_{\text {II }}$ & 37 \\
\hline & & 39.7 & $\mathrm{PuM}_{\text {III }}$ & 27 \\
\hline$\cdot$ & & 42.6 & $\operatorname{Pu} \Sigma N$ & 20 \\
\hline \multirow[t]{3}{*}{$102.0 \pm 1$} & & $78.9 \cdots$ & $\mathrm{PuL}_{\mathrm{I}}$ & $<2$ \\
\hline & & 79.7 & $P u L_{I I}$ & 6.5 \\
\hline & $\therefore$ & 83.9 & $\mathrm{PuL}_{\text {III }}$ & 4.0 \\
\hline
\end{tabular}




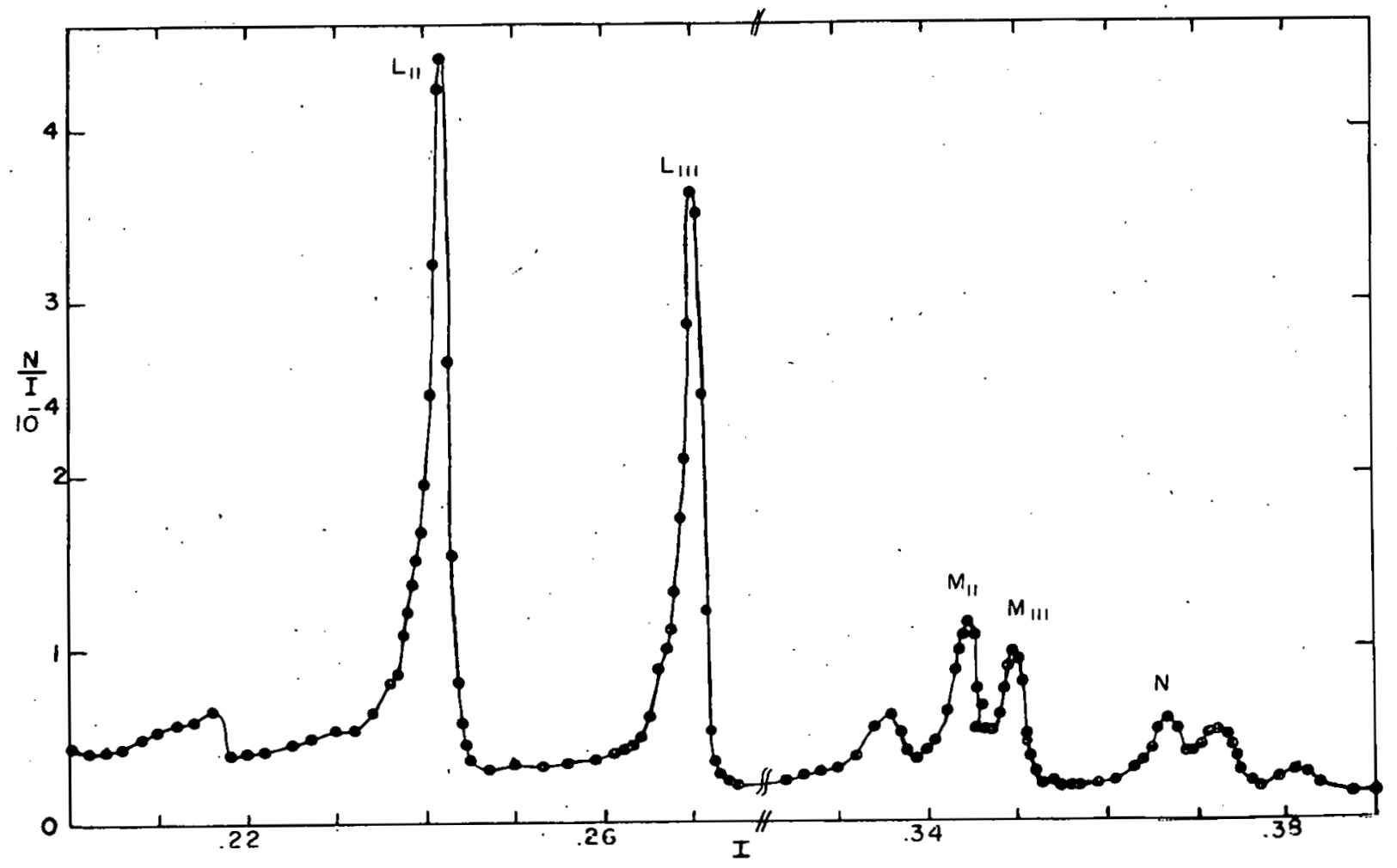

Fig. 8-Electron lines of $\mathrm{Np}^{238}$. 
The value (obtained in the present study) of $1.26 \pm 0.05$ for the $44.1 \mathrm{kev}: \mathrm{L}_{\mathrm{II}} / \mathrm{L}_{\mathrm{III}}$ ratio is in reasonably good agreement with the value 1.35 obtained by Slatis et al. 27 and in only fair agreement with the value 1.43 obtained for the same transition following $\mathrm{Cm}^{242}$ alpha decay. It should be noted that in the present study there was almost no uncertainty in the delineation of the low energy tails of the $44.1_{L_{\text {II }}}$ and $44.1_{L_{\text {III }}}$ lines. In none of the previous investigations was this uncertainty absent. Thus the line intensity determinations in the-present work are subject to much smaller errors than those of previous studies.

Because of the presence of lines of the $\mathrm{Np}^{239}$ impurity and $\mathrm{K}$ Auger lines in the same energy region, the measured intensities of the ${ }^{102} \mathrm{~L}_{\mathrm{II}}$ and ${ }^{102} \mathrm{~L}_{\text {III }}$ lines are somewhat uncertain. However, the value $1.62 \pm 0.2$ for the $102.0 \mathrm{kev} \mathrm{L}_{\mathrm{II}} / \mathrm{L}_{\mathrm{III}}$ ratio is in good agreement with the value given by Slatis et al ${ }^{27}(1.56)$, but in poor agreement with the value (about 1) obtained for the same transition following $\mathrm{Cm}^{242}$ alpha decay. The poor agreement with the $\mathrm{Cm}^{242}$ results can probably be ascribed to the use of an inferior method of sample preparation and the large uncer. tainties in line shapes in the $\mathrm{Cm}^{242}$ investigation.

As indicated in Table 4, limits of $<3$ percent and $<15$ percent can be set for the amount of $I_{I}$ conversion of the $44.1 \mathrm{kcv}$ and the $102.0 \mathrm{keg}$ gamma rays, respectively. These values are in agreement with the calculations of Gellman et al ${ }^{6}$ for electric quadrupole radiations. Thus an E2 assignment for both these gamma rays is justified. The absence of appreciable $L_{I}$ conversion in each case rules out the $M l$ and El assignments.

The present'work confirms the spin assignment made for the first two excited states of $\mathrm{Pu}^{238}$ made by $\mathrm{Asaro}^{9}$ and Slatis et al ${ }^{27} \mathrm{~A}$ 
unique decay scheme cannot be drawn which is consistent with all the available data: However, it is felt that the ground, first excited, and second excited states in $\mathrm{Pu}^{238}$ have been established as shown in Fig. 7 , with the possibility existing that the second excited state has a spin of $0+$ or $2+$.

\section{E. Thallium $198 \mathrm{~m}$}

1. L lines : of the $48: 4,261.5$, and $284 \mathrm{kev}$ gamma rays. - . A

1.9-hour isotope of thallium was first observed and assigned to $T l^{198}$ by Orth et al: ${ }^{32}$ Recently this activity has been independently assigned by two different groups of investigators to the decay of an isomeric state. The previously unobserved ground state decays by electron capture to $\mathrm{Hg}^{198}$ with a half-life of $5.3 \pm 0.5$ hours.

Michel and Templeton ${ }^{33}$ of this laboratory produced these activities by the $\mathrm{Au}^{197}(\mathrm{~d}, 3 \mathrm{n}) \mathrm{Tl}^{198}$ reaction in the laboratory:s 60 -inch cyclotron. Mass separation was made on a time-of-flight isotope separator $^{2}$ and the 1.75 -hour and 5.3-hour activities shown to be $\mathrm{T}^{198}$. Bergstr $\forall m,: H i l l$, and DèPasquali ${ }^{34}$ at the University of Illinois produced the same activities by bombarding mercury with $11.5-\mathrm{Mev}$ deuterons." Among the many"electron lines they observed were several approximately 1.9-hour: lines assignable to two gamma rays converting in thallium with energies of 282.4 and $260.7 \mathrm{kev}$, and a third gamma ray of $48.7 \mathrm{kev}$ whose assignment was not unambiguous: The authors suggested that all three gamma rays were in cascade from an isomeric state having the unusually high spin of 9 with odd parity. Because of the unusual decay scheme suggested, the ambiguity of the $48.7 \mathrm{kev}$ gamma ray's assignment, and the uncertainties in the photographically determined 
intensities, further work on this isomer was thought to be desirable.

In this investigation 1 mil gold foil was bombarded in the

laboratory ${ }^{8} \mathrm{~s} 60$ inch cyclotron with $40 \mathrm{Mev}$ helium ions to produce the $\mathrm{Tl}^{198 \mathrm{~m}}$ by the $(\mathrm{d}, 3 \mathrm{n})$ reaction. This choice of foil thickness and bombarding energy was effective in minimizing the production of $\mathrm{Tl}^{199}$.

The thallium was chemically separated from the gold target by the following process: 1) the gold was dissolved in aqua regia leaving the gold and thallium in solution as $\mathrm{Au}^{+3}$ and $\mathrm{Tl}^{+3}$ ions, respectively; 2) sulfur dioxide gas was bubbled through the solution to reduce the $\mathrm{T} 1^{+3}$ to $\mathrm{T} 1^{+1}$ and the gold to the metal; 3) the solution was centrifuged and supernatant containing $\mathrm{T}^{+1}$ and traces of $\mathrm{Au}{ }^{+3}$ carried through varying purification procedures including an ethyl acetate extraction and an anion column separation; 4) the final step in the purification procedure was the use of a column containing Dowex $\mathrm{A}-2$ anion resin. Hydrochloric acid was used as the eluant. The solution containing thallium was passed through the column in

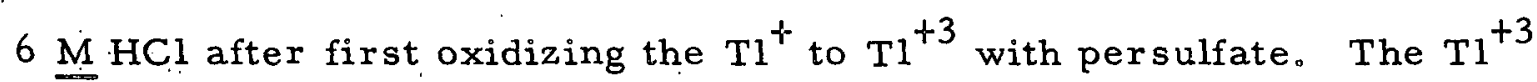
sticks at the top under these conditions. Successively more dilute hydrochloric acid solutions were used for washing out impurities, 5) the $\mathrm{Tl}^{+3}$ was finally stripped from the column with water saturated with sulfur dioxide gas. This carrier-free solution was used to make the spectrometer samples.

The only sample prepared which gave well resolved electron peaks was one in which the thallium was vaporized onto $\therefore$ palladium leaf from a tungsten filament. The palladium leaf had a thickness of $157 \mu \mathrm{g} / \mathrm{cm}^{2}$. This vaporized sample had the dimensions $1 \mathrm{~mm} \times 6 \mathrm{~mm}$. 
The experimental data are summarized in Table 5. The spectrum itself is shown in Figs. $9 \mathrm{a}$ and $9 \mathrm{~b}$. The $\mathrm{K}$ Auger lines are discussed bëlow. The L Auger lines were also observed, but no inferences can be made therefrom because of the large and uncertain window absorption correction necessary at such low energies. In Table 5 the gamma ray energies are also given. Except for the $48.4 \mathrm{kev}$ gamma ray, the energy values of the Illinois group ${ }^{34}$ are more accurate and will be used in the following discussion.

It should be mentioned that there was initially present a very small percentage of 7.4 hour $\mathrm{Tl}^{199}$. The only $\mathrm{T} 1^{199}$ electron line which coincided with any of those from $\mathrm{Tl}^{198 \mathrm{~m}}$ was the $50.0 \mathrm{~L}_{\mathrm{I}} \cdot$ This line was of insignificant abundance at the time the $48.4 \mathrm{~L}_{\text {II }}$ and $48.4 \mathrm{~L}_{\text {III }}$ lines of $\mathrm{Tl}^{198 \mathrm{~m}}$ were observed, but several hours later it was a useful calibration point for determining the energy of the $48.4 \mathrm{kev}$ gamma ray.

The ratios given in Table 5 depend considerably upon the half-life assumed when the decay corrections were made." The limits of error do not necessarily encompass those introduced by the unknown uncertainty in halfolife. We used a half blife value of 1.75 hours, which was measured by Michel and Templeton ${ }^{33}$ on a separated sample.

Bergstr $b \mathrm{~m}$ and co-workers ${ }^{34}$ found that the $260.7 \mathrm{kev}$ gamma ray was definitely the cascade initiator, being of the M3 or M4 type with a possible admixture of electric radiation. Our $\mathrm{K} / \mathrm{L}$ ratio $(1.0)$ is in excellent agreement with that for pure M4 radiation. $35-37$ According to the curves of Tralli and Lowen, ${ }^{38}$ where $\mathrm{L}_{I I I} / \mathrm{L}_{\mathrm{I}}$ is plotted as a

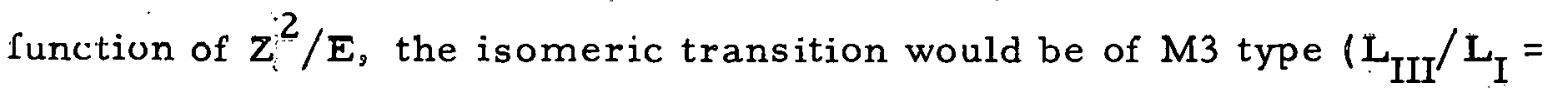
0.80 for $M 3$ and 1.4 for M4). However, these curves are based on 
Table 5.

Thallium $19.8 \mathrm{~m}$ Electron Lines

\begin{tabular}{|c|c|c|c|c|}
\hline $\begin{array}{c}\text { Gamma } \\
\text { energy } \\
(\mathrm{kev})\end{array}$ & $\begin{array}{c}\text { Electron } \\
\text { energy } \\
\text { (kev) }\end{array}$ & $\begin{array}{c}\text { Conversion } \\
\text { shell }\end{array}$ & $\begin{array}{l}\text { Abundance } \\
\text { (Arbitrary } \\
\text { Units) }\end{array}$ & $\begin{array}{c}\text { Conversion } \\
\text { ratios } \\
\end{array}$ \\
\hline \multirow[t]{6}{*}{$43.4 \pm 0.2$} & $(33.1)$ & $\mathrm{TI} \mathrm{L}_{\mathrm{I}}$ & $<1.5$ & $\mathrm{~L}_{\mathrm{II}} / \mathrm{L}_{\mathrm{III}}=1.11 \pm 0.1$ \\
\hline & 33.7 & T.1 L II & 37.3 & : \\
\hline & .35 .8 & T1 L $\mathrm{L}_{\text {III }}$ & .33 .6 & . \\
\hline & 45.2 & $\left.\mathrm{~T} 1 \mathrm{M}_{\mathrm{II}}\right)$ & 18.9 & \\
\hline & 45.6 & $\mathrm{Tl} \mathrm{M}_{\text {III }}$ & & $\cdot$ \\
\hline & 47.4 & $T 1 \mathrm{~N}_{\mathrm{I}}$ & 5.3 & \\
\hline \multirow[t]{4}{*}{$261.5 \neq 2$} & 177 & $\mathrm{Tl} \mathrm{K}$ & 44.3 & $\mathrm{~K} / \mathrm{L}=1.0 \pm 0.1$ \\
\hline & 246 & T1 $L_{I}$ & 26.0 & . \\
\hline & 249 & $\mathrm{~T} 1 \mathrm{~L}_{\mathrm{III}}$ & 17.8 & \\
\hline & 257 & $\mathrm{~T} 1 \mathrm{M} \mathrm{N}$ & 11.9 & . \\
\hline \multirow[t]{2}{*}{$284 \pm 3$} & 199 & $\mathrm{TIK}$ & 19.1 & $\mathrm{~K} / \mathrm{L}=9 \pm 1$ \\
\hline & 268 & $\mathrm{Tl} \mathrm{L} I$ & 2. $\mathrm{i}$ & ' \\
\hline
\end{tabular}




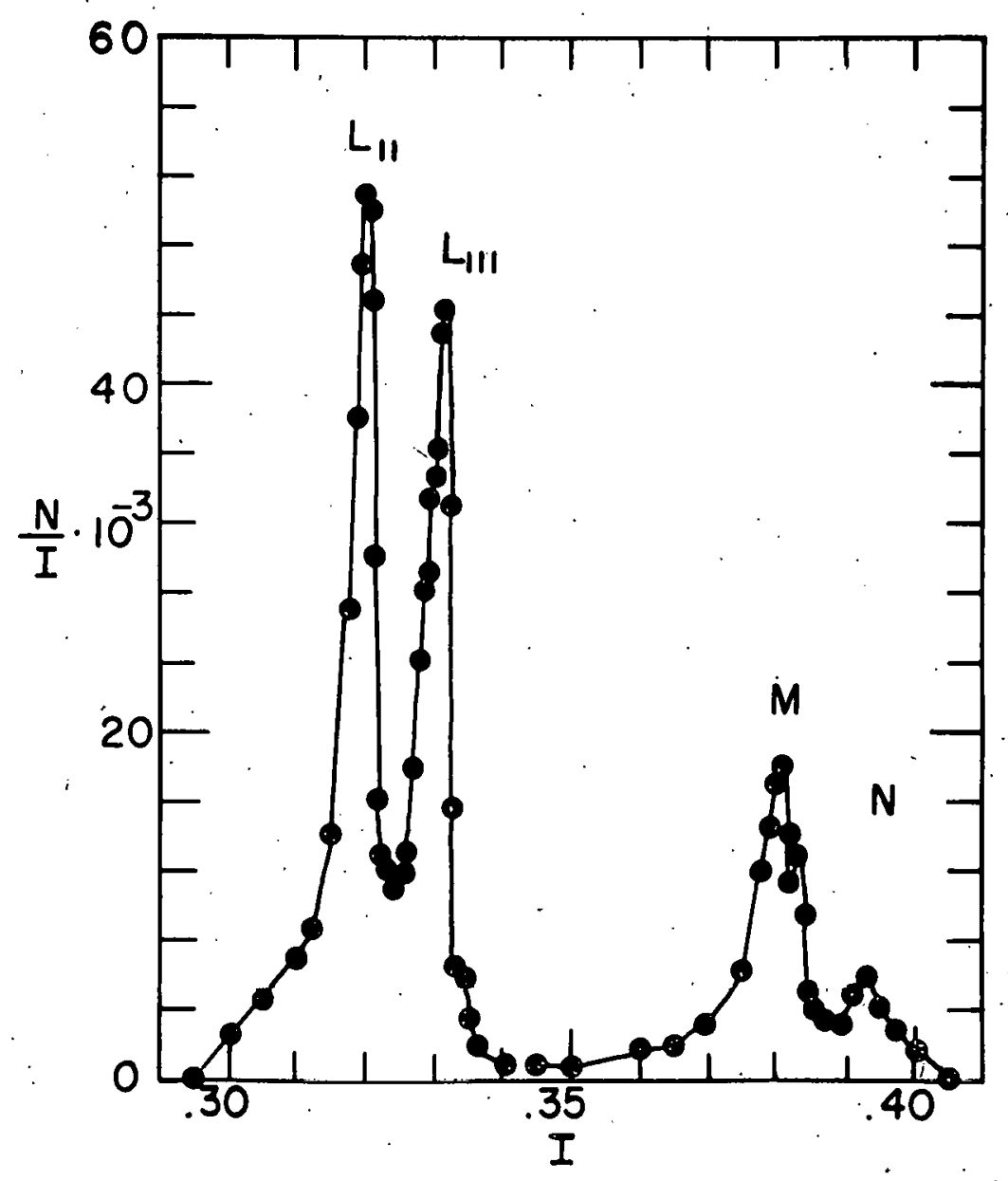

Fig. 9a - Thallium 198m electron spectrum. 
$-46-$

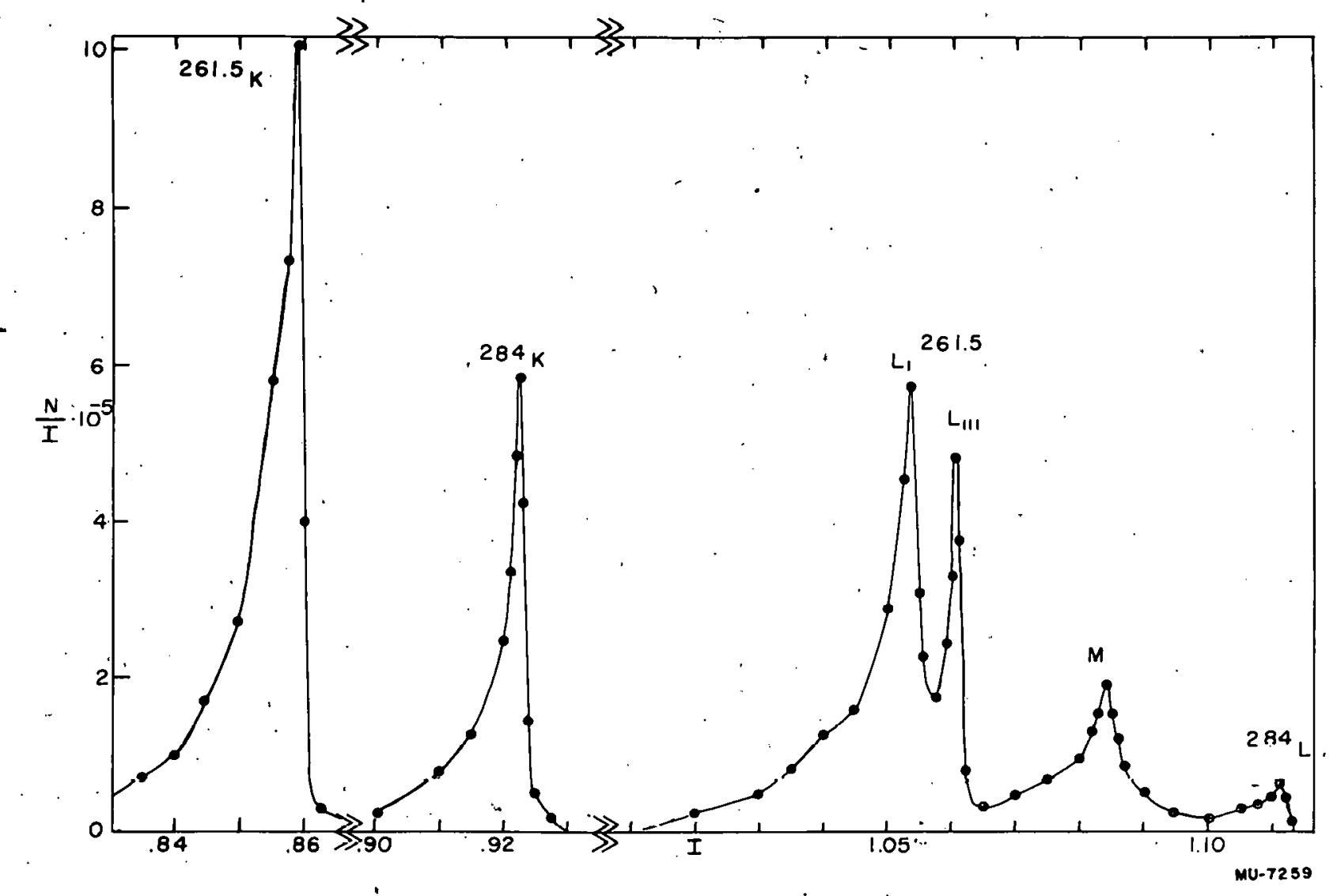

Fig. 9b-Thallium $198 \mathrm{~m}$ electron spectrum. 
approximate calculations and were performed for $Z=35$. Mihelich $^{39}$ has reported a summary of experimental $\mathrm{L}_{\mathrm{III}} / \mathrm{L}_{\mathrm{I}}$ conversion ratios for some M4 transitions in the region of atomic number around thallium. Fig. 10 shows this data with the inclusion of our value of $0.68 \pm 0.07$ for the $260.7 \mathrm{kev}$ gamma ray of $\mathrm{Tl}^{198 \mathrm{~m}}$. It is apparent that a smooth curve could be drawn through the experimental points shown, supporting an M4 isomeric transition for $\mathrm{T} 1{ }^{198 \mathrm{~m}}$.

The experimental mean life of the $260.7 \mathrm{kev}$ gamma ray may be calculated using the theoretical $\mathrm{K}$ conversion coefficients for M4 radiation from the tables of Rose et al. ${ }^{40}(18)$, our $260.7 \mathrm{~K} / \Sigma 260$ ratio $(0.44)$, and the half life of the isomeric state (1.75 hour s). The mean life thus calculated is $3.7 \times 10^{5}$ seconds. The theoretical value one obtains using the nomogram of Weisskopf's lifetime-energy-spin formula prepared by Montalbetti 41 is $5 \times 10^{5}$ seconds. This agreement mày be fortuitous. However, the M4 assignment is reasonable from the comparisons which have been made with existing theories and empirical correlations.

Because of the high intensity of the $\mathrm{T}^{199} 50.0 \mathrm{~L}_{\mathrm{I}}$ line, Bergstrom et $\stackrel{\text { al. }}{ }^{34}$ were unable to resolve the $48.4 \mathrm{~L}_{\text {III }}$. line. As a result they designated the $48.4 \mathrm{~L}_{\mathrm{II}}$ line as $48.7 \mathrm{~L}_{\mathrm{I}}{ }^{\circ}$ The two lines observed in this study can only be an $\mathrm{L}_{\text {II }}-\mathrm{L}_{\mathrm{III}}$ pair, and using the $50.0_{\mathrm{L}_{\mathrm{I}}}$ line of $\mathrm{Tl}{ }^{199}$ as a standard, one arrives at an energy of $48.4 \pm 0.2 \mathrm{kev}$ for the gamma ray. The $\mathrm{L}_{\mathrm{II}} / \mathrm{L}_{\mathrm{III}}$ ratio is in better agreement with E2.(1.6) than with El (about 1.8) or M1 (about 900), although only Ml can be ruled out on this basis. ${ }^{6}$ The El assignment was eliminated by a scintillation spectrometer experiment. which determined the total conversion coefficient of the gamma $r a y$ to be 


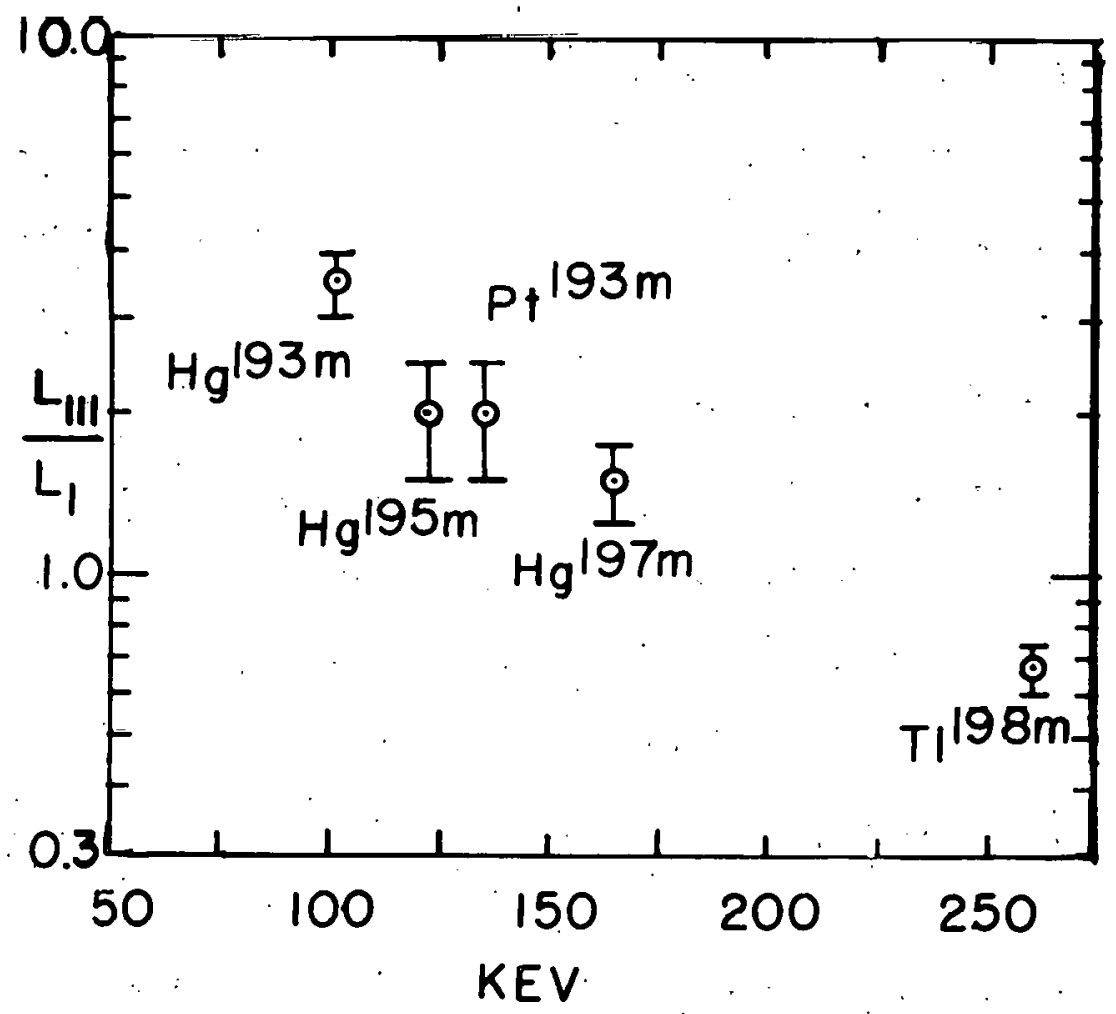

Fig. 10-Experimental LIIV/LI ratios for M4 transitions in the region of atomic numbers near 80 versus energy in kev. 
greater than 10. Therefore, the E2 assignment seems to be the only reasonable one.

The Illinois group has shown the 260.7 and 282.4 kev gamma rays to be converting in thallium. Coincidence measurements performed by Stephens 23 of this laboratory have shown the $282.4 \mathrm{kev}$ gamma ray to be in coincidence with $\mathrm{K}$ x-rays. Thus it appears that the $282.4 \mathrm{kev}$ and $260.7 \mathrm{kev}$ gamma rays are in cascade. Assuming no electron capture from excited states of $\mathrm{T}^{198}$ the $\mathrm{K}$ conversion coefficient of. the $282.4 \mathrm{kev}$ gamma ray can be calculated from the intensity ratio $\left(282_{K}\right) /\left(260_{K}+L+M_{0} \ldots\right)$.... The value $(0.24)$ thus obtained may indicate a mixture of $\mathrm{E} 2(0.076)$ and $\mathrm{Ml}(0.52)$ radiations. 40 The high $\mathrm{K} / \mathrm{L}$ ratio $(9 \pm 1)$ of this gamma ray supports an $\mathrm{Ml}$ assignment. 37

If the $48.4 \mathrm{kev}$ gamma ray is emitted in cascade with the other two and is assumed to be E2 radiation, the total intensity of its conversion electrons should equal the total intensity of those of the $260.7 \mathrm{kev}$ gamma ray. As can be seen from Table 5, these intensities are equal within experimental error. This does not exclude the possibility of an approximately 50 percent electron capture branching from the 1.75 hour isomeric state, with the $48 \mathrm{kev}$ transition taking place in $\mathrm{Hg}^{198}$. The $\mathrm{L}_{\mathrm{II}}-\mathrm{L}_{\mathrm{III}}$ binding energy differences are too similar in mercury and thallium to allow an assignment on that basis. However, if electron capture were occurring, one would expect gamma rays from levels in $\mathrm{Hg}^{198}$ in high intensity with a 1.75 hour half-life. A scintillation spectrometer experiment gave no indication of such gamma rays. Thus, it may be concluded that the three gamma rays are very probably emitted in cascade as suggested by the Illinois group. 34 
2. Spin assignments -0 Decay scheme of $\mathrm{Tl}^{198 \mathrm{~m}}$.If one assumes. that the assignments of multipolarity are correct and that the three gamma rays are in cascade, a tentative decay scheme can be constructed (see Fig. 11) in which the spin difference between the 1. 75 hour $\mathrm{T} 1^{198 \mathrm{~m}}$ and the 5.3 hour $\mathrm{Tl}^{198}$ can be as high as 7 . with a parity. change. The fact that no crossover radiation was observed supports this large spin difference. The positions of the $282.4 \mathrm{kev}$ and the $48.4 \mathrm{kev}$ transitions may be as shown in Fig. 11 go or reversed. The spin alternative to the left in Fig. 11 is based on the assumption of a 2 - ground state for $T 119834$ The alternative to the right is based on the assumption of a coupling between the spins of the 81st proton and the 117 th neutron. The $260.7 \mathrm{kev}$ M4 transition would then represent a transition of the 81 st proton from an $h_{11 / 2}$ to a $d_{3 / 2}$ configuration, the 117 th neutron remaining in an $\mathrm{f}_{5 / 2}$ configuration; the $282.4 \mathrm{kev} \mathrm{M1}+\mathrm{E} 2$ lranstion may perhaps represent a transition of the same proton between the $d_{3 / 2}$ and $s_{1 / 2}$ configurations, the neutron again remaining in the $f_{5 / 2}$ configuration; the $48.4 \mathrm{kev} E 2$ transition then represents $a$ transition of the odd neutron from the $f_{5 / 2}$ to a $p_{1 / 2}$ configuration, the proton remaining in an $s_{1 / 2}$ configuration. This interpretation, of course, is extremely speculative.

Also shown in Fig. 11 is the electron capture decay from $\mathrm{Pb}^{198}$ which was observed by Neumann and Perlman. 42 If the 25 minute $\mathrm{Pb}^{198}$ parent of $\mathrm{Tl}^{198 \mathrm{~m}}$ is the $0+$ ground state of $\mathrm{Pb}^{198}$, then $\mathrm{Tl} 198 \mathrm{~m}$. must have a low spin and $\mathrm{Tl}^{198}$ must have a high spin. The assignment of a high spin to $\mathrm{Tl}^{198}$ is in sharp disagreement with the interpretation of its electron capture decay given by Bergstrym and co=workers. 34 


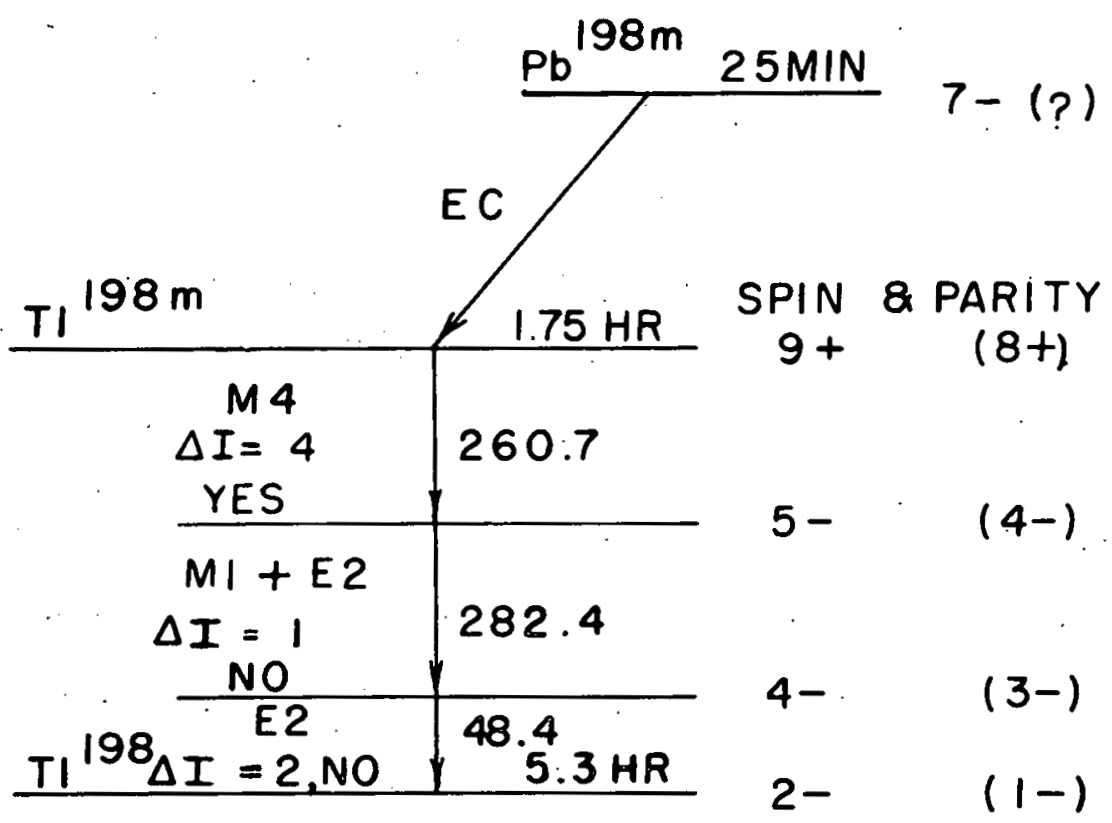

Fig. 11 - Decay scheme of $T^{198}$. 
These workers ${ }^{8}$ data indicate that the electron capture decay of $\mathrm{Tl}^{198}$ goes predominantly to the $2+$ first excited state of $\mathrm{Hg}^{198}$. Thus of the two isomeric states of $\mathrm{Tl}^{198}$ the 1.75 hour $\mathrm{Tl}^{198 \mathrm{~m}}$ most probably has the higher spin. The fact that other even-even lead isotopes have high spin isomers suggests that $\mathrm{Pb}^{198}$ might also have one. For example, the isomeric state of $\mathrm{Pb}^{204}$ has been suggested to be $6+{ }^{43}$ or $7-。 44$ Very recently Maeder and Wapstra ${ }^{45}$ have found indication of a 9. isomeric state in $\mathrm{Pb}^{202}$. Alburger 46 assigned the isomeric level in $\mathrm{Pb}^{206}$ as 7 .

If $\mathrm{Pb}^{198 \mathrm{~m}}$ has a similar high spin, direct electron capture decay from a high spin $\mathrm{Pb}^{198 \mathrm{~m}}$ to a high spin $\mathrm{Tl}^{198 \mathrm{~m}}$; would be possible. It may, therefore, be concluded that there is indeed another case of isomerism in $\mathrm{Pb}^{198}$.

3. Auger electron spectrum。- - The $\mathrm{K}$ Auger electrons emitted in the $\mathrm{K}$ electron capture of the 5.3 hour $\mathrm{T} 1^{198}$ daughter of $\mathrm{Tl} 198 \mathrm{~m}$ were investigated. Although some $\mathrm{K}$ xorays of thallium were present from the $K$ conversion of the $260.7 \mathrm{kev}$ and the $282.4 \mathrm{kev}$ gamma rays, greater than 70 percent of those present were those of mercury. Because of the presence of the $K$ Auger lines of two adjacent elements the assignment of resolved lines becomes somewhat ambiguous. However, reliable relative intensities of the $\mathrm{KL}_{\mathrm{p}} \mathrm{L}_{\mathrm{q}}, \mathrm{KL}_{\mathrm{p}} \mathrm{Y}_{\mathrm{q}}$ and $\mathrm{KX}_{\mathrm{p}} \mathrm{Y}_{\mathrm{q}}$ (where $\mathrm{X}$ and $Y$ refer to the $M_{2} N_{2}$ etc atomic orbitals) groups of lines can be obtained from the data. These relative intensities would correspond to those for an atomic number between 80 and 81 .

The K Auger spectrum uncorrected for decay is shown in Fig. 12. The decay corrections were not large since all the lines were observed within a period of 1.5 hours. Using a half-life of four hours for decay 


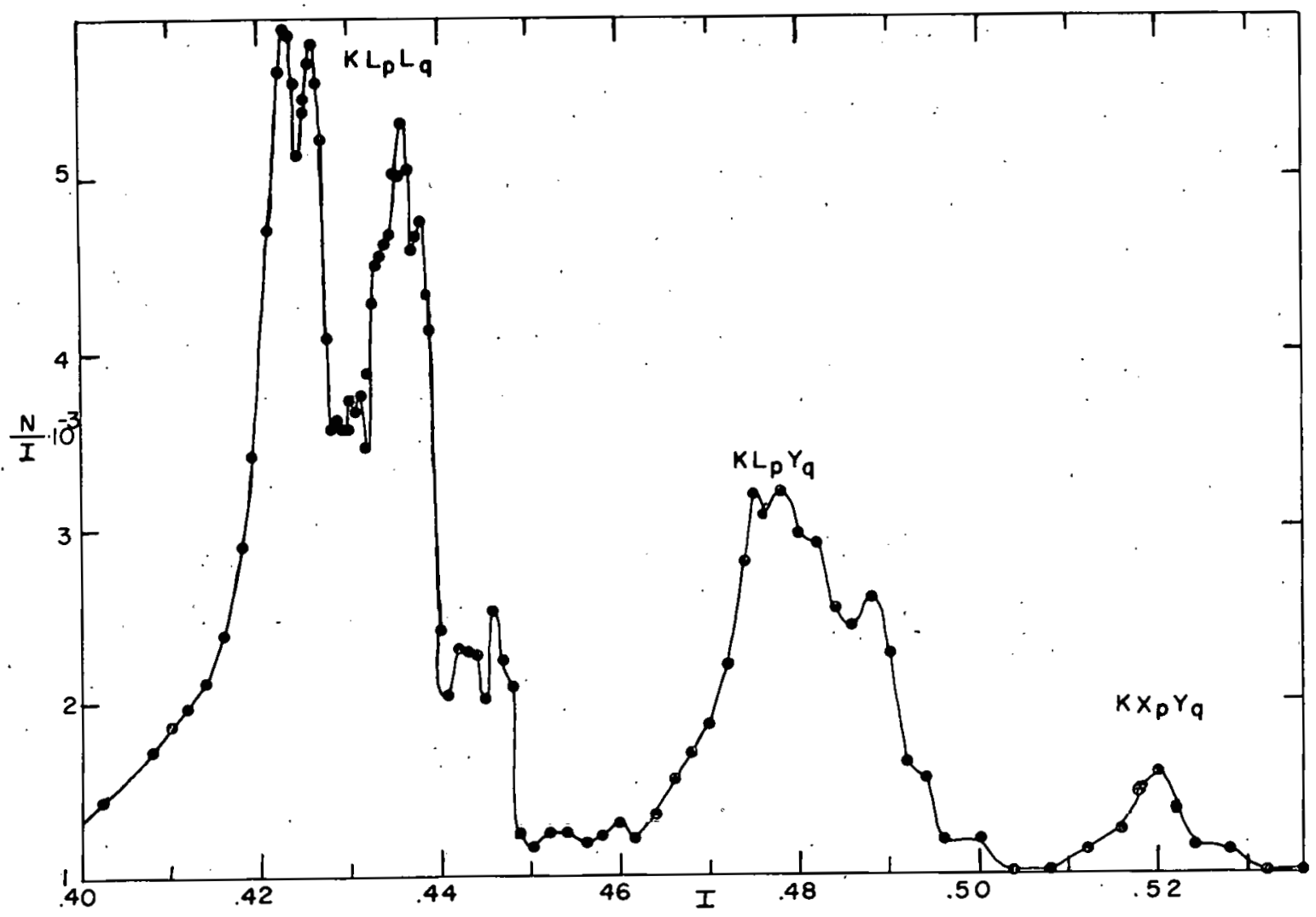

Fig. $12-\mathrm{K}$ Auger electrons of $\mathrm{Tl}^{198}-\mathrm{Tl}^{198 \mathrm{~m}}$. 
corrections, the ratio $\mathrm{KL}_{\mathrm{p}} \mathrm{L}_{\mathrm{q}}: \mathrm{KL}_{\mathrm{p}} \mathrm{Y}_{\mathrm{q}}: \mathrm{KX} \mathrm{Y}_{\mathrm{q}}$ becomes 1.0:0.5310.05: $0.063 \pm 0.02$. The half -life used for decay correction was taken as the observed decay period of one of the initial points on the spectrum.

Broyles ${ }^{47}$ reports the value $1.0: 0.7 \pm 0.15$ for the $K L_{p} L_{q}: K L_{p} Y_{q}$ of mercury. The limits of error of Broyles ${ }^{8}$ and the present work mutually encompass the ratio $1.0: 0.56$. Thus the present work is in fair agreement with Broyles" results. However, it is not in good agreement with the theoretical calculations of Pincherle. ${ }^{48}$ Pincherle's value for the $\mathrm{KL}_{\mathrm{p}} \mathrm{L}_{\mathrm{q}}: \mathrm{KL}_{\mathrm{p}} \mathrm{Y}_{\mathrm{q}}: \mathrm{KX}_{\mathrm{p}} \mathrm{Y}_{\mathrm{q}}$ ratio is $1.00: 0.716: 0.103$ using nonrelativistic unscreened, hydrogen-like wave functions. These ratios are supposed to be good for all atomic numbers. However, since relativistic effects are much greater at larger atomic numbers one would not expect close agreement with Pincherle's values. Massey and Burhop 49 have found that consideration of relativity increases the theoretical KLL Auger yield. If similar relativistic effects have less influence on the $\mathrm{KL}_{\mathrm{p}} \mathrm{Y}_{\mathrm{q}}$ and $\mathrm{KX}_{\mathrm{p}} \mathrm{Y}_{\mathrm{q}}$ Auger yields, the discrepancy between the results of the present work and the calculations of Pincherle 48 would be resolved.

\section{F. Protactinium 228}

1. L lines assigned to 57.8 and $130 \mathrm{kev}$ gamma rays. Protactinium 228 was first produced by Ghiorso et al ${ }^{50}$ in bombard. ments of thorium with $80 \mathrm{Mev}$ deuterons. These workers found the EC/a branching ratio to be about 50. No previous work has been reported on the electron spectrum of $\mathrm{Pa}^{228}$ since the investigators mentioned above studied only the alpha particle radiations of the se isotopes. 
A sample of $\mathrm{Pa}^{228}$ also containing some $\mathrm{Pa}^{232}, \mathrm{~Pa}^{230} ;$ and $\mathrm{Pa}^{229}$ was obtained from a bombardment of thorium with 115 Mév protons. Because of the presence of a visible amount of solid material in the final protactinium fraction, it was decided to use a $0.001-i n c h$ thick platinum counting disk for the sample backing.

Because of the presence of $\mathrm{Pa}^{229}, \mathrm{~Pa}^{230}$, and $\mathrm{Pa}^{232}$ no unambiguous assignments can be made for four prominent lines appearing at $22,26,30$, and $33 \mathrm{kev}$. However; relatively certain àsignments can be made for four electron lines at $38.2,41.5,110$, and $114 \mathrm{kev}$, respectively. As seen in Table 6 these lines have been assigned to gamma rays in $\mathrm{Th}^{228}$ which have been previously observed in Ac ${ }^{228}$ beta minus decay. ${ }^{51}$ The gamma rays are also observed in $\mathrm{U}^{23.2}$ alpha decay. The $\mathrm{L}_{\mathrm{II}} / \mathrm{L}_{\text {III }}$ ratio for each gamma ray is consistent with an E2 assignment. 6

Table 6

Electron Lines from $\mathrm{Pa}^{228}$ Decay

\begin{tabular}{|c|c|c|c|}
\hline $\begin{array}{c}\text { Gamma } \\
\text { energy } \\
\text { (kev) }\end{array}$ & $\begin{array}{l}\text { Electron } \\
\text { energy } \\
\text { (kev) }\end{array}$ & $\begin{array}{l}\text { Intensity } \\
\text { (Arbitrary } \\
\text { Units) }\end{array}$ & $\begin{array}{l}\mathrm{e}^{\circ} / \overline{\mathrm{B}} \text { disintegration } \\
\text { of } \mathrm{Ac} 2 \mathrm{C} \text { from Ref. } 51\end{array}$ \\
\hline \multirow[t]{2}{*}{$57.8 \pm 1$} & 38.2 & $28 \pm 5$ & 0.238 \\
\hline & 41.5 & $20 \pm 5$ & 0.202 \\
\hline \multirow[t]{2}{*}{$130 \pm 2$} & 110 & $3 \pm 0.5$ & 0.033 \\
\hline & 114 & $2 \pm 0.5$ & 0.023 \\
\hline
\end{tabular}

2. Decay scheme of $\mathrm{Pa}^{228}-$-It is of interest to note that the electron capture decay of $\mathrm{Pa}^{228}$ populates directly or indirectly the first two excited states of $\mathrm{Th}^{228}$ in about the same ratio of intensities as does the beta decay of $\mathrm{Ac}^{228}{ }^{51}$ The closed cycles calculation 52 
of the decay energy for $\mathrm{Pa}^{228}$ is $2.06 \mathrm{Mev}$. Since this value is not far different from the decay energy exhibited by $A c^{228}$, it is not improbable that the electron capture of $\mathrm{Pa}^{228}$ populates the excited states of $\mathrm{Th}^{228}$ in much the same manner as $\mathrm{Ac}^{228}$. Thus the similarities noted above for the first two excited states are not surprising.

\section{G. Protactinium 230}

1. Electron spectrum。- Protactinium 230 was first identified by Studier and Hyde ${ }^{53}$ in bombardments of $\mathrm{Th}^{232}$ with deuterons. The $\mathrm{EC} / \beta^{-}$branching ratio is about $92: 8^{54}$ and alpha branching occurs to the extent of 0.003 percent ${ }^{55}$ Measurements of the electron and gamma radiations were made by Osborne et al. ${ }^{56}$ by absorption techniques: They report a gamma ray of $0.94 \mathrm{Mev}$ and $\mathrm{K}$ and $\mathrm{L} \mathrm{x}-\mathrm{rays}$ with the relative abundances $14: 9: 5$. Osborne et al 56 also observed beta particles with energy maxima at $0.22 \mathrm{Mev}$ and $0.43 \mathrm{Mev}$ with relative intensities of around four to one.

The present work was undertaken to study in greater detail the electron and gamma radiations emitted in the decay of $\mathrm{Pa}^{230}$. The. activity was produced by the reaction $\mathrm{Th}^{232}(\mathrm{p}, 3 \mathrm{n}) \mathrm{Pa}^{230}$ using around $100 \mathrm{Mejv}$ protons trom the laboratory's 184 -inch synchro-cyclotron. The $\mathrm{Pa}^{232}, \mathrm{~Pa}^{228}$, and $\mathrm{Pa}^{229}$ also produced in the bombardment were allowed to decay for about one month before chemical separations were performed. The $\mathrm{Pa}^{230}$ was separated from the thorium target by di-isopropyl-ketone extraction techniques. $\$ 7,58$ It was apparent some time after the beta spectrometer samples were made that for some reason a large amount of $\mathrm{Zr}^{95}$ and $\mathrm{Nb}^{95}$ activity had followed protactinium in the 


$$
-57-.22
$$

chemical separation. The sample used also contained an unknown amount of the $\mathrm{U}^{230}$ decay chain."

The sample was mounted on a double layer of gold leaf by evaporation of an $H F$ solution containing the activity. The material was visible on the gold leaf so the reason for the relatively poor resolution obtained is probably. sample thickness and not back-scatter ing. The spectra were obtained using the semi-automatic system described previously.

A beta continuum underlying the electron lines corresponds: well with that which would be expected from the beta particles of $\mathrm{Zr}^{95}$ and $\mathrm{Nb}^{95}$. The presence of these nuclides in high abundance was shown by gamma scintillation spectrometer studies which will be discussed below. The lines for which the interpretation is fairly certain are listed in Table 7. Since electron capture is about ten times as frequent as beta minus decay in this nuclide;. all of the lines have been assigned to gamma transitions in $\mathrm{Th}^{230}$.

The electron lines assigned (see Table 7) to $52 .{ }^{2} \mathrm{M}$ and $52.2 \mathrm{~N}$ also fit energywise with the expected $L_{\text {II }}$ and $L_{\text {III }}$ lines of a $69 \mathrm{kev}$ gamma ray. A line appears in the spectrum which might be assigned to the $M+N$ line of this gamma ray. Thus the high abundance of the lines assigned as $52.2_{\mathrm{M}}$ and $52.2_{\mathrm{N}}$ relative to the $52.2^{2} \mathrm{~L}_{\mathrm{II}}$ and $52.2^{2} \mathrm{~L}_{\mathrm{III}}$ lines is perhaps due to the presence in the sample of considerable $\mathrm{U}^{230}$. However, this explanation is not consistent with the relatively high intensity of the line postulated as $69 \mathrm{M}+\mathrm{N}^{2}$ nor with the absence of lines from the $110 \mathrm{kev}$ gamma ray of $1 \mathrm{~h}^{226} \cdot 9$ It is possible that the approximately $69 \mathrm{kev}$ gamma ray follows the beta decay of $\mathrm{Pa}^{230}$ although the first excited state of $\mathrm{U}^{230}$ is expected to be at a lower energy. 
Table 7

El ectron Lines of $\mathrm{Pa}^{230}$

\begin{tabular}{|c|c|c|c|c|c|}
\hline $\begin{array}{l}\text { Gamma } \\
\text { energy } \\
\text { (kev) }\end{array}$ & $\begin{array}{c}\text { Electron } \\
\text { energy } \\
\text { (kev) }\end{array}$ & & . & $\begin{array}{l}\text { Conversion } \\
\text { shell }\end{array}$ & $\begin{array}{c}\text { Intensity } \\
\text { (Arbitrary Units) }\end{array}$ \\
\hline $52.2 \pm 1$ & 3.3 .3 & & & ThL & $1.5 \pm 0.7$ \\
\hline . & 35.9 & . & .. & $T_{h} L_{\text {III }}$ & $1.0 \pm 0.5^{\circ}$ \\
\hline$\therefore$ & $\cdots 48.5$ & & & ThMM & $1.4 \pm 0.5^{*}$ \\
\hline . & 52.9 & & & ThN & $1.0 \pm 0.5^{*}$ \\
\hline $90 \rightarrow 94$ & 76.7 & & & ThL & $0.2 \pm 0.1$ \\
\hline $293 \pm 10$ & 183 & & & ThK & $1.0 \pm 0.5$ \\
\hline & 276 & $\therefore$ & & ThL & $0.1 \pm 0.05$ \\
\hline $305 \pm 10$ & 194 & & . & ThK & $5.7 \pm 0.5$ \\
\hline . & 284 & & & ThL & $1.0 \pm 0.2$ \\
\hline & 302 & & & $\mathrm{Th}_{\mathrm{M}}+\mathrm{N}$ & $0.2 \pm 0.2$ \\
\hline
\end{tabular}

* See text. 
The most reasonable explanation of this discrepancy is that selfabsorption within the sample is attenuating the $\mathrm{L}_{\mathrm{II}}$ and $\mathrm{L}_{\text {III }}$ lines with respect to the $M$ and $N$ lines.

The $\mathrm{K}$ and $\mathrm{L}$ lines of gamma rays of $293 \pm 10 \mathrm{kev}$ and $305 \pm 10 \mathrm{kev}$ decay with the half -life of $\mathrm{Pa}^{230}$ within the limits of error of the measurement. The $\mathrm{K} / \mathrm{L}$ ratios of each are large (about 10 and about 6 , respectively) which is indicative of $\mathrm{Ml}$ or $\mathrm{El}$ radiation. The high intensity of the electron peaks of these radiations with respect to those of the $52 \mathrm{kev}$ gamma ray make the Ml assignment seem more likely.

The beta spectrum of $\mathrm{Pa}^{230}$ was not observed with any reasonable certainty because of the relatively high intensity of the $\mathrm{Zr}^{95}$ and $\mathrm{Nb}^{95}$ beta spectra. The maximum energy of the $\mathrm{Pa} 230$ beta spectrum is expected to be $430 \mathrm{kev}$ from closed cycle calculations 52

2. Scintillation spectrometry of $\mathrm{Pa}^{230}$ gamma rays.-- The gamma rays emitted by $\mathrm{Pa}^{230}$ were observed in the 50-channel scintillation spectrometer of this laboratory. The spectra obtained are shown in Figs. 13a and 13b. In agreement with the absorption experiments of Osborne ct al. , 56 a gammi ray of $940 \pm 20 \mathrm{kev}$ thorium $\mathrm{K}$ x-rays, and thorium $L \mathbf{x}$-rays were observed. In addition to these radiations, however, gamma rays with energies $305 \pm 10 \mathrm{kev}, 1000 \pm 40 \mathrm{kev}, 1060 \pm 30 \mathrm{kev}$, $1180 \pm 40 \mathrm{kev}(?), 460 \pm 15 \mathrm{kev}$, and $540 \pm 20 \mathrm{kev}$ were observed. Of course, one of the more prominent peaks in the spectrum was that from the $721 \mathrm{kev}$ gamma ray of $\mathrm{Zr}^{95}$ and the $745 \mathrm{kev}$ gamma ray of $\mathrm{Nb}^{95}$. The assignment of the $750 \mathrm{kev}$ peak to these activities was proved by its asymmetry and by its increasing intensity relative to other peaks in the spectrum with time. A summary of the data on the gamma rays is given in Table 8 . The corrected intensities were calculated using the 


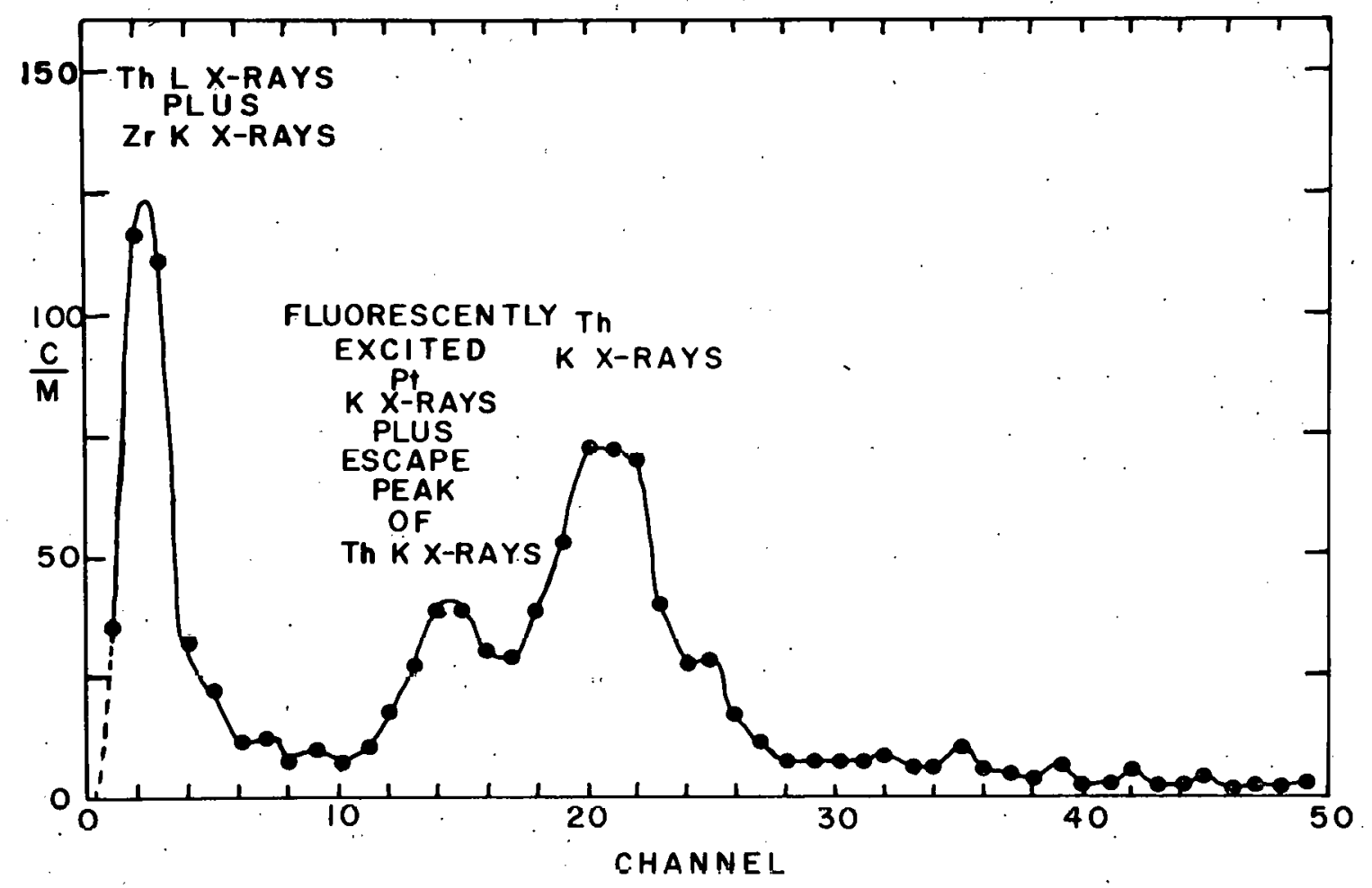

Fig. 13a-Gamma spectrum of $\mathrm{Pa}^{230}$. 


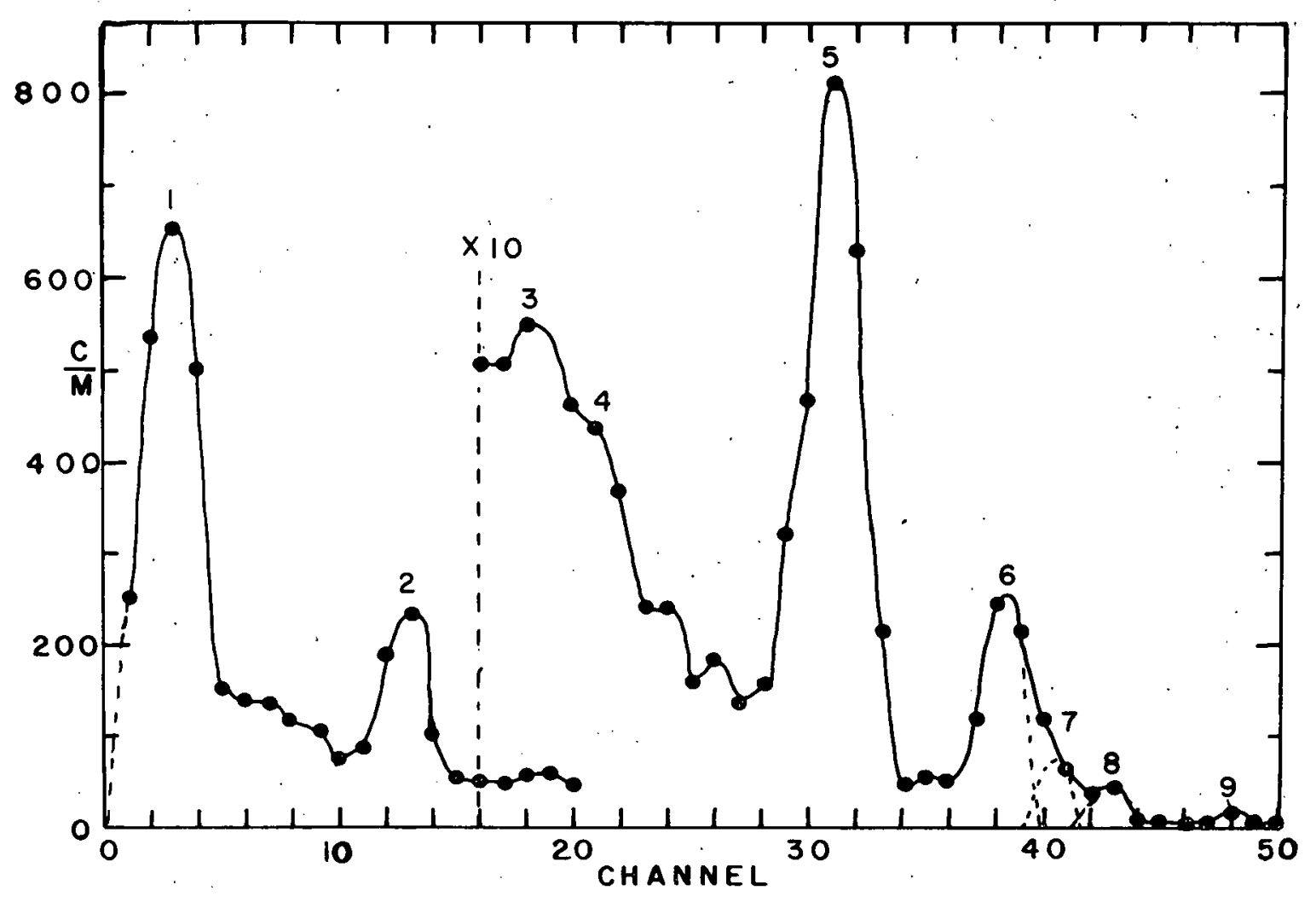

Fig. 13b-Gamma spectrum of $\mathrm{Pa} 230$. 
curve of counting efficiency for sodium iodide crystals given by Mc Laughlin and O'Kelley. 59

-Table 8

Protactinium 230 Gamma Rays

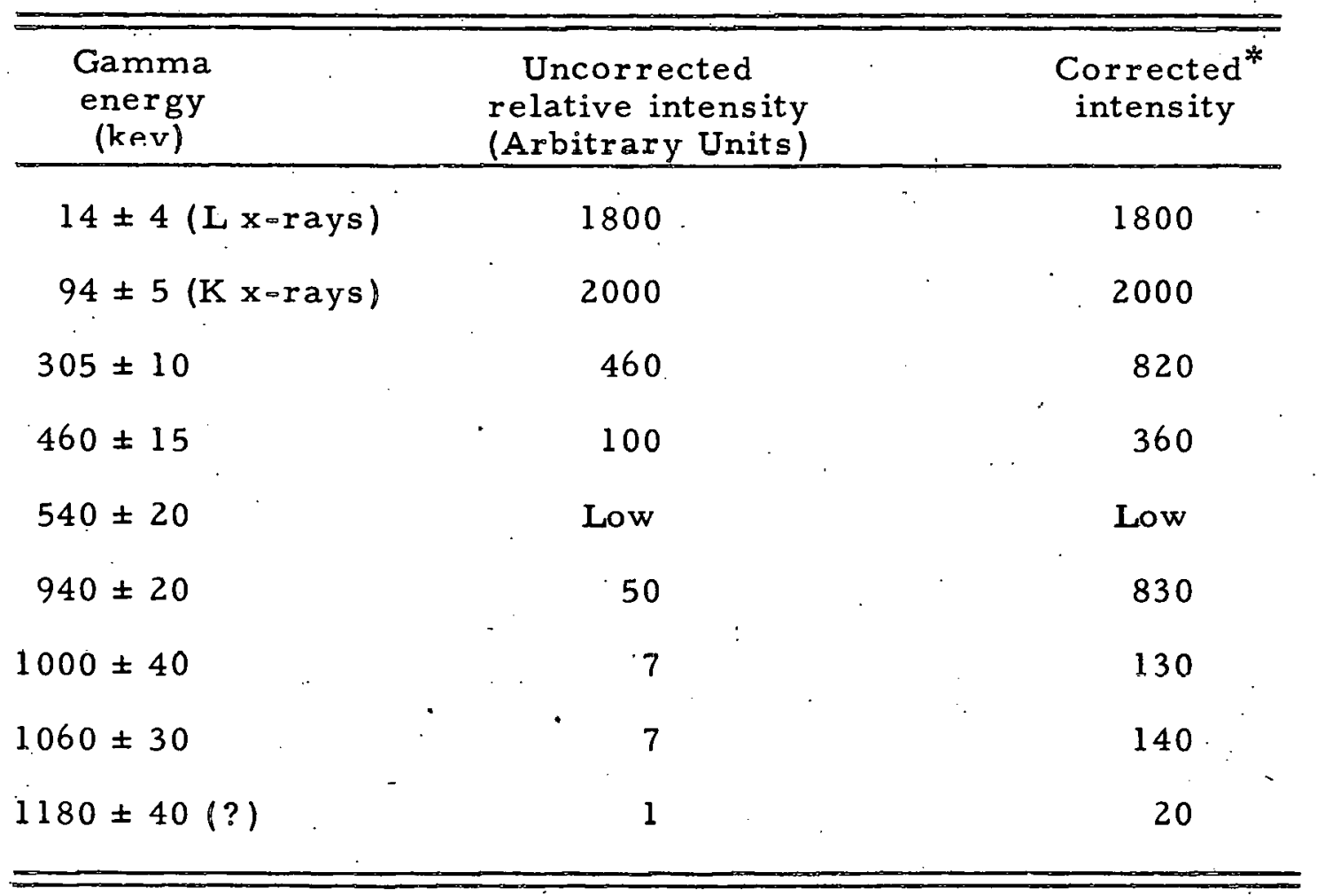

* See text。

3. Decay scheme of $\mathrm{Pa}^{230}$ olevels in $\mathrm{Th}^{230}$-orrom the present work no unambiguous decay scheme can be drawn. However, reasoning from relative intensities of gamma rays and electron lines separately, the following inferences can be made: 1) at least $40 \pm 10$ percent of the electron capture decay populates one or a pair of levels about $940 \mathrm{kev}$ above the ground state; 2) at least 40 percent of the electron capture disintegrations give rise to a $310 \pm 10 \mathrm{kev}$ gamma ray. This gamma ray. is very likely of $M 1$ or $E l$ character from the $K / \mathbb{L}$ conversion ratio: 3) a significant fraction of the electron capture disintegrations directly or indirectly. populate the first excited state of $\mathrm{Th}^{230}$; 4) no appreciable 
fraction of the electron capture decay gives rise to gamma radiation of the energy difference between the second and first excited states of $\mathrm{Th}^{230}(120 \mathrm{kev}) .9$

H。 Neptunium 236

1. L lines assigned to $43.4 \mathrm{kev}$ and $44.2 \mathrm{kev}$ gamma rays. $=0$ Neptunium 236 was first produced and mass assigned by James, et al. 60 from bombardments of uranium with deuterons. In the present study, uranium foil containing $>99$ percent $\mathrm{U}^{235}$ was bombarded with $12.5 \mathrm{Mev}$ deuterons in the 60 -inch cyclotron of this laboratory. The chemical separation and purification included an oxidation-reduction cycle and a final anion exchange column separation. The sample for the present investigation was prepared by evaporation of a drop of distilled water containing the activity from a palladium leaf backing.

The only previous study of the radiations of 22 -hour $\mathrm{Np}^{236}$ is that of Orth and $O^{\prime}$ Kelley。 ${ }^{61}$ These workers report an EC/ $\beta$ branching ratio of around 2, a two component beta spectrum with maximum energies of 360 and $510 \mathrm{kev}$, respectively, and a $150 \mathrm{kev}$ gamma ray. An electron spectrum was observed in the present work which was similar to that observed in the previous work. ${ }^{61}$. However, certain lines in the spectrum showed greater complexity than before. The appearance of this complexity, coupled with the results of recent scintillation spectrometer studies ${ }^{62}$ requires a reinterpretation of the electron data.

The lines designated as $L$ Augers by $O^{\prime}$ Kelley were resolved into four lines which correspond well energywise to the $L_{\text {II }}$ and $L_{\text {III }}$ lines of gamma rays with energies $43.5 \pm 1 \mathrm{kev}$ and $44.2 \pm 1 \mathrm{kev}$, respectively. These energies depend upon the arbitrary assumption that the slightly 
more intense pair of $\mathrm{L}$ lines arise from conversion in plutonium following beta decay, and that the less intense pair arise from conversion in uranium following electron capture. The electron data are summarized in Table 9.

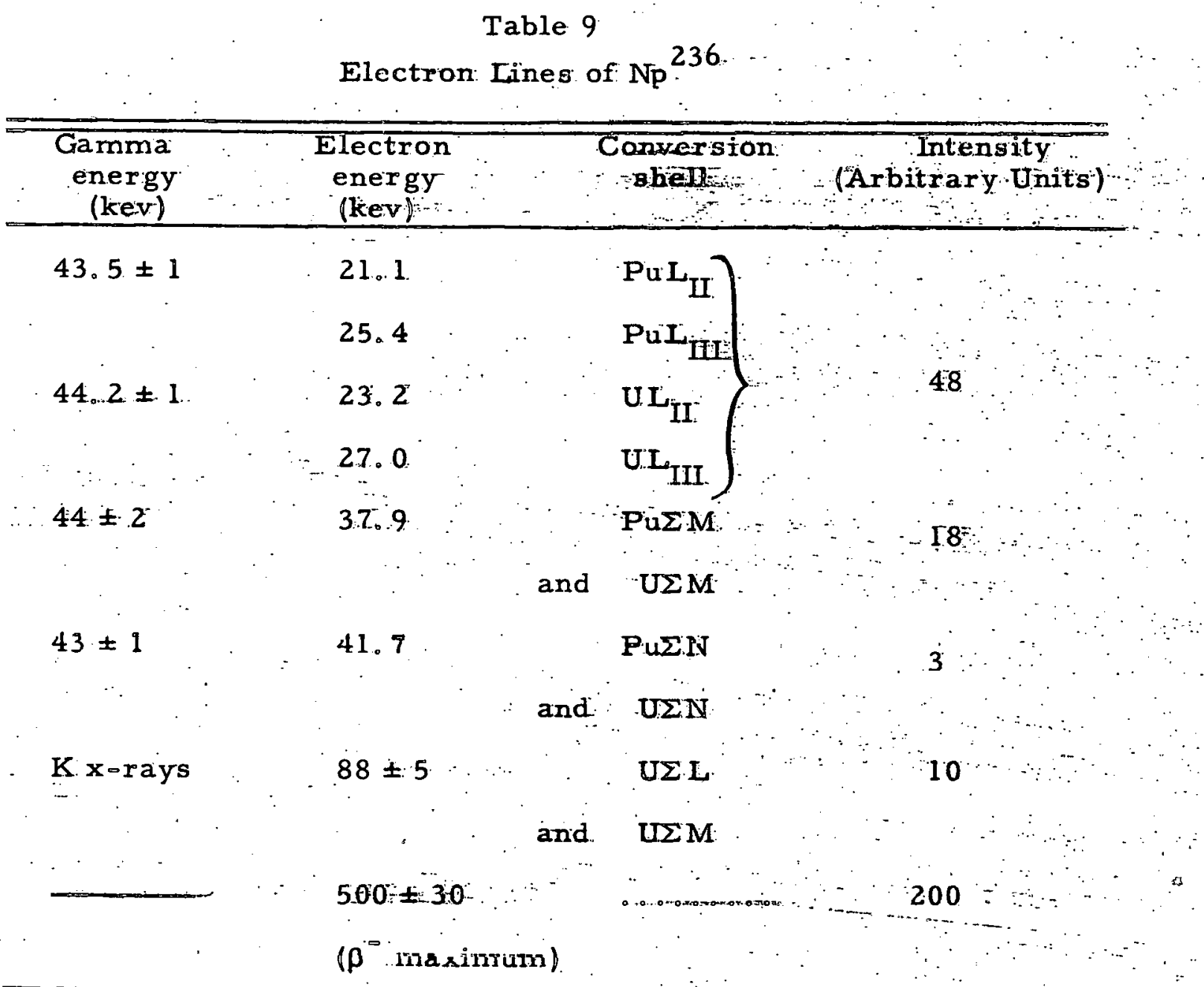

The line designated $150_{\mathrm{K}}$ by Orth and $\mathrm{O}^{\prime} \mathrm{Kelley}$ also may be inter preted as the unresolved $\Sigma M$ conversion lines of the 43.5 and 44.2 kev: gamma rays. A line also appeared which may be assigned to the unresolved N line: of the-two gamma rays. K Auger lines were also observed. 
2. Decay scheme of $\mathrm{Np}^{236}$. - The beta spectrum was observed both on the double focusing spectrometer where the intensity was too low for a Fermi analysis and on a magnetic lens spectrometer. A Fermi analysis by $O^{\prime}$ Kelley of the data from the magnetic lens spectrometer gave a maximum beta energy of $518 \pm 10 \mathrm{kev}{ }^{63}$ The Fermi-Kurie plot exhibited a marked concavity toward the abscissa which is indicative of a forbidden beta transition. However, it is not impossible that the forbidden shape was caused by some variation in counting efficiency of the detector used.

Scintillation spectrometer experiments performed by Jaffe et al。 62 indicate that approximately 1.66 times as many $\mathrm{K}$ x-rays as $\mathrm{L}$ x-rays are emitted in $\mathrm{Np}^{236}$ decay. No significant amount of gamma radiation was observed. A $4 \pi$ count of the beta particles from the same sample used in the scintillation spectrometer experiments gave an.EC/ $\beta^{-}$ratio of $(43 \pm 3):(57 \pm 3)$, assuming only $\mathrm{K}$ electrons are captured. From the relative $K$ and $L x-r a y$ intensities, the number of $K$ and $L$ vacancies produced per 100 disintegrations can be calculated by using the following assumptions: 1) that 72 percent of the $K$ vacancies are filled by $L$ electrons ${ }^{64}$; 2) that the $\mathrm{K}$ Auger yield is 0.03 at the atomic number $92 ; 3$ ) that the L Auger yield in this region of atomic number is $0.5 ;^{22} 4$ ) that 43 percent of the disintegrations take place by capture of $\mathrm{K}$ electrons; 5) that the intensity of the $\mathrm{K}$ - -rays is 1.66 times that of the $\mathrm{L}$ x-rays. From this calculation one can conclude that for each 100 disintegrations, $21 \mathrm{~L}$ vacancies arise from either $\mathrm{L}$ electron capture or gamma ray conversion. From the very approximate values of electron intensities one can conclude that the abundance of conversion electrons is about 35 percent 
that of the beta spectrum. Since 57 percent of the disintegrations take place by beta particle emission; one is led to a value 20 conversion electrons per 100 disintegrations. Thus within the limits of error of these intensity measurements, all of the $L$ vacancies arising by means other than by the filling of $K$ vacancies arise from $L$ conversion of the 43.4 and $44.2 \mathrm{kev}$ gamma rays. However, the limits of error are such that as many as 5 to $10 \mathrm{~L}$ vacancies per 100 disintegrations may be arising from $L$ capture. It appears safe to conclude that the" lower limit for the $\mathrm{K} / \mathrm{L}$ capture ratio is around 4 .

The intensities of the $\mathrm{L}$ lines of the 43.4 and the $44.2 \mathrm{kev}$ gamma rays are roughly comparable. Thus one can set an upper. limit of about 10 events per 100 disintegrations which populate each of the first excited states of $\mathrm{Pu} .^{236}$ and $\mathrm{U}^{236}$. The intensities given in Table 9 are subject to considerable uncertainty, but the values should be reliable to \pm 25 percent.

The interpretations of the data from the present study are in sharp disagreement with those of Orth and $O^{7} \mathrm{Kelley.}{ }^{61}$ One reason for the Iarge discrepancy between the two sets of data may be the different relative amount of $\mathrm{Np}^{234}$ present in each cas Hoff ${ }^{1.9}$ reports an upper limit of 1.0 for the $\mathrm{K} / \mathrm{L}$ capture ratio for $\mathrm{Np}^{234}$ : Since considerable amounts of $\mathrm{Np}^{234}$ were present in the samples of $\mathrm{Np}^{236}$ investigated by Orth and $O^{\prime}$ Kelley, one would expect their $\mathrm{K} / \dot{\mathrm{L}}$ capture ratio to be somewhat in error. Also, the absorption methods which they used are less reliable for intensity measurements than the scintillation spectrometer used in the present study: The discrepancy in the interpretation of the electron line spectrum resulted from 
spectrometer calibration uncertainties in the low energy region at the time the previous experiments were performed.

A decay scheme which is consistent with the available data is shown in Fig. 14.

\section{DISCUSSION OF RESULTS}

\section{A. Theoretical Calculations}

The use of the term "conversion coefficient" is misleading. Theoretical interpretation of the processes of radiative /emission of gamma quanta) and non-radiative (emission of orbital electrons) transitions indicate that they may be considered nearly independent of each other. 65 That is, if radiative transitions in nuclei are assumed to arise from a radiator (electric dipole, electric quadrupole, magnetic dipole, etc.) located at the center of the nucleus, then it is found that the radiative emission rate is almost independent of the non radiative emission rate for a given transition. Thus a nuclear transition rate is the sum of the rates of gamma and electron emission, the two processes. occurring side by side with nearly independent rates and there is little if any so-called "conversion" of gamma radiation into electron "radiation".

The reasoning leading to the above conclusions is briefly as follows: ${ }^{65}$ If the nucleus were stripped of its orbital electrons, the total nuclear transition rate would equal the rate of emission of gamma quanta. However, in the presence of the orbital electrons, the nuclear transition rate is augmented by the possibility of a nother mode of nuclear de excitation, namely orbital electron emission. The emission of orbital electrons arises from the interaction of the radiation field of the nuclear radiator with the orbital electron cloud. This interaction 


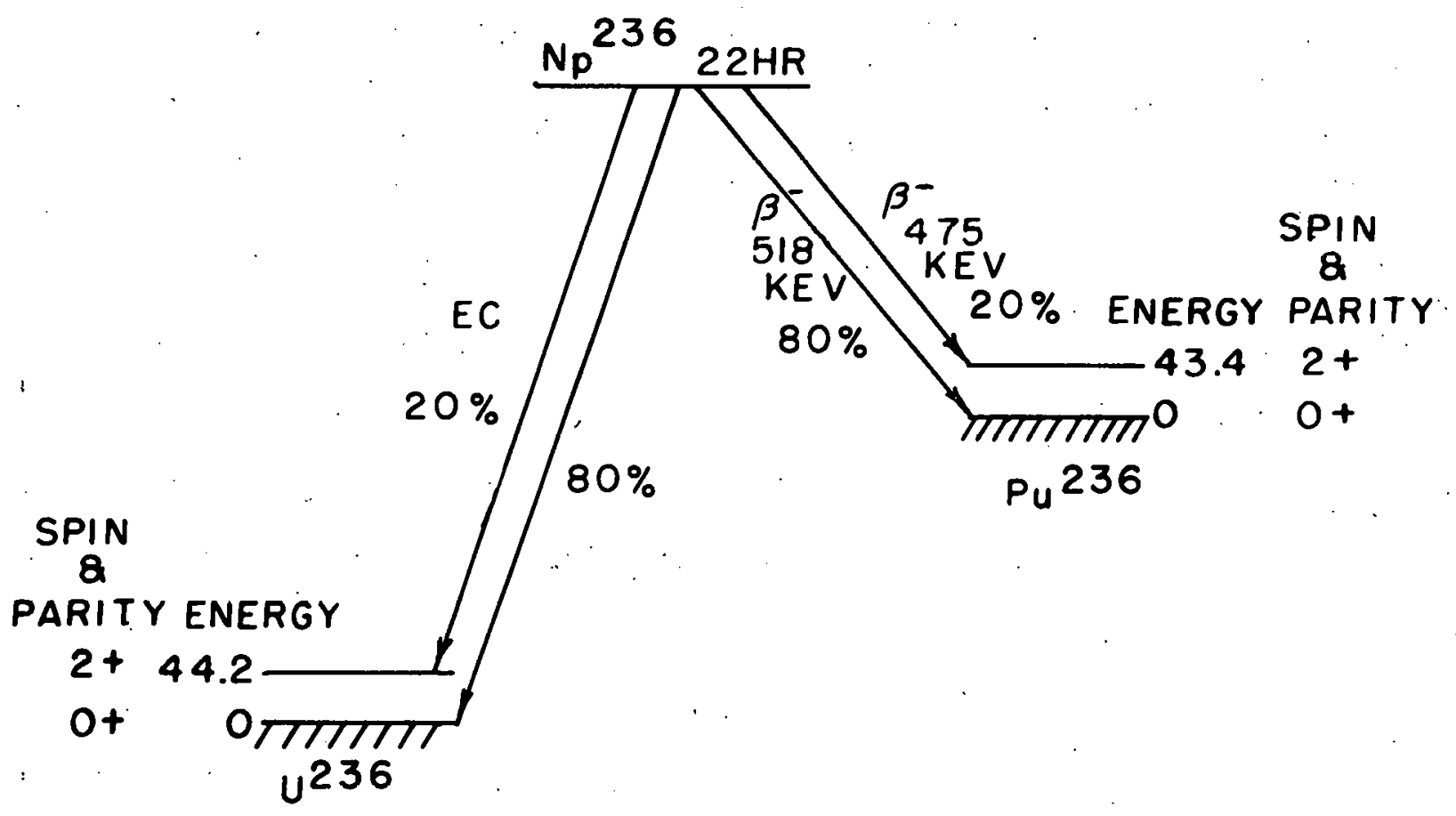

Fig. 14 -Decay scheme of $\mathrm{Np}^{236}$. 
thus provides a mechanism in addition to gamma emission for the occurrence of the nuclear transition.

The so-called "conversion coefficient", then, has been most commonly defined as the orbital electron emission rate divided by the gamma emission rate. Some writers, however, still use the term "conversion coefficient" to indicate the fraction of the total nuclear transitions which take place by orbital electron emission. The former, commonly used definition will be used in this discussion.

Theoretical calculations of $\mathrm{L}$ conversion coefficients for the heavier elements have been performed by Fisk 66 and Gellman et alo 67,6 Since the calculations made by Gellman et al. ${ }^{67,6}$ are more extensive than any previously made for this region of atomic number, and were made using exact relativistic equations, the author has chosen to present comparisons of experimental values with these calculations only. Figures 15a through $16 \mathrm{i}$ are based on the se calculations. No exact calculations exist at present for $L$ shell conversion coefficients (for $Z>80$ ) where the effects of screening were taken into account. However, Reitz ${ }^{68}$ has found the screening correction for the $K$ shell conversion coefficient to be a positive one to thirteen percent of the "unscreened" values. Whether the same or a larger screening correction holds for any of the $L$ shells remains to be seen. Rose et al.." ${ }^{69}$ believe the screening correction will be appreciable for the L shells especially at high atomic number.

\section{B.a. Empirical Correlations:}

Mihelich ${ }^{70}$ has reviewed the experimental data on. L conversion ratios through early 1952. "His multipolarity assignments based upon earlier, less extensive; and in some cases less exact calculations are 


$$
\underline{-70-}
$$

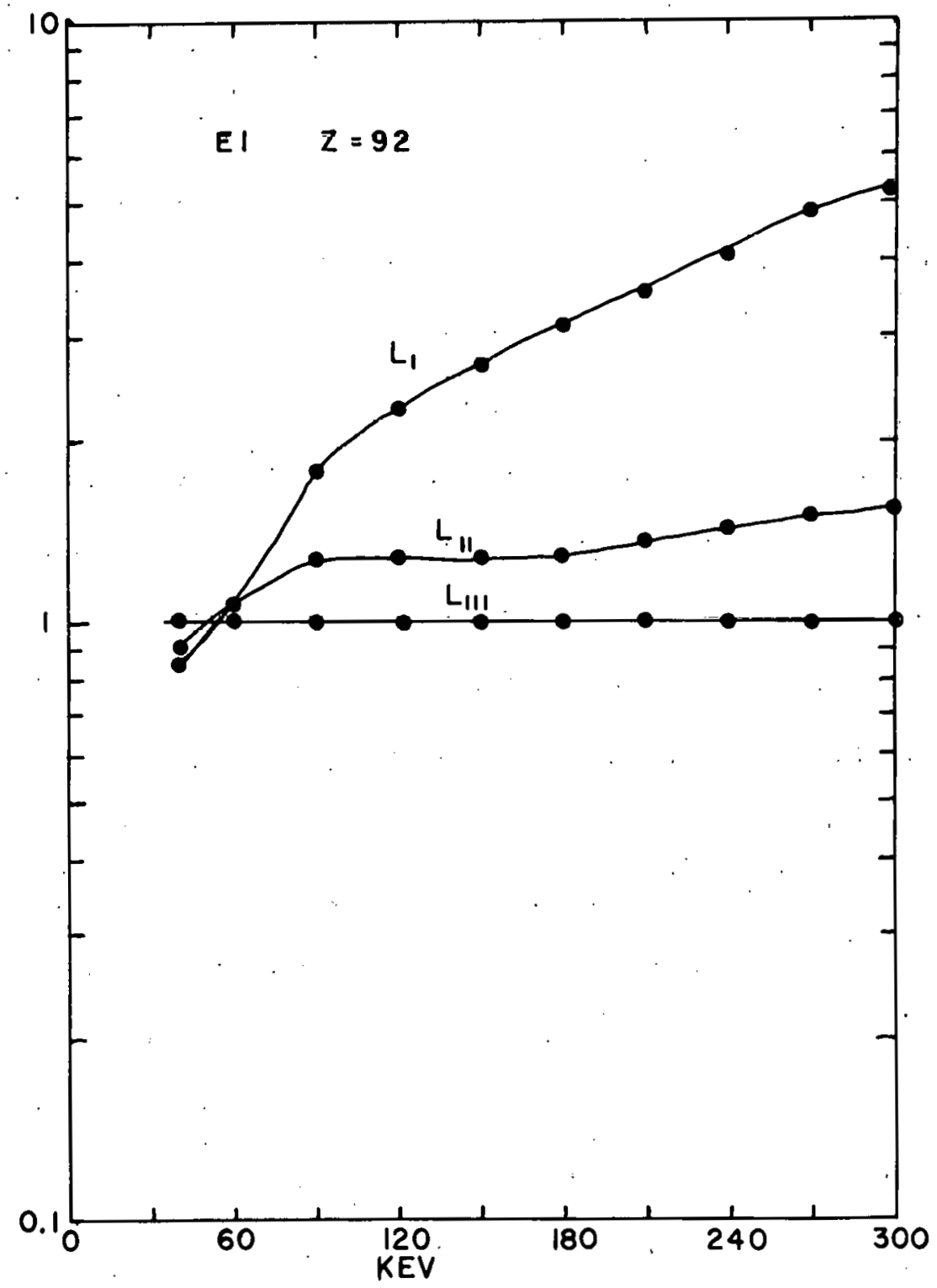

Fig. $15 a-L_{1}: L_{I I}$ LIII ratios based on the calculations of Gellman et al. 6 


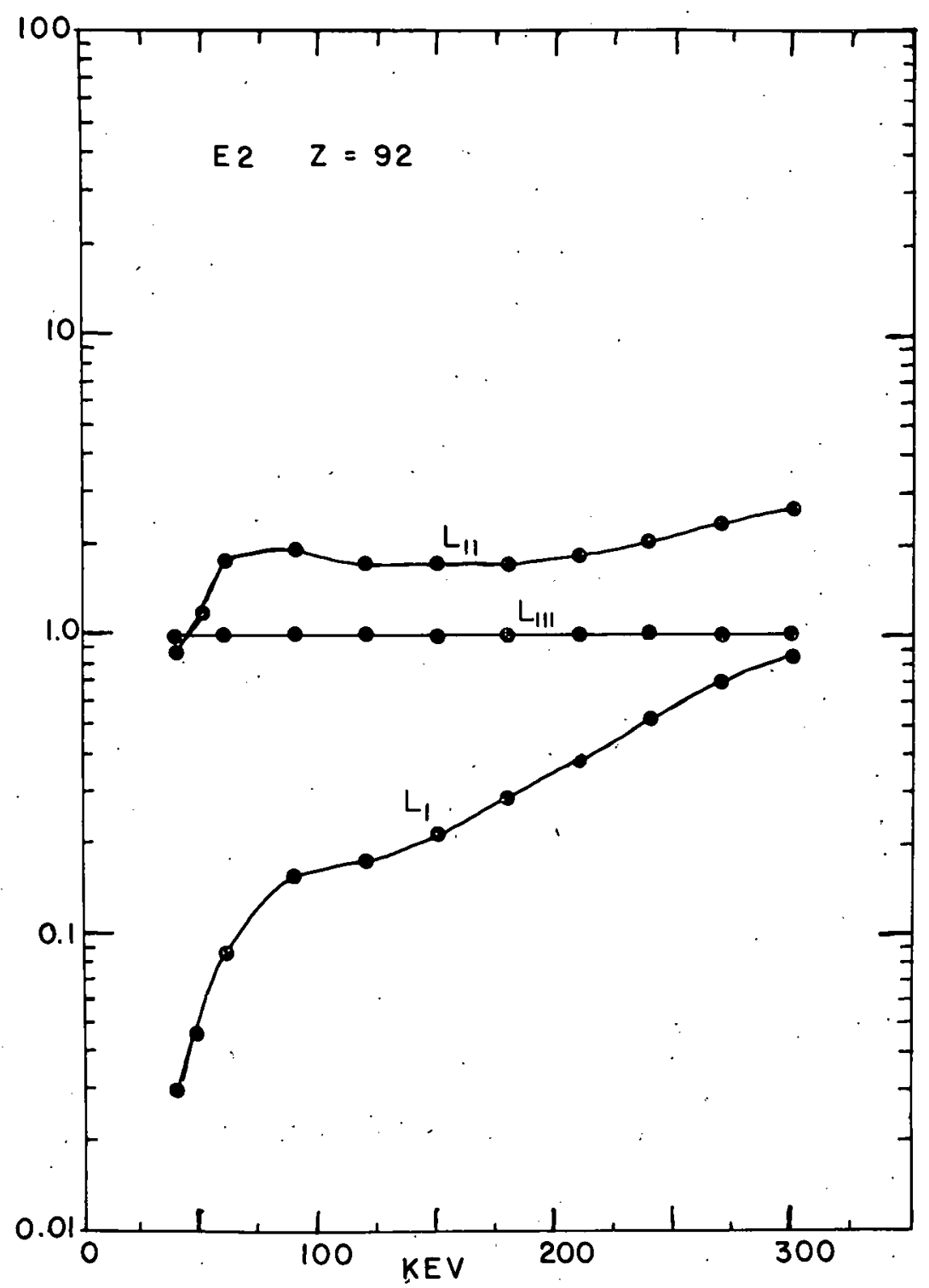

Fig. $15 b-\mathrm{L}_{\mathrm{I}}: \mathrm{L}_{\mathrm{II}}: \mathrm{L}_{\mathrm{III}}$ ratios based on the calculations of Gellman et al. 6 


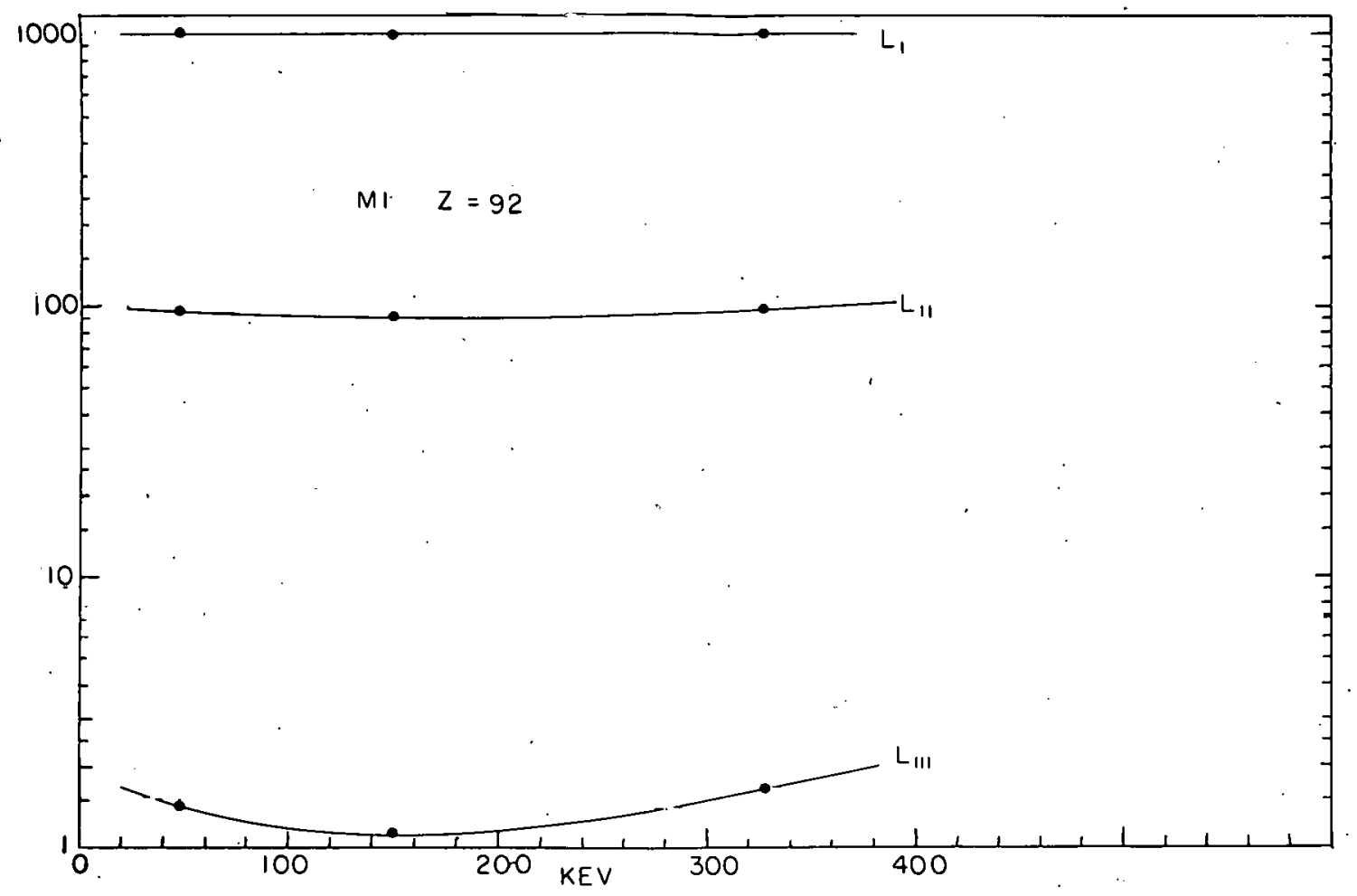

Fig. $15 c-L_{I}: L_{I I}: L_{I I}$ ratios based on the calculations of Geliman et al. ${ }^{8}$ 


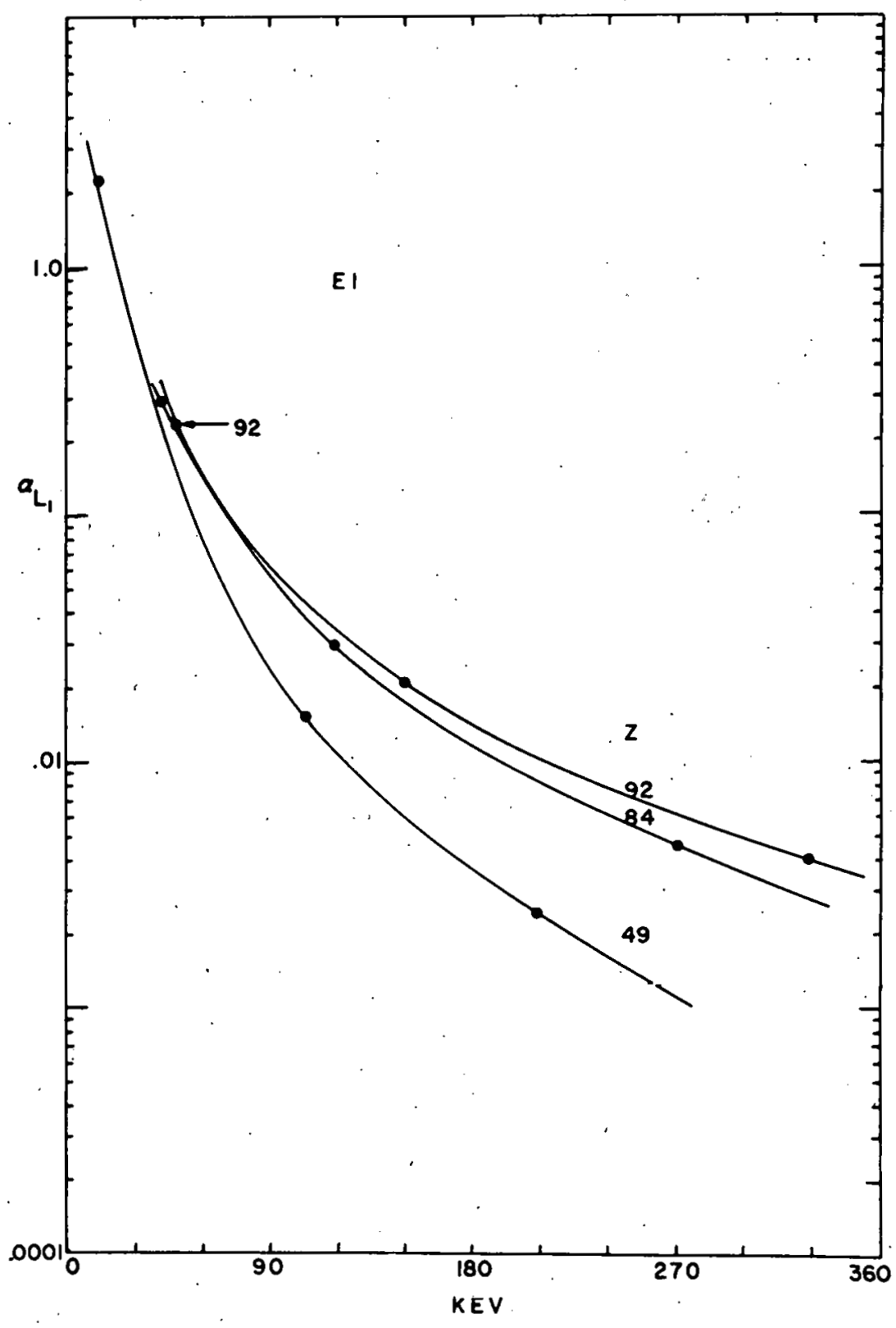

Fig. 16a-Curves for interpolating the tables of Gellman et al ${ }^{6}$. 


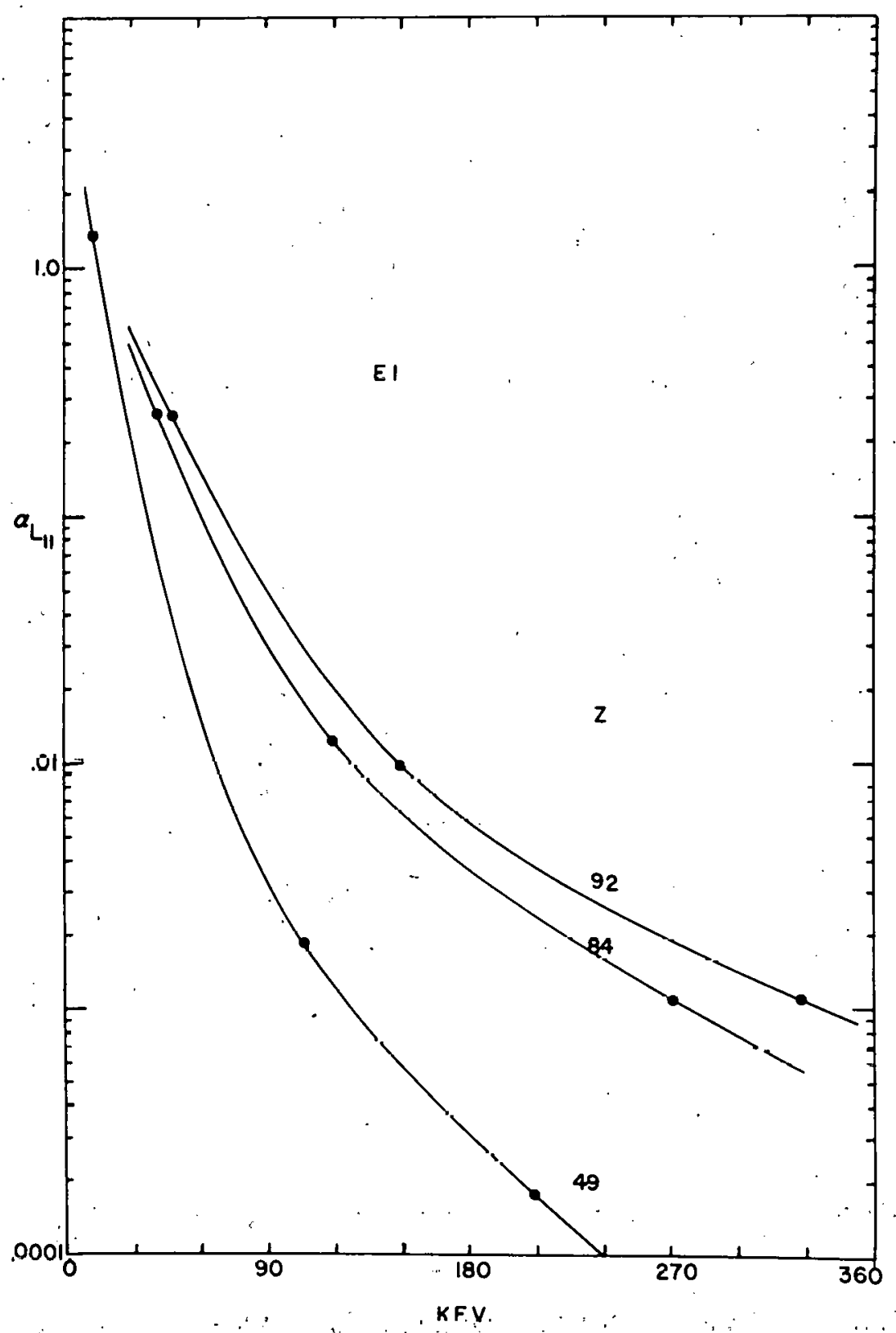

Fig. 16b-Curves for interpolating the tables of Gellman et al. ${ }^{6}$. 


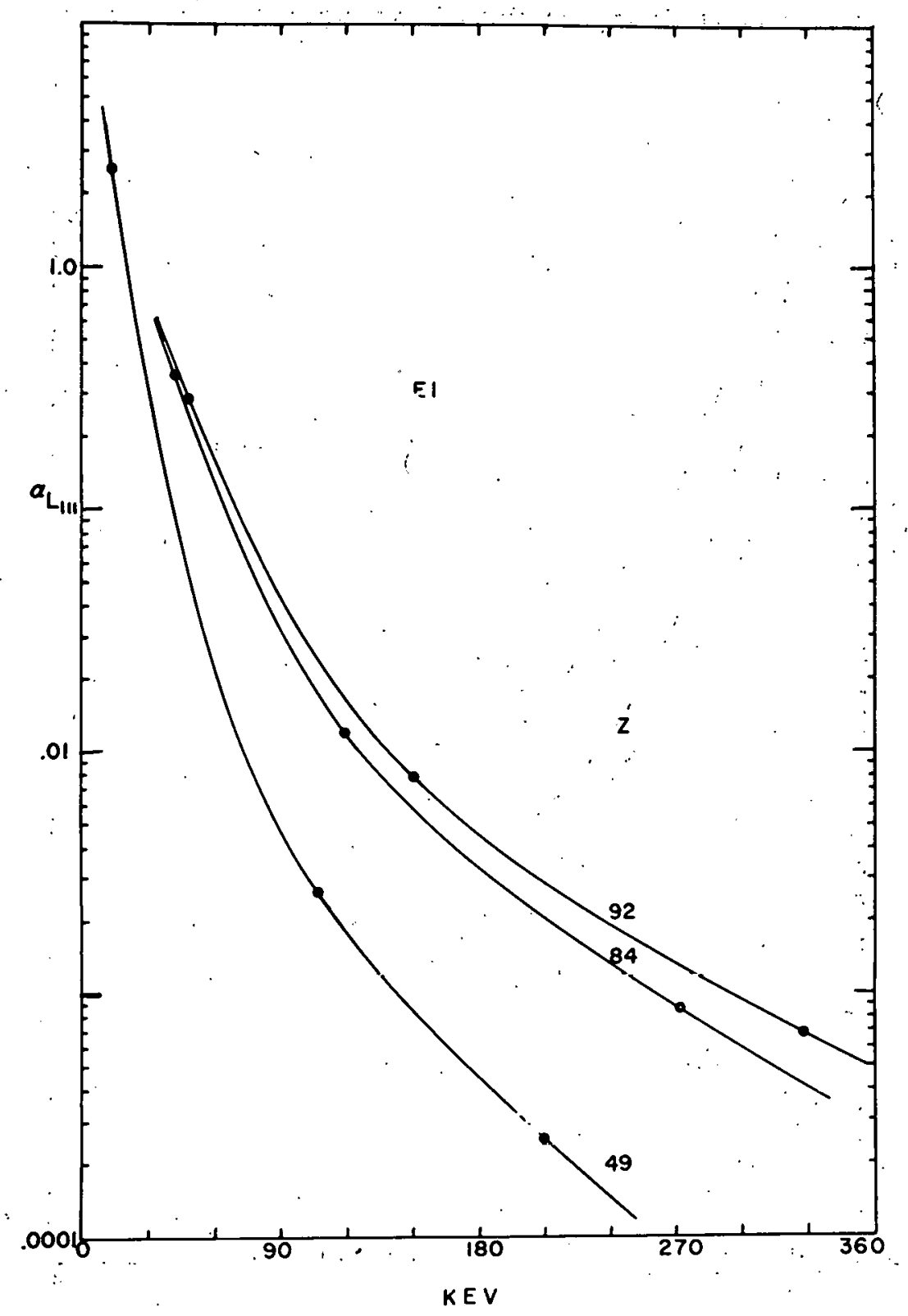

Fig. 16c-Curyes for Interpolating the tables of Gellman et al. 


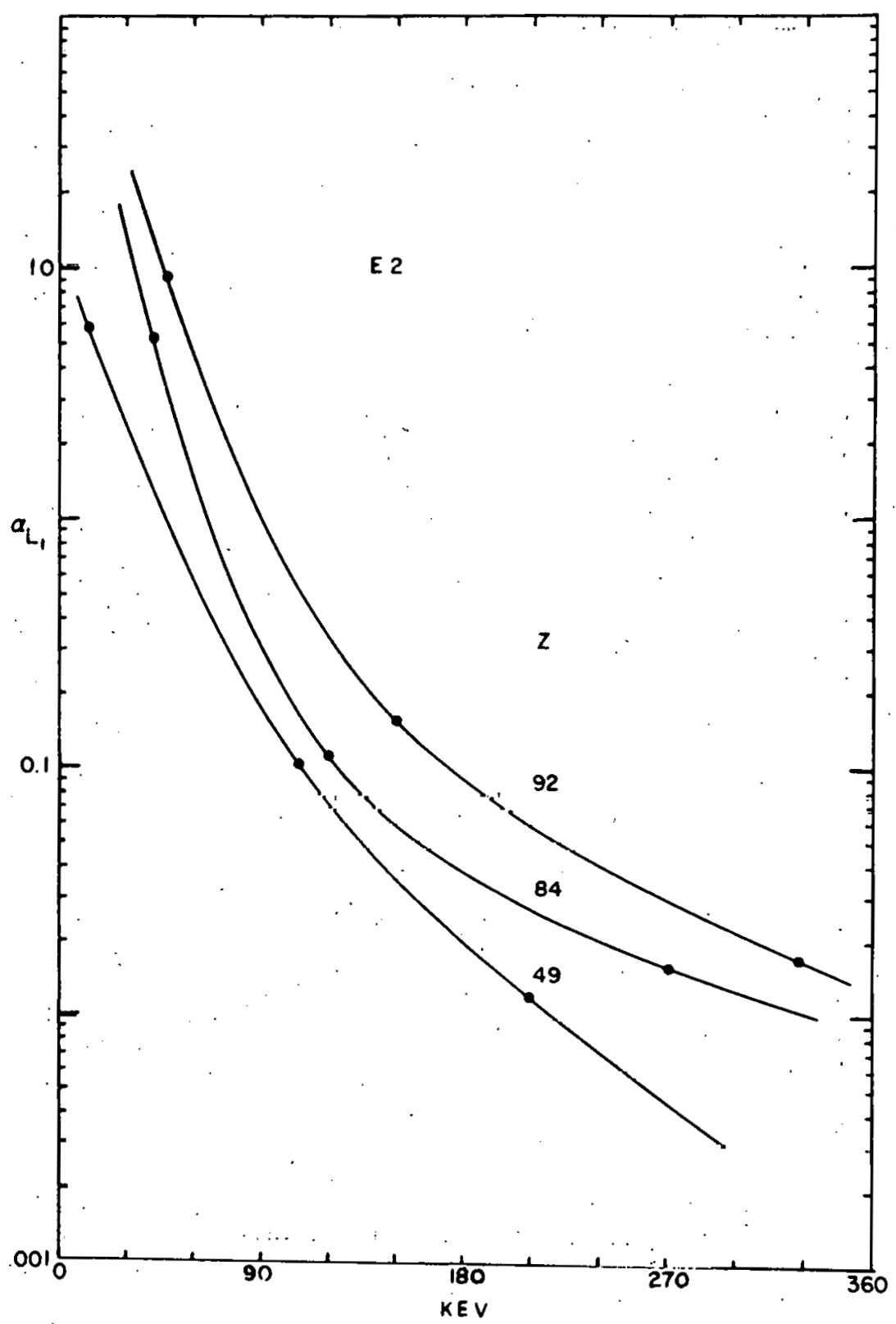

Fig. 16d-Curves for interpolating the tables of Gellman et al. 6 . 


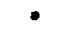

$-77-$

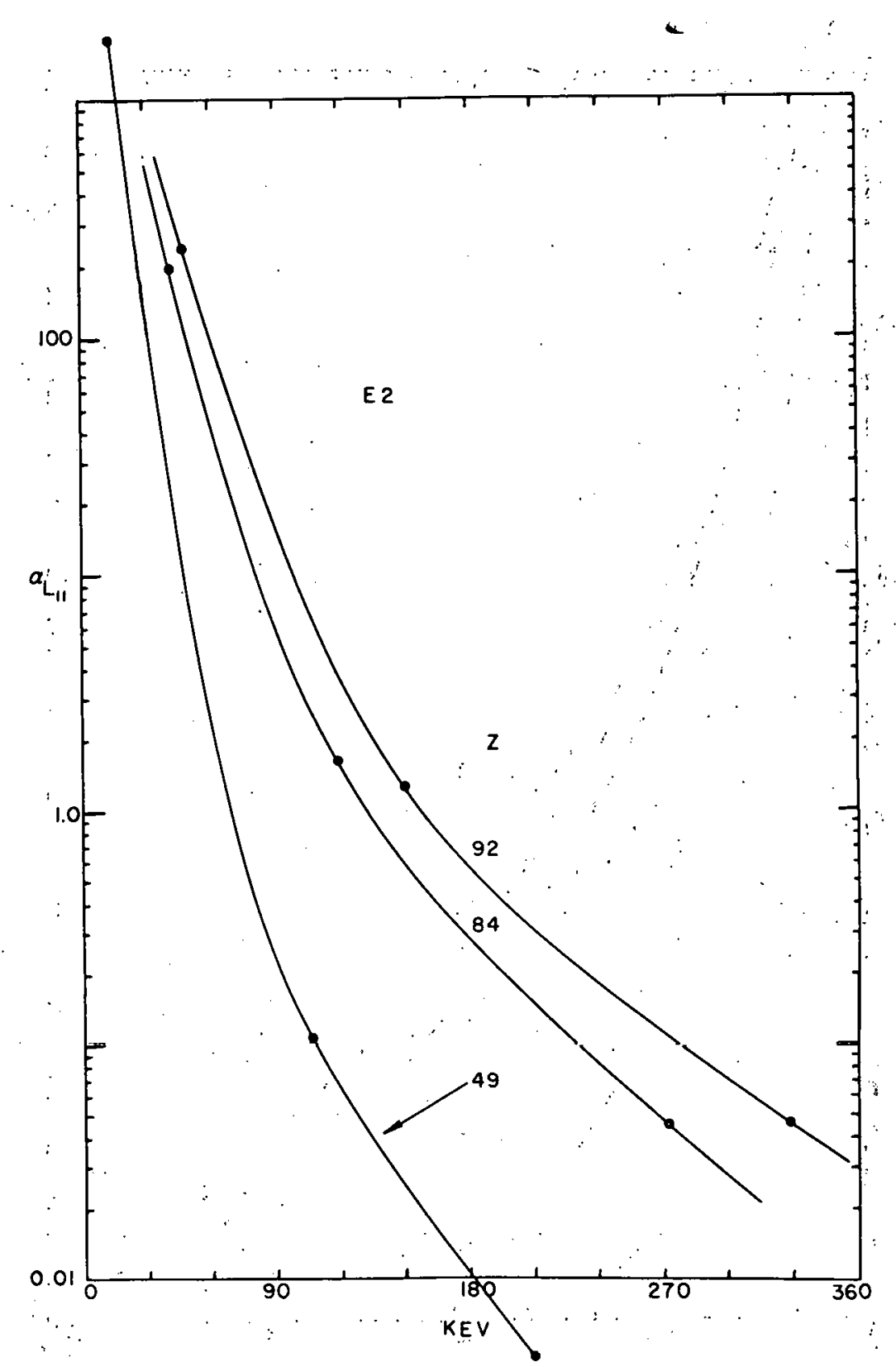

Fig. 16e -Curves for interpolating the tables of Gilman et al: 6 : 


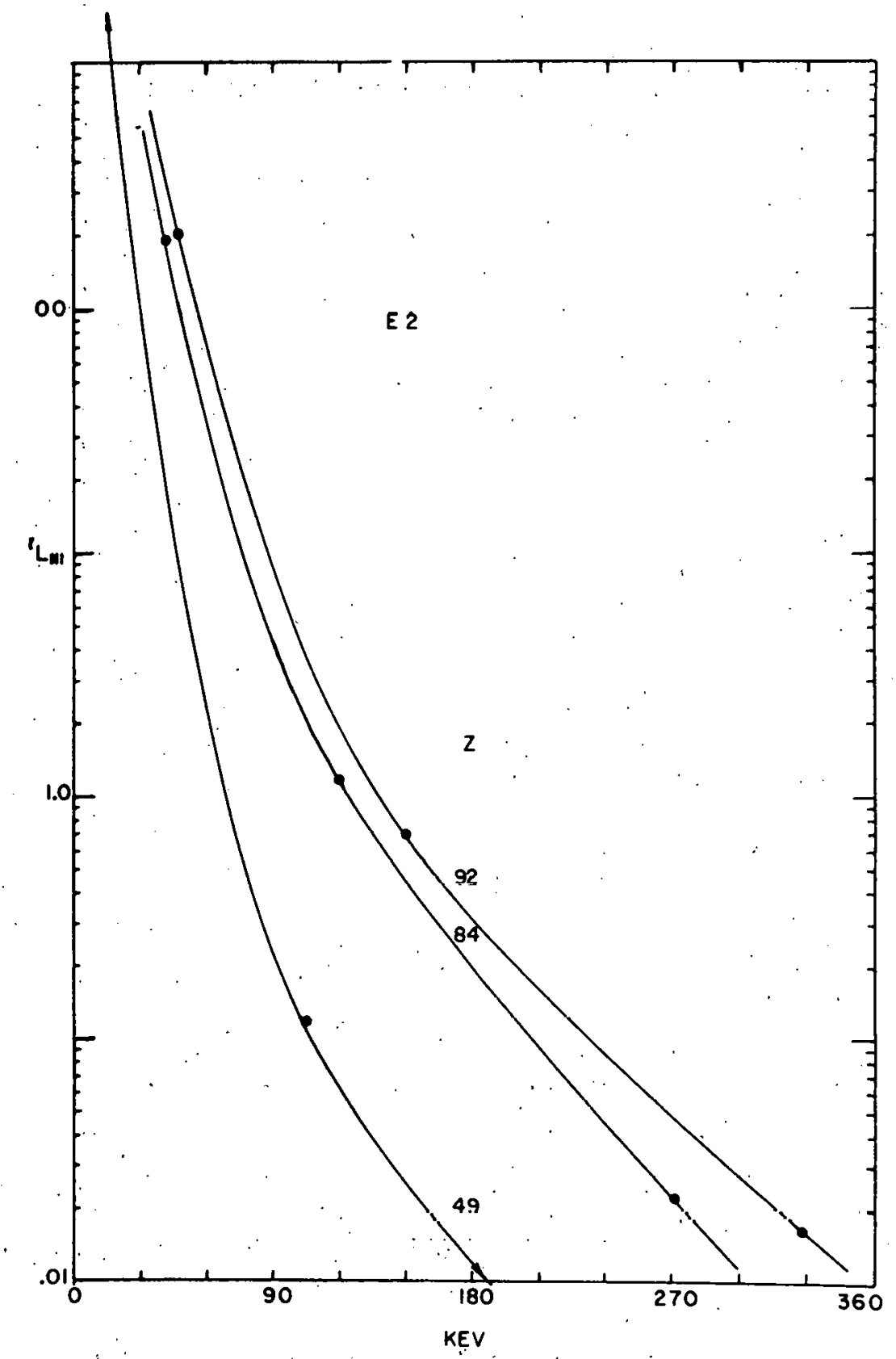

Fig. 16f - Curves for interpolating the tables of Gellman et al. 6 . 


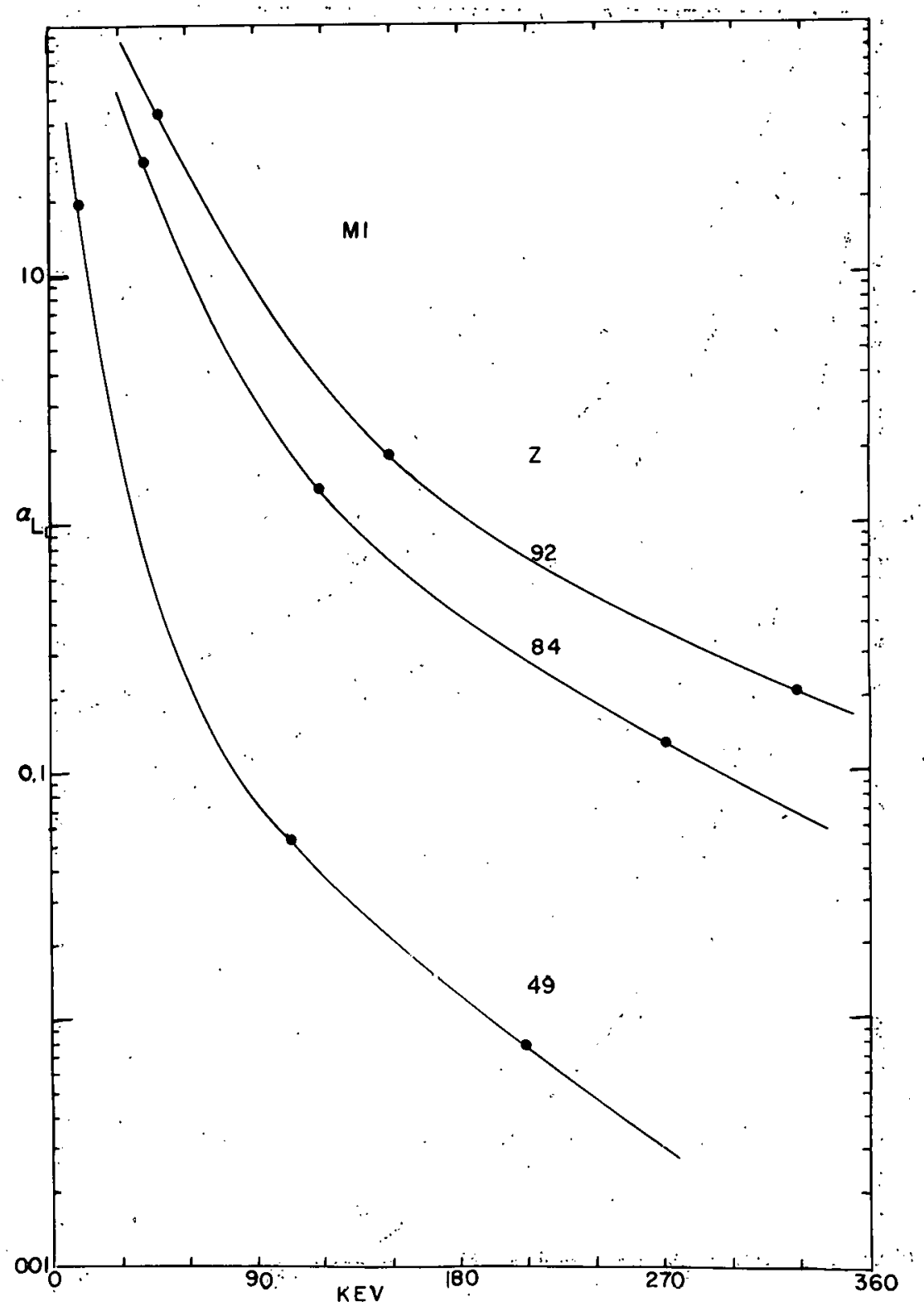

Fig. $16 \mathrm{~g}$ - Curves for interpolating the täbleș of Gellman et al. ${ }^{6}$. 


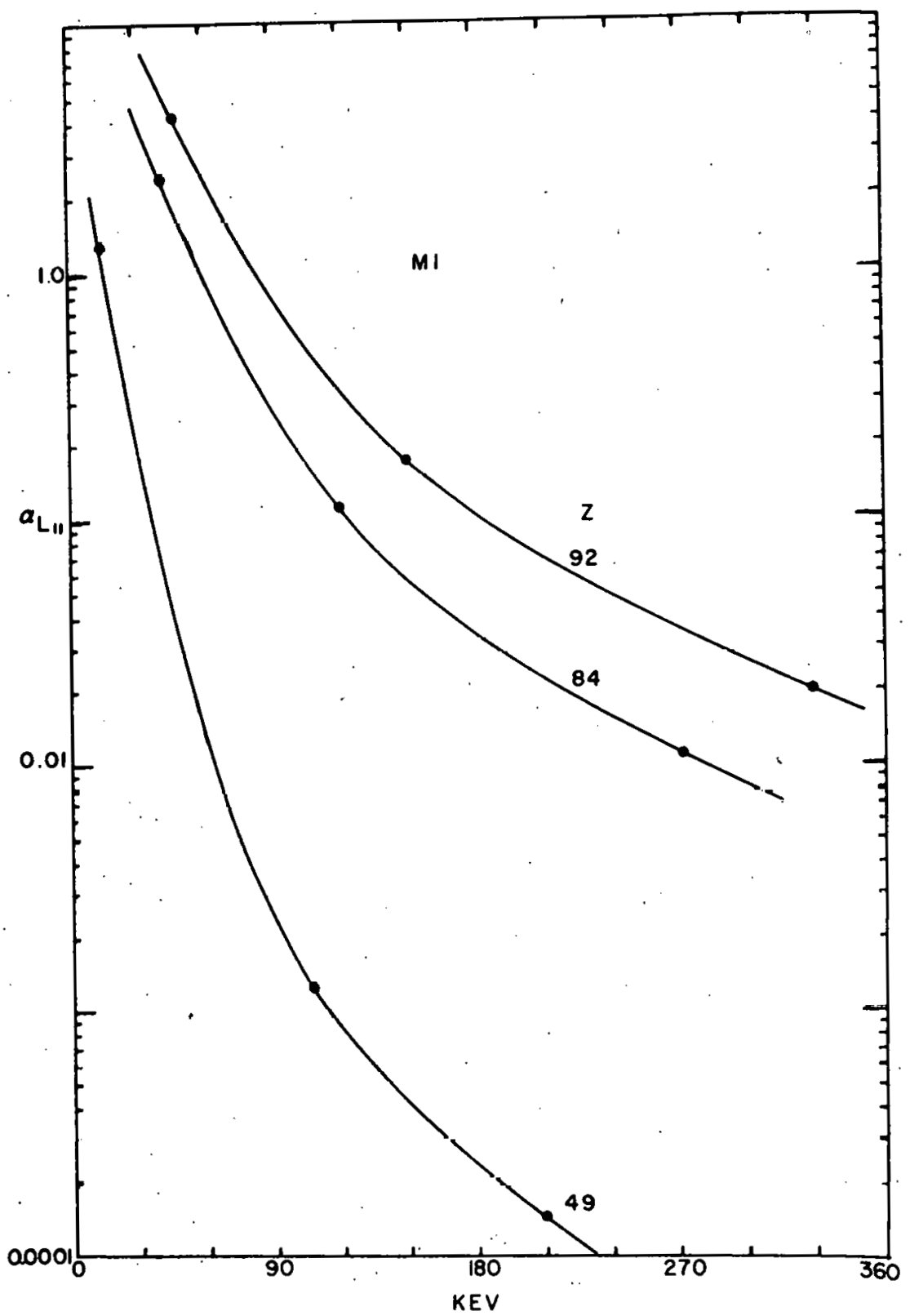

Fig. $16 \mathrm{~h}$-Curves for interpolating the tables of Gellman et al. ${ }^{6}$. 


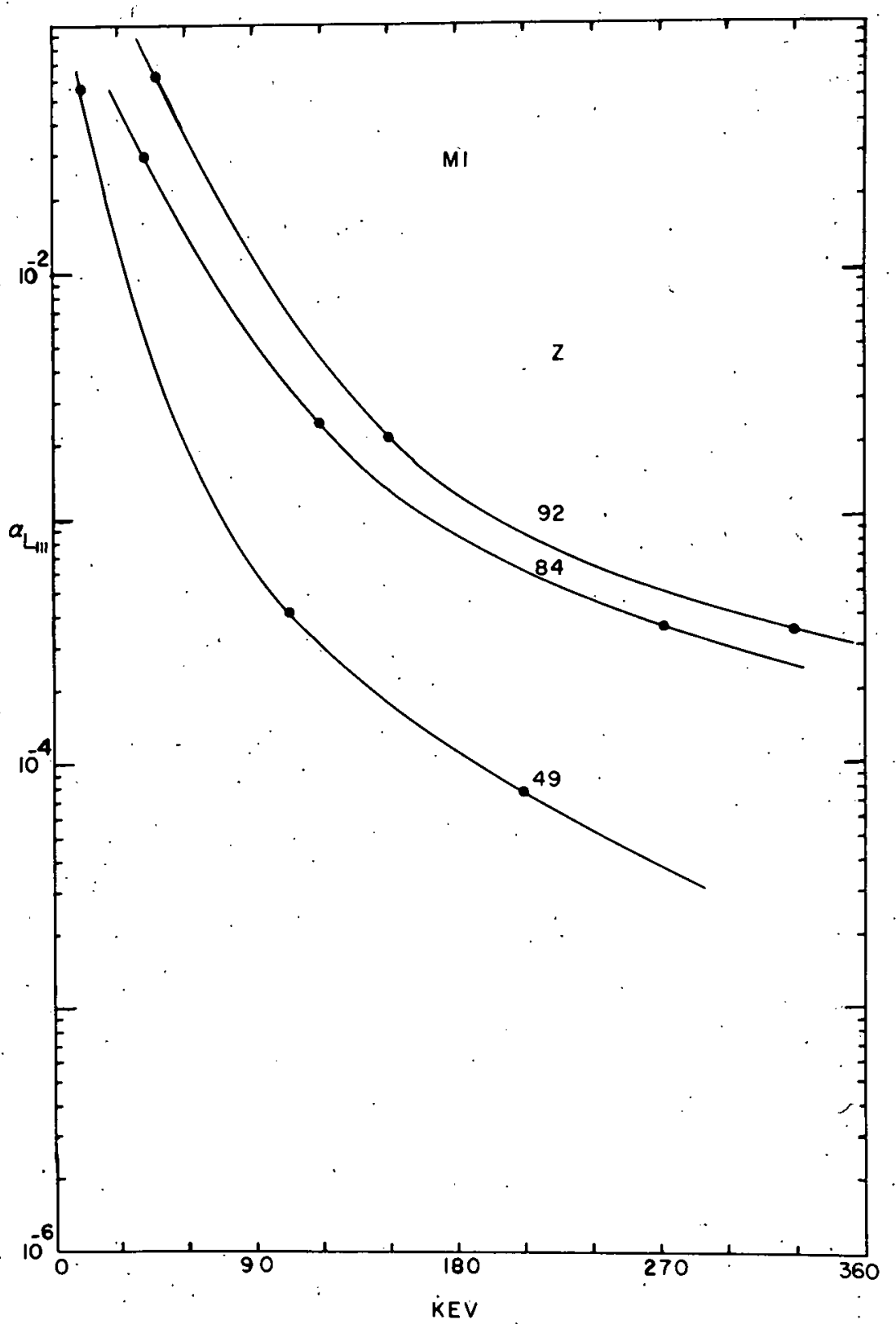

Fig. 16i-Curves for interpolating the tables of Gellman et al. 6 . 
in good general agreement with those which would be predicted by a comparison with the more recent tables of Gellman et al. ${ }^{6}$.

Swan and Hill ${ }^{71}$ have found experimental data on several electric quadrupole radiations to be in reasonably good agreement with the predictions of Gellman et al. 6

Mihelich ${ }^{39}$ has summarized experimental conversion ratios for M4 transitions in a recent paper. These data are the bases for Fig. 10 (see $\mathrm{Tl}^{198 \mathrm{~m}}$ ) in which the author has compared results for an M4 transition in this work with those reviewed by Mihelich.

C. Comparison of Experimental. Data with Predictions.

1. Electric dipole transitions. - - The 59.6 and $26.4 \mathrm{kev}$ gamma transitions which occur in the alpha decay of $\mathrm{Am}^{241}$ have been characterized with reasonable certainty as electric dipole radiations. 5,9 The $59.6 \mathrm{kev}$ gamma ray has a total conversion coefficient of $0.92 \pm 0.1$ and a total $\mathrm{L}$ conversion coefficient of $0.72 \pm 0.07$. From the $L_{I}+L_{I I}: L_{\text {III }}$ ratio of 4.4 , the $L_{\text {III }}$ conversion coefficient is 0.17 . This value is in excellent agreement with the value 0.15 from interpolation of the tables of Gellman et al. ${ }^{6}$ The sum of the conversion coefficients for the $L_{I}$ and $L_{I I}$ subshells is $0.72-0.17=$ 0.55. This value is in very poor agreement with the value 0.32 from inter polation of the tables of Gellman et al. 6 Some, but certainly not all of the difference between these values can be ascribed to errors inherent in inter. polation. The only obvious explanation for this discrepancy is the possibility that the screening correction for either or both the $L_{I}$ and $L_{I I}$ subshells is much larger percentagewise than those found by Reitz ${ }^{68}$ for the $K$ shell.

A priori the screening correction would be expected to be very similar percentagewise for the $\mathrm{L}_{I I I}\left(\mathrm{P}_{1 / 2}\right)$ and $\mathrm{L}_{I I I}\left(\mathrm{P}_{3 / 2}\right)$ shells. This seems borne out by the good agreement of $\mathrm{L}_{\mathrm{II}} / \mathrm{L}_{\text {III }}$ ratios of E2 transitions 
with the "unscreened" calculations of Gellman et al. ${ }^{6}$ Similarly, the percentagewise screening correction for the $I_{I_{1}}\left(s_{1 / 2}\right)$ shell might be expected to be of different magnitude from those of the $\mathrm{L}_{\text {II }}$ and $\mathrm{L}_{\text {III }}$ shells. Thus $\mathrm{L}_{\mathrm{I}}: \mathrm{L}_{\mathrm{II}}: \mathrm{L}_{\text {III }}$ ratios for radiations (El and all magnetic radiations) which convert appreciably in the $L_{I}$ shell ${ }^{6}$ would not be expected to agree as well with the unscreened ratios as those converto ing only in the $\mathrm{L}_{\text {II }}$ and $\mathrm{L}_{\text {III }}$ shells (E2, E3, E4, etc.). That this is so is borne out by the data on the $59.6 \mathrm{kev}$ El gamma ray under consideration here and the $46.5 \mathrm{kev} \mathrm{Ml}$ gamma ray following $\mathrm{RaD}$ decay.

The $\left(L_{I}+L_{I I}\right) / L_{I I I}$ ratio expected ${ }^{6}$ for the $59.6 \mathrm{kev}$ gamma ray is 1.9. The experimentally determined value is 4.4. From the above considerations it would seem that the screening effect for the $L_{I}$ shell changes the "unscreened" conversion coefficient by a factor of about 3. This, of course, assumes that the percentagewise screening correction of the $\mathrm{L}_{\text {II }}$ shell is the same as that of the $\mathrm{L}_{\text {III }}$ shell.

Wu et al ${ }^{72}$ have obtained an accurate $\mathrm{L}_{I}: \mathrm{L}_{\mathrm{II}}: \mathrm{L}_{\mathrm{III}}$ ratio for the 46. $5 \mathrm{kev} \mathrm{Ml}$ radiation following RaD beta minus decay. The value $(140: 10.7: 1.0)$ they obtain is in very poor agreement with that $(915: 99: 1.0)$ calculated from the tables of Gellman et al. ${ }^{6}$ It seems that both the $L_{\text {II }}$ and $L_{I}$ intensities are about seven times the expected intensities with respect to the $\mathrm{L}_{\text {III }}$ intensity. This would indicate that the screeno ing correction for the $\mathrm{L}_{\mathrm{II}}$ shell is more similar to that of the $\mathrm{L}_{\mathrm{I}}$ shell than it is to that of the $L_{\text {III }}$ shell. Thus one might conclude that perhaps a screening effect is not the only effect operating in the se two cases to alter the $L_{I}: L_{I I}: L_{I I I}$ ratios from those expected。 6 
The 26. $4 \mathrm{kev}$ gamma ray is given an El assignment from its deduced total $\mathrm{L}$ conversion coefficient of $3.75 \pm 1.2$. The value obtained from an extrapolation of the tables of Gellman et al ${ }^{6}$ is 2.3. The difference between these values is probably not significant since extrapolation of the theoretical curves involves great uncertainty. It is interesting, however, that the experimental value is larger than the theoretical value as in the case of the $59.6 \mathrm{kev}$ gamma transition.

2. Magnetic dipole radiation, -0 The only transition given an $\mathrm{Ml}$ assignment was the $33.1 \mathrm{kev}$ gamma ray of $\mathrm{Am}^{241}$. Although this assignment is by no.means certain, it appears to be the only one consistent with all the available data. The experimental value for the $\mathrm{L}_{\mathrm{I}^{\circ}} \mathrm{L}_{\text {II }}$ ratio of $>5$ is to be compared with the theoretical value of 10 obtained by extrapolating the tables of Gellman et al. ${ }^{6}$ Failure to observe the $L_{\text {III }}$ line is consistent both with theoretical ${ }^{6}$ and empirical evidence ${ }^{70}$ on othe, Ml liansiliuns.

3. Electric quadrupole transitions. - Most of the gamma transitions for which data is reported in this thesis have been given E2 assignments. Conversion has been observed in the $L_{\text {II }}$ and $L_{\text {III }}$ shells only. In two cases $\left(\mathrm{Np}^{238}\right.$ and $\mathrm{T} 1^{198 \mathrm{~m}}$ ) limits can be set for the relative amount of $\mathrm{L}_{\mathrm{I}}$ conversion. The experimental $\mathrm{L}_{\mathrm{II}}: \mathrm{L}_{\mathrm{III}}$ ratios are compared with the theoretical ones in Table 10 .

Of course, the theoretical values are not necessarily accurate because of the fact that only three values were determined by Gellman et al. 6 for each $\mathrm{L}$ shell and given $Z$. Thus the interpolations are subject to errors of significant magnitude. The accuracy of the various experimental ratios are given in the section on experimental data. Within the conservative limits of error of both the interpolated 
theoretical values and the experimental ones, the agreement in every case is good. In the three cases $(7,8,11$ in Table.10) where a resolution of the lines was sufficiently good to set limits on $L_{I}$. conversion, the upper limits set are about equal to the values interpolated from the tables of Gellman et al. ${ }^{6}$

Table 10

Summary of Data on Electric Quadrupole Transitions

\begin{tabular}{|c|c|c|c|c|}
\hline & $\begin{array}{c}\text { Gamma } \\
\text { ènergy } \\
\text { (kev) }\end{array}$ & $\begin{array}{l}\text { Observed in } \\
\text { decay of: }\end{array}$ & $\begin{array}{l}\text { Experimental } \\
\mathrm{L}_{\mathrm{I}}: \mathrm{L}_{\mathrm{II}}: \mathrm{L}_{\mathrm{III}}\end{array}$ & $\begin{array}{l}\text { Theoretical } \\
\mathrm{L}_{\mathrm{I}}: \mathrm{L}_{\mathrm{II}}: \mathrm{L}_{\mathrm{III}} \\
\text { (E2) }\end{array}$ \\
\hline 1 . & $99.5 \pm 1$ & $\mathrm{Am}^{241}$ & $: 2: 1$ & $0.016: 1.85: 1$ \\
\hline 2. & $41.0 \pm 2$ & $\mathrm{Am}^{242 \mathrm{~m}}$ & _: $1.37: 1$ & $0.034: 1.0: 1$ \\
\hline 3. & $43.3 \pm 2$ & $A \cdot m^{242 m}$ & $: 1.4: 1$ & $0.04: 1.1: 1$ \\
\hline 4. & $57.8 \pm 1$ & $\mathrm{~Pa}^{228}$ & $: 1.4: 2$ & $0.075: 1.6: 1$ \\
\hline 5. & $130 \pm 2$ & $\mathrm{~Pa}^{228}$ & _.1.5:1 & $0.018: 1.8: 1$ \\
\hline 6. & $52.2 \pm 1$ & $\mathrm{~Pa}^{230}$ & _ $1.5: 1$ & $0.06: 1.3: 1$ \\
\hline 7. & $44.1 \pm 1$ & $\mathrm{~Np}^{238}$ & $<0.04: 1.26: 1$ & $0.04: 1.1: 1$ \\
\hline 8 。 & $102.0 \pm 1$ & $N p^{238}$ & $<0.3: 1.6: 1$ & $0.17: 1.8: 1$ \\
\hline 9. & $42.4 \pm 1$ & $\mathrm{~Np}^{236}$ & $L^{2}: 1: 1^{*}$ & $0.04: 1.1: 1$ \\
\hline 10 . & $44.2 \pm 1$ & $\mathrm{~Np}^{236}$ & {$\left[1: 1^{*}\right.$} & $0.04: 1.1: 1$ \\
\hline 11. & $48.4 \pm 0.2$ & $\mathrm{Ti}^{198 \mathrm{~m}}$ & $<0.05: 1.11: 1.0$ & $0.05: 1.3: 1$ \\
\hline
\end{tabular}

* See Section III-H.

It is clear that a theoretical calculation of $\mathbf{L}$ conversion coefficients at smaller intervals of energy and atomic number is required if one desires a quantitative check of theoretical ratios of L conversion. The best values in Table 10 are those for the $44.1 \mathrm{kev}$ gamma ray of $\mathrm{Np}^{238}$ and the $48.4 \mathrm{kev}$ gamma ray of $\mathrm{Tl}^{198 \mathrm{~m}}$. The 
limits of error of these two values are probably less than those of the interpolated theoretical ones. These two determinations should provide an excellent check for a more extensive set of theoretical calculations than those of Gellman et al. 6

4. Mixtures of magnetic dipole and electric quadrupole radiation $_{0}$ Only two transitions of all those investigated gave any reasonable indication of being an $\mathrm{Ml}-\mathrm{E} 2$ mixture. The first is the $43.4 \mathrm{kev}$ transition tollowing Am ${ }^{241}$ alpha decay Here the $\mathrm{L}_{\mathrm{I}}: \overline{\mathrm{L}}_{\mathrm{II}} \overline{\mathrm{L}}_{\mathrm{III}}$ ratio was $0.5: 1.0: 1.0$. If all the $L_{I}$ conversion arises from the $M 1$ radiations present, a 20 percent $\mathrm{Ml}, 80$ percent $\mathrm{E} 2$ mixture is indicated. However, the uncertainty in the ratios is rather large because of the fact that the $43.4 \mathrm{kev} L$ lines were situated on the low energy tail of the $59.6 \mathrm{kev} L$ lines in the spectrum.

The other case is that of the $282.4 \mathrm{kev}$ gamma ray of $\mathrm{Ti}^{198 \mathrm{~m}}$. Here the deduced $\mathrm{K}$ conversion coefficient $(0.24)$ was lower than that expected $(0.52)$ from the tables of Rose et al ${ }^{40}$ for pure Ml radiation. Since the expected conversion coefficient ${ }^{40}$ for $\mathrm{E} 2$ radiation of this same energy is 0.076 , a 64 percent $\mathrm{E} 2$ - 36 percent $\mathrm{M} 1$ mixture is indicated.

5. Higher multipole radiation. - The only transition of higher multipolarity which was investigated was the $260: 7 \cdot \mathrm{kev}$ gamma ray of $\mathrm{T} 1$ 198m . As can be seen in Fig. 10 the $\mathrm{L}_{\mathrm{III}} / \mathrm{L}_{\mathrm{I}}$ ratio for this gamma ray would fit on a smooth curve with those of other M4 transitions in, the same region of atomic number. The conversion of magnetic radiation primarily in the $L_{I}$ and $L_{I I I}$ shells as predicted by Tralli and Lowen ${ }^{38}$ seems substantiated. Other criteria of comparison $(\mathrm{K} / \mathrm{L}$ 
ratios and lifetime) are in excellent agreement with those of well known M4 transitions (see Section III-Ë). Thus qualitative comparisons with the theory (for $\mathrm{Z}=35$ ) of Tralli and Lowen 38 and quantitative comparisons with theoretical lifetimes, 41 and empirical correlations of $\mathrm{K} / \mathrm{L}^{37}$ and $\mathrm{L}_{\mathrm{III}} / \mathrm{L}_{\mathrm{I}}{ }^{39}$ ratios lead to an $\mathrm{M} 4$ assignment for this transition.

6. Conclusion. - The results of the investigations presented in this thesis thus indicate very good agreement with the theoretical predictions of Gellman et alo ${ }^{6}$ except for the one case of electric dipole radiation. The unexpectedly large $L_{I}$ and/or $L_{\text {II }}$ conversion coefficients found may possibly arise from a large screening effect on these shells. Such a large screening effect for $L$ shells would not have been expected from the calculations of Reitz ${ }^{6.8}$ for the $\mathrm{K}$ shell. It may be that screening is not the only effect altering the $\mathrm{L}_{I}: \mathrm{L}_{\mathrm{II}}: \mathrm{L}_{\text {III }}$ ratios in this case.

\section{ACKNOW LEDGMENTS}

Most of the work described in this thesis could not have been done without the advice, cooperation, and support given the author by the entire staff of the University of California Radiation Laboratory. The author particularly appreciated the help of Earl Hostetter, Frederick R。Reynolds, Herman P. Robinson, A. Hartzell, and M. C. Michel on instrumental problems. The advice and assistance given by G. D. O'Kelley of the California Research and Development Company along similar lines is also appreciated. Many helpful discussions of experimental data were held with F. Asaro, H. Jaffe。 E. K. Hyde, R. W. Hoff, D. Feay, H. Mathur, J。 O. Rasmussen, Jr。, C. I. Browne, Jr。: G. D. O'Kelley, W。. Nervik, M.C.Miche1, 
F. S. Stevens, and Io Bergstrom。

I am grateful for the various activities provided by E. K. Hulet, R. W. Hoff, L. S. Slater, G. H. Higgins, W: W. T. Crane, H. Mathur, D. Feay, J. O. Rasmussen, Jr。 S。 R. Gunn, H. Jaffe, E. K. Hyde, G. D. O'Kelley, and V.K. Fischer.

The assistance of A. Passell, D. Strominger, P. R。 Gray, T. K. Pionteki, and $H_{\text {。 }}$. Jensen in operating the spectrometer and making extensive calculations was sincerely appreciated.

I wish to thank the staff of the electronics department for their maintenance and improvement of the spectrometer power supply, the inspection technicians for their supervision of the pumping system, and the members of the Health Chemistry department for their help in minimizing radiation hazards.

I express my appreciation to L. Higgins, W. Goldsworthy, and E. Powers for their considerable efforts in the design and construction of the twin lens spectrometer.

I thank Professor Isadore Perlman for his continued advice and encouragement in every phase of this work.

This work was performed under the auspices of the United States Atomic Energy Commission. 


\section{APPENDIX I}

Miscellaneous Data on the Isotopes $\mathrm{Pu}^{241,240}, \mathrm{Pm}^{150}$, and $\mathrm{Fr}^{223}$

1. Plutonium 241, 240. - The beta spectrum of $\mathrm{Pu}^{241}$ from a $0.5 \mathrm{mg}$ sample of pile irradiated plutonium was observed on the double focusing beta spectrometer. A mass analysis of the sample indicated. the following isotopic composition:

$\begin{array}{cc}\text { Mass number } & \frac{\text { Percent by mass }}{239} \\ 240 & 49.86 \\ 241 & 16.93 \\ 242 & 9.78\end{array}$

The sample was mounted on a single gold leaf $\left(87 \mu \dot{\mathrm{g}} / \mathrm{cm}^{2}\right)$.

A Fermi-Kurie plot of the beta spectrum is shown in Fig. 17. The fact that the plot is straight back to about $12 \mathrm{kev}$ probably does not indicate that the counter window transmits 100 percent of all electrons down to $12 \mathrm{kev}$. Previous experiments seemed to indicate that the window transmitted electrons down to about $17 \mathrm{kev}$ with 100 percent efficiency. The delay of the sharp downward turn of the plot is ascribed to extensive self mabsorption and back scattering in the sample. These effects tend to accentuate the lower energy. portions of a beta spectrum and hence in this case presumably compensated the loss due to window absorption as far down as $12 \mathrm{kev}$. The window energy cut-off determined from this. Fermi-Kurie plot is about $4.5 \mathrm{kev}$. Thus the common supposition that the energy of electrons transmitted 100 percent is between four and five times the window cut-off energy seems substantiated. 
Previous work on this isotope has characterized it as a 14 year beta emitter with a maximum beta energy of $20.5 \mathrm{kev}$. 7367 its decay by alpha emission has been observed and the energy reported'as $4.91^{65}$ and $4.893 \mathrm{Mev}^{9}$ The maximum beta energy determined from this experiment is $20.5 \pm 1 \mathrm{kev}$, in excellent agreement with Freedman et al. 76

In addition to the beta spectrum, a reasonably definite indication of the $L$ and $M$ lines of a $43 \pm 3$ kev gamma ray was observed. This gamma ray very probably arises from $\mathrm{Pu}{ }^{240}$ alpha decay to the first excited state in $U^{236}$. This assignment is based on its abundance and energy。 Other values given for this gamma ray are $49.6 \mathrm{kev}, 7647 \mathrm{kev}, 76$ $48 \mathrm{kev}, 7645.0 \pm 0.2 \mathrm{kev}, 77$ and $44 \pm 2 \mathrm{kev} .9$

2. Promethium 150: $-\infty$ sample of $\sim 10^{7}$ disintegrations per minute of $\mathrm{Pm}^{150}$ was obtained from a proton bombardment of neodymium enriched in Indss 150 in the laboratory"s 60 -inch cyclotron. The neodymium was bombarded as the oxide in a pistol grip holder. The beta spectrometer sample was prepared by simply taking up the oxide as a slurry in conductivity water and evaporating the material on a 0.001 inch platinum plate. The mass of the neodymium oxide on this sample was of the order of two milligrams.

The half - life of this isotope has been determined as 2.7 hours by Long and Pool, ${ }^{78}$ Fisher, ${ }^{79}$ and Kurbatov and Pool. ${ }^{80}$ Beta particles of 2.0 $01 \mathrm{Mev}$ (about 70 percent) and 3.00 Mev (about 30 percent) and gamma rays of $1.4 \mathrm{Mev}$ and $0.3 \mathrm{Mev}$ have been reported by Fisher. ${ }^{79}$ An absorption measurement reported by Long and Pool ${ }^{78}$ gives the beta energy as $2.4 \mathrm{Mev}$. 


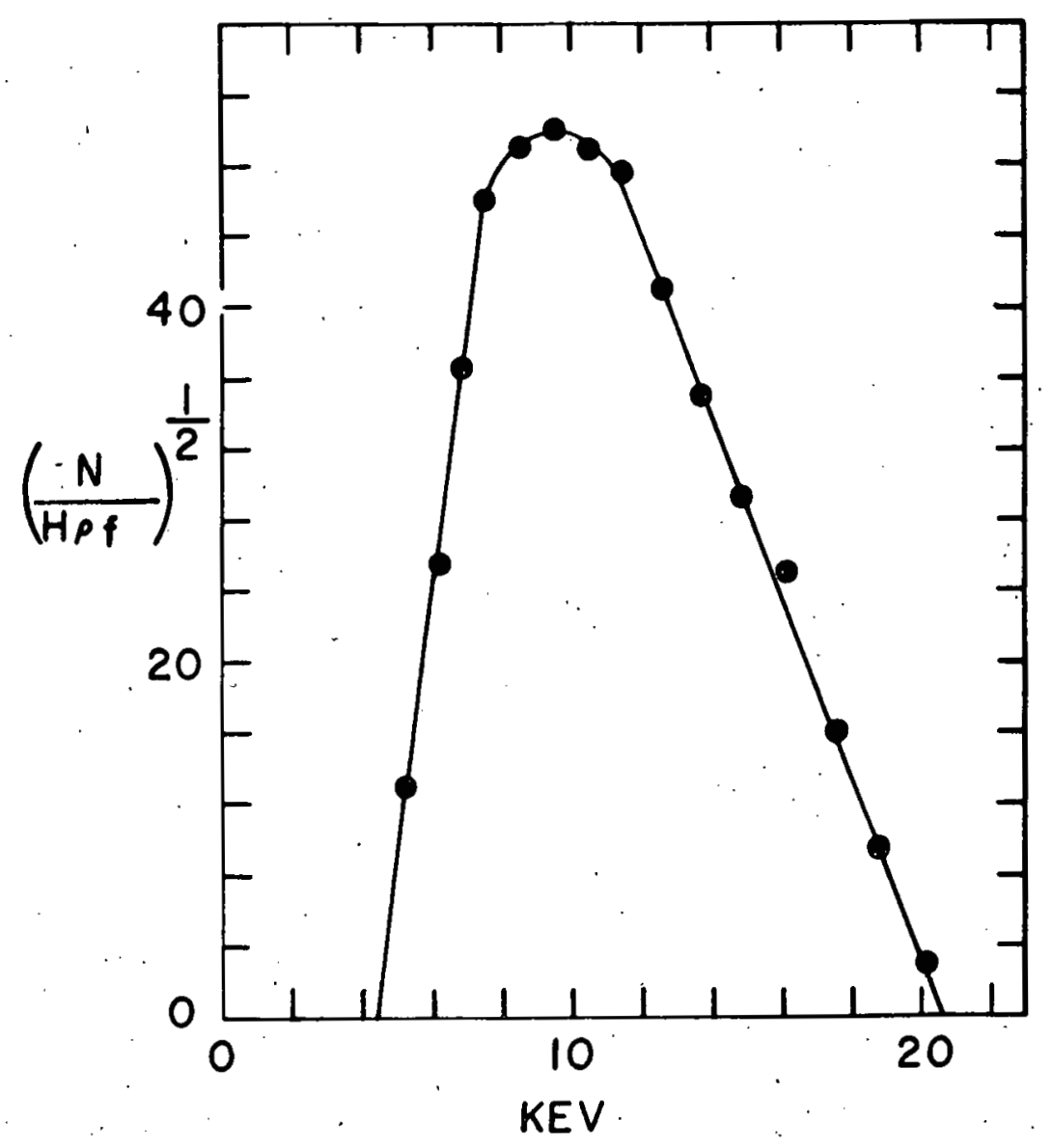

Fig. 17-Fermi-Kurie plot of $\mathrm{Pu}^{241}$ beta spectrum. 
Because of the low intensity of the sample and the relatively short half olife, only one electron line of $\mathrm{Pm}^{150^{\circ}}$ was characterized. No electron line of any appreciable abundance appeared below this line at $290.6 \mathrm{kev}$. This line was interpreted as a $\mathrm{K}$ conversion line of a $337 \pm 2 \mathrm{kev}$ gamma ray (a slight indication of an L line was observed). The region in which the L'line occurred was not swept with sufficiently close intervals to allow a relative abundance measurement to be made. Hibdon and Muehlhause ${ }^{81}$ have reported gamma rays from the neutron capture of $\mathrm{Sm}^{149}$ to be $336.7 \mathrm{kiev}$ and $440.2 \mathrm{kev}$. The energy of the former is in excellent agreement with the above value from this experiment. Thus it appears that a significant proportion of the beta decay of $\mathrm{Pm}^{150}$ decays through the level giving rise to this $337 \mathrm{kev}$ gamma ray.

Scharff-Goldhaber ${ }^{20}$ has interpreted the $336.7 \mathrm{kev}$ gamma ray as the transition between the first excited state of $\mathrm{Sm}^{150}$ and the ground state. From the observation of a $440.2 \mathrm{kev}$ gamma ray, the second excited state is supposed 20 to be at $777 \mathrm{kev}$. From the data on $\mathrm{Pm}^{150}$, it can be said that the $44{ }_{\mathrm{K}}$ line is less than about $1 / 3$ of the $337 \mathrm{~K}$ line。 Recent experiments at this laboratory indicate that several high-energy gamma rays (around 1.5 Mev) of high intensity are also emitted in $\mathrm{Pm}^{150}$ beta decay。 82 Thus one might reasonably conclude that the primary route of decay is to levels about $1.5 \mathrm{Mev}$ or higher above the ground state from which are emitted the several high energy gamma rays, a significant fraction of which cascade through the first excited state to ground. Apparently the second excited state is involved to a smaller extent in these cascades than the first excited state. It is 
of interest to note that this pattern of decay is noted among other odd-odd beta emitters in the medium and heavy elements where sufficient decay energy exists, for example, $\mathrm{Np}^{238}$ and $\mathrm{Ac}^{228}$.

3. Francium 223 (AcK). --Several experiments were attempted to determine the beta spectrum of $\mathrm{Fr}^{223}$. The sample was prepared by E. K. Hyde of this laboratory using a procedure involving a silicotungstic acid precipitation. ${ }^{83}$ The activity was milked from a 20 millicurie source of $\mathrm{Ac}^{227}$ which had originally been made in a pile bombardment of $\mathrm{Ra}^{226}$ by the reactions:

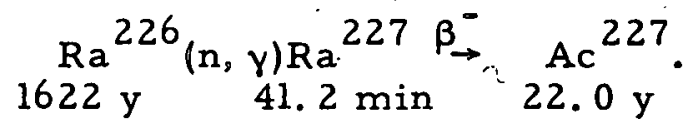

The $\mathrm{Fr}^{223}$ arises from the 1.2 percent alpha decay branching of $\mathrm{Ac}^{227}$. The half-life of $\mathrm{Fr}^{223}$ is 21 minutes. ${ }^{84}$

Previous work on the beta spectrum of $\mathrm{Fr}^{223}$ indicates a beta energy of $1.2 \mathrm{Mev}{ }^{\varepsilon 5-\delta 7}$ The data here obtained indicates a twocomponent beta spectrum, the most abundant component having an energy of $1.0 \pm 0.1 \mathrm{Mev}$. Because of the much lower intensity of the higher energy component the limits of error for its energy are greater than $0.1 \mathrm{Mev}$. The value obtained was $1.3 \pm 0.15 \mathrm{Mev}$. The large limits of error quoted are due primarily to spectrometer calibration uncertainties at the time of the experiment.

Electron lines which might.be assigned to gamma rays with energies $45 \pm 7 \mathrm{kev}$ and $230 \pm 20 \mathrm{kev}$, were observed in a very fast sweep of the spectrum. Recent work by Hyde ${ }^{88}$ using a scintillation spectrometer shows that gamma transitions occur at the energies $49.8 \pm 0.2,80 \mathrm{kev}, 215 \mathrm{kev}$, and $310 \mathrm{kev}$. Previous workers had found by absorption methods gamma transitions of $90,89,90 \sim 330,87$ 
and $48.6 \mathrm{kev} .87$

From the high intensity of the $49.8 \mathrm{kev}$ photon relative to the beta particles 88 it is quite reasonable to assume that it is of El character. Hyde 88 found that none of the other gamma rays observed are in coincidence with the $49.8 \mathrm{kev}$ gamma ray. A unique decay scheme cannot be constructed for $\mathrm{Fr}^{223}$ without further information.

\section{APPENDIX II}

\section{A Twin Lens Beta Spectrometer for Coincidence Measurements}

\section{A. Purpose and Design of the Instrument}

The decision to construct a back-to aback double beta spectrometer was based upon the usefulness of such an instrument in elucidat ing decay schemes, especially among heavy element isotopes where a large proportion of the gamma transitions take place primarily with the ejection of orbital electrons. Thus this unit was designed to be an electron-electron coincidence spectrometer, consisting essentially of two thin lens beta spectrometers connected at the sample end so that both could simultaneously receive radiation from the same sample, yet operate independently. The design arrived at was a.modification of one described by K. Siegbahn。 ${ }^{91}$ A schematic diagram of the instrument and a block diagram of its associated equipment is given in Fig。18。

\section{B. Brief Description of Major Components}

1. Lens coils.- The lens coils are designed for low voltage high current, motor-generator power and hence require cooling. The cooling system is similar to that described by Freedman. 92 Units consisting of copper tubing sandwiched between two copper plates 


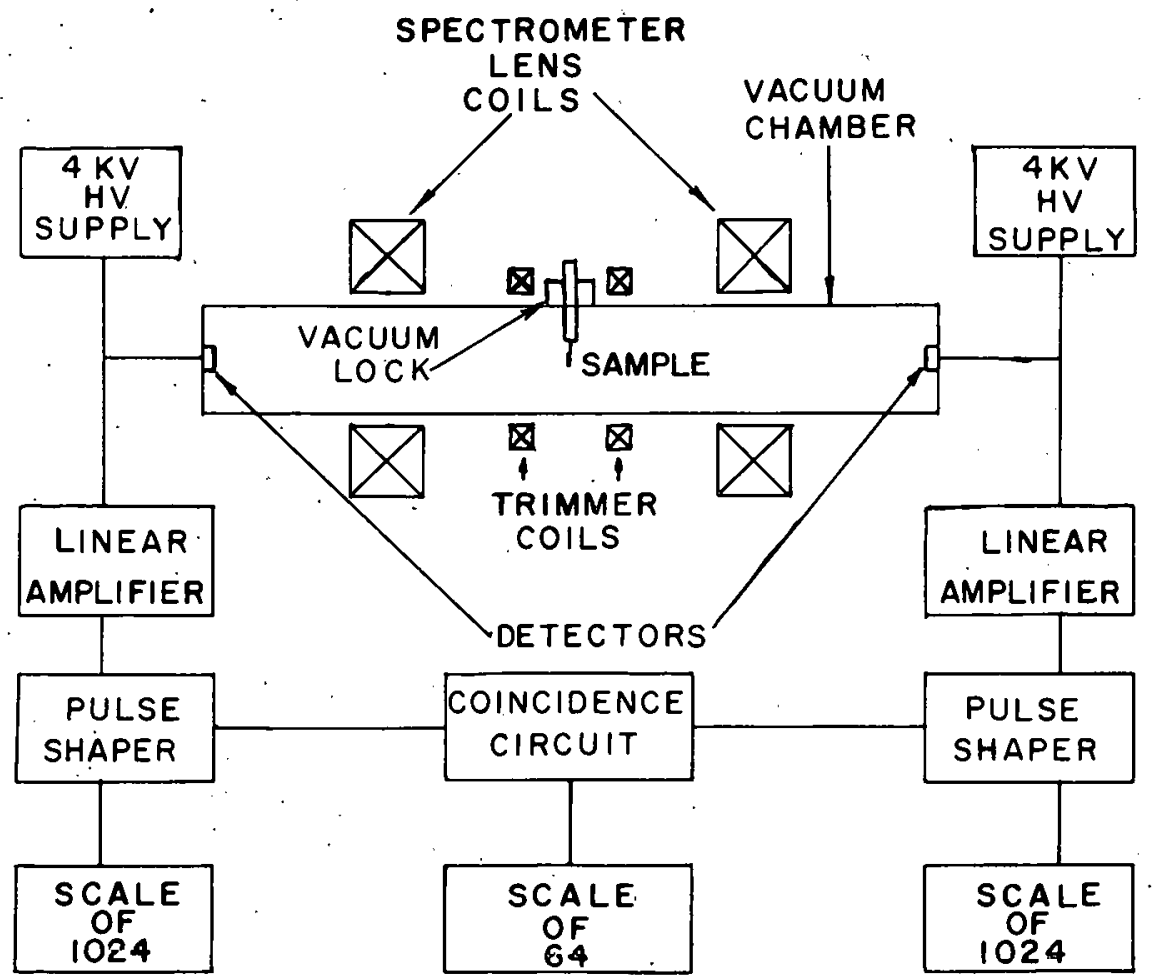

Fig. 18-Block and schematic diagram of twin lens beta spectrometer and associated equipment. 
were built pancake fashion at two positions between the coil windings Copper cooling coils are also soldered to the external surface of the lens spool. The coils are supported independently on a welded aluminum stand。

2. Trimmer lenses.- A smaller lens coil near the sample is connected in series opposition with the lens on the same side to cancel the effect of that spectrometer on the other.

3. Vacuum chamber. - The vacuum chamber was made by rolling and welding 0.250 inch aluminum alloy sheet. It is supported at each end by a three-point suspension coming from the coil mount and in addition, at the center by a two point mount coming from the aluminum stand. The latter is necessary for the making of initial adjustments.

4. Sample entrance section $-\infty$ The sample vacuum lock entrance is contained on an independent section of the vacuum chamber and may be altered or removed easily without changing the two remaining longer sections. Thus, if it is desired later to make the instrument an electron-electron angular correlation instrument, the sample entrance section may be changed to a bellows and a new support stand made, no change being necessary in the longer vacuum chamber sections or other components. The sample entrance section also has, at $180^{\circ}$ from the sample, an entrance for a light pipe in case triple; alpha-electron or photon-electron coincidence experiments are desired. A single channel recording pulse-analyzer has been built to accommodate such experiments. 
5. Counting equipment. -o The counters, amplifiers, and coincidence circuits have been designed for resolving times down to $0.1 \mu \mathrm{sec}$. The detectors are ordinary side window counters to be used as low pressure proportional counters. Should it be desirable to change to a scintillation counter system, alternate end plates have been constructed for the vacuum chamber to accommodate a standard laboratory photo-tube, light-pipe assembly. To take full advantage of the shorter resolving times of a scintillation counter, however, a new pair of amplifiers and a new coincidence circuit would be required. The advantage of the present system over the scintillation counter's is that it counts with 100 percent efficiency down to energies below 20 kev whereas the counting efficiency of most scintillation counter systems declines rapidly below $100 \mathrm{kev}$.

6. Automatic counting control. -- One of the two spectrometers may be automatically operated step-wise over any given spectrum while the other remains focused on only one energy region. Thus the long time counts often necessary may be taken without the presence of a human operator. The automatic count control may be set to collect any given number of counts at each of 100 points at large or small intervals on any part of the spectrum. An over oride system insures against the system's spending more than any given maximum time (<30 minutes) at any point on the spectrum. The design of this system is a copy of that designed by Olsen and $\mathrm{O}^{\prime} \mathrm{Kelley}{ }^{93}$ of the California Research and Development Company. 


\section{Expected Operating Characteristics}

Each end of the spectrometer has been designed to transmit about 1 percent of the total electron radiation from the sample at any given energy at a resolution of about 2 percent if ring focusing is used. Without ring focusing the resolution will probably be closer to 3 or 4 percent. The latter is sufficient resolution for a great many experiments which the instrument is expected to perform: 
VIII. REFERENCES

1. G. D. O'Kelley, Ph. D. thésis, University of California Radiation Laboratory Unclassified Report UCR L-1243 (June 1951).

2. M. C. Michel, Ph. D. thesis; University of California Radiation Laboratory Unclassified Report UCR L-2267 (July 1953).

3. J. L. Wolfson, Chalk River Classified Report PR-P-16 (December 1952).

4. J. K. Beling, J. O. Newton, and B. Rose, Phys. Rev. 86, 797 (1952).

5. Ibid., 87,670 .

6. A. Gellman; B. A. Griffith, and J. P. Stanley, ibid., 85, 944.

7. H. Jaffe, unpublished data (July 1953).

8. E. L. Church, Argonne National Laboratory Classified Report ANL-5141 (November 1953).

9. F. Asaro, Ph. D. thesis, University of California Radiation Laboratory Unclassified Report UCRL-2180 (June 1953).

10. F. Asaro, unpublished data (Septembe r 1953).

11. F. Wagner, Jr., M. S. Freedman, D. W. Engelkemeier, and J. R. Huizenga, Phys. Rev. 89,502 (1953).

12. M. S. Fred and F. S. Tomkins, Phys. Rev。 89, 318 (1953).

13. J.' G. Conway and R. D. Mc Laughlin, Phys. Rev. (to be published)

14. J. O. Rasmussen, Jr., Arkiv fdr Fysik, Bd 7, Nr 16 (1953).

15. G. T. Seaborg, R. A. James, and A. Ghiorso, "The Transuranium Elements: Research Papersii |McGraw-Hill Book Co., Inc., New York, N. Y., 1949), National Nuclear Energy Series, Plutonium Project Record, Vol. 14B, p. 1554.

16. G. T. Seaborg, R. A. James, and L. O. Morgan, ibid., p. 1525. 17. W. M. Manning and L.' B." Asprey, ibid., p. 1595. 
18. G. D. O'Kelley, G. W. Barton, Jr。,W. W. T. Crane, and

I. Perlman, Phys. Rev。 80, 293 (1950)。

19. R。 W. Hoff, Ph. D。 thesis, University of California.Radiation

Laboratory Unclassified Report UCR L-2325 (September 1953).

20. G. Scharff-Goldhaber, Phys.Rev. 90, 587 (1953).

21. F. Asaro and I. Perlman. ibid, 87, 393 (1952).

22. B。, B. Kinsey。Can。 J。 Research, 26A, 404 (1948).

23. F.S. Stephens, private communication (February 1954)。

24. E. L. Church, private communication to G. T. Seaborg (October 1953).

25. C。A. Prohaska, $\mathrm{Ph}$ 。 D thesis, University of California Radiation Laboratory Unclassified Report UCRL-1395 (August 1951).

26. D. C. Dunlavey and G. T. Seaborg, Phys. Rev. 87, 165 (1952)。

27. H. Slattis, J. O. Rasmussen, Jr。, and H. Atterling, ibid。, 93, $646(1954)$

28. M. S. Freedman, A. H, Jaffey, and F. Wagner, Tr., ihid., 79, $410\langle 1950\rangle$.

29. G. T. Seaborg, E。 M. McMillan, Jo W. Kennedy, and A. C. Wahl, ibid., 60, 366 (1946): "The Transuranium Elements: Research Papers"! (McGraw-Hill Book Co., Inc。, New York, N. Y。, 1949), National Nuclear Energy Series, Plutonium Project Record, Vol. $14 \mathrm{~B}$, p. 1 。

30. Ibid., p. 43.

31. A。 Ho Jaffey and L. B。 Magnusson, ibid。, p.978.

32. D。A. Orth, L。 Marquez, W. J Heiman, and D. H, Templeton; Phys。Rev: 75, 1100 (1949)。

33. M. C. Michel and D. H. Templeton, unpublished data (1953).: 
34. I. Bergstrym, R. D. Hill, and G. DePasquali, Phys. Rev。92, 918 (1953).

35. W. L. Bendel, Ph. D. the sis, University of Illinois (1953).

36. I. Bergstrbm, K. Nyby, S. Thulin, A. H. Wapstra, and

B. Astrbm, Arkiv f\&r. Fysik, Bd7, Nr. 22 (1953).

37. M. Goldhaber and A. W. Sunyar, Phys. Rev. 83, 906 (1951).

38. N. Tralli and I. S. Lowen, ibid. , 76, 1541 (1949).

39. J. W. Mihelich and A. deShalit, ibid., 93, 135 (1954).

40. M. E. Rose, G. H. Goertzel, and C. L. Perry, Oak Ridge National Laboratory Unclassified Report ORNL-1023 (June 1951).

41. R. Montalbetti, Can. J. Phys. 30, 660 (1952).

42. H. M. Neumann and I. Perlman, Phys. Rev. 78, 191 (1950).

43. H. Frauenfelder, J. S. Lawson, Jr., W. Jentschke, and G. DePasquali, ibid., 92, 1241 (1953).

44. M. Goldhaber and R. D. Hill, Revs. Modern Phys. 24, 179 (1952).

45. D. Maeder and A. H. Wapstra, Physica (in press).

46. D. E. Alburger and M. H. L. Pryce, Phys. Rev. 92, 514 (1953).

47. C. D. Broyles, D. A. Thomas, and S. K. Haynes, ibid., 89, 715 (1953)。

48. L. Pincherle, Nuovo Cime, 12, 91 (1935).

49. H. W. S. Massey and E. H. S. Burhop, Proc. Roy. Soc. (London) A153, 661 (1936).

50. A. Ghiorso, W. W. Meinke, and G. T. Seaborg, Phys. Rev. 74, 695 (1948).

51. C.G. Kyles, C. G. Campbell, and W. J. Henderson, Proc. Plyys. Soc. (London) 66, 519 (1953). 
52. G. T. Seaborg, R.A. Glass, and S. G. Thompson, J.Am. Chem. Soc。(to be published).

53. M. H. Studier and $E_{0} K_{0}$. Hyde, Phys. Rev。 74, 591 (1948)。,

54. M. Ho Studier and R. Jo Bruehlman, Argonne National Laboratory Classified Report ANL-4252 (February 1949).

55. W. W. Meinke and G. T. Seaborg, Phys. Rev. 78, 475 (19.50):

56. DoW. Osborne, $R, C$. Thompson, and $Q$. Van Winkle, "The Transuranium Elements: Research Papers" (McGraw-Hill Book Co., Inc., New York, N. Y., 1949/, National Nuclear Energy Series, Plutonium Project Record, Vol. 14B, p. 1397.

57. W. W. Meinke, Atomic Energy Commission Unclassified Document AECD-2750 (August 1949).

58. Ibid., AECD-3084 (March 15, 1951).

59. P.W. Mc Laughlin and G。D。 O'Kelley, California Research and Development Company Unclassified Report MT A-40 (September 1953)。

60. R. A. James, A。 E。 Florin, H, Ho Hopkins, Jr., and A. Ghiorso; "The Transuranium Elements: Research Papers" (McGraw-Hill Book Co., Inc., New York, N. Y., 1949), National Nuclear Energy Series, Plutonium Project Record, Vol。14B, p。1604.

61. D. A. Orth and G。D. U'Kelley, Yhys. Kev。 $8 Z_{2} 758$ (1951)。

62. H. Jaffe, G. Higgins, and W. W. T. Crane, private communication (January 1954)。

63. G. D. O'Kelley, private communication (January 1954).

64. A. H. Compton and S. K. Allison, "X-Rays in Theory and Experiment ${ }^{31}$ (D. Van Nostrand Co。, Inc., New York, N. Y。, 1935), P. 640 。 


$$
-10.3 .
$$

65. H. M. Taylor and N. F. Mott, Proc. Roy. Soc. (London) 142A, 215 (1933).

66. J.. B. Fisk, ibid., 143A, 674 (1934).

67. H. Gellman, B. A. Griffith, and J. P. Stanley, Phys. Rev. 80, 866 (1950).

68. J. R. Reitz, ibid., 777, 10 (1950):

69. M. E. Rose, G. H. Goertzel, B. I. Spinrad, J. Harr, and P. Strong, ibid., 83, 79 (1951).

70. J. W. Mihelich, ibid., 87, 646 (1952).

71. J. B. Swan and R. D. Hill, ibid., 91, 424 (1953).

72. C. S. Wu, F. Boehm, and E. Nagel, ibid., 319.

73. G. T. Seaborg, R. A. James, and L. O. Morgan, "The Transuranium Elements: Research Papers" (McGraw "Hill Book Co., Inc., New York, N. Y., 1949), National Nuclear Energy Series, Plutonium Project Record, Vol。14B, p. 1525.

74. G. T. Seaborg, R. A. James, and A. Ghiorso, ibid., P. 1554.

75. S. G. Thompson, K. Street, Jr., A Ghiorso, and F. L. Reynolds, Phys: Rev::80,:1108:(1950).

76. M. S. Freedman, F. Wagner, Jr., and D. W. Engelkemeier, ibid., 88, 1155 (1952)。

77. D. West, J. K. Dawson, and C. J. Mandelberg, Atomic Energy Research Establishment Unclassified Report AERE-N/R 902 (April 1952).

78. J. K. Long and M. L. Pool, Phys. Rev. 85, 137 (1952).

79. V. K. Fischer, Ph. D. thesis, University of California Radiation Laboratory Unclassified Report UCRL-1629 (January 1952); Phys. Rev. 87, 859 (1.952): 


\section{$-104-$}

80. J。 Do Kurbatov and $M_{0}$ L。 Pool, ibid。, 63, 463 (1943) A。

81. C。T。Hibdon and C。O. Muehlhause, ibid, 88,943 (1952):

82. V。K. Fischer, private communication (February 1954)。

83. E. K. Hyde, J。 Am. Chem. Soc 74,4181 (1952)

84. M. Perey, Compt. rend. 208, 97 (1939); J. phys. et radium 10, 435 (1939).

85. M. Perey and M。 Lecoin, ibid。, 439.

86. M. Perey and M。 Lecoin, Nature, 144, 326 (1939).

87. M。 Lecoin, $M$ 。 Perey, M。Riou, and J。Teillac, J。 phys . et radium, $11,227(1950)$ 。

88. E. K. Hyde, University of California Radiation Laboratory Unclassified Report UCR L-2470 (January 27, 1954)。

89. M。 Lecoin, M。 Perey, and San-Tsiang-Tsien, Cahiers phys. No. 26, 10 (1944).

90. M。 Perey, Jo chim-phys. 43, 155, 269 (1946)。

91. Ko Siegbahn, Arkiv f fr. Fysik, Bd4, Nr. 10, 1952.

92: M. S. Freedman; W。 J. Ramler, and B. Smaller, Atomic Energy Commission Unclassified Report AECU 1995 (March 1952)。

93. J. L. Olsen and G. D。 O'Kelley, California Research and Development Company Unclassified Report MTA-37 (September 1953). 